Portland State University

PDXScholar

1983

\title{
Geophysical strain and tilt : measurement methodology and analysis of data
}

Robert MacKay

Portland State University

Follow this and additional works at: https://pdxscholar.library.pdx.edu/open_access_etds

Part of the Geophysics and Seismology Commons, and the Physics Commons Let us know how access to this document benefits you.

Recommended Citation

MacKay, Robert, "Geophysical strain and tilt : measurement methodology and analysis of data" (1983). Dissertations and Theses. Paper 3347.

https://doi.org/10.15760/etd.5006

This Thesis is brought to you for free and open access. It has been accepted for inclusion in Dissertations and Theses by an authorized administrator of PDXScholar. Please contact us if we can make this document more accessible: pdxscholar@pdx.edu. 
AN ABSTRACT OF THE THESIS OF Robert Mackay for the Master of Science in Physics presented August 24, 1983.

Title: Geophysical Strain and Tilt: Measurement Methodology and Analysis of Data

APPROVED BY MEMBERS OF THE THESIS COMMITTEE:

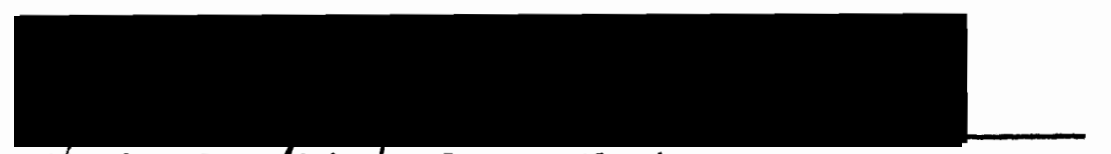

Shripad Tuljapurkar, Chairman

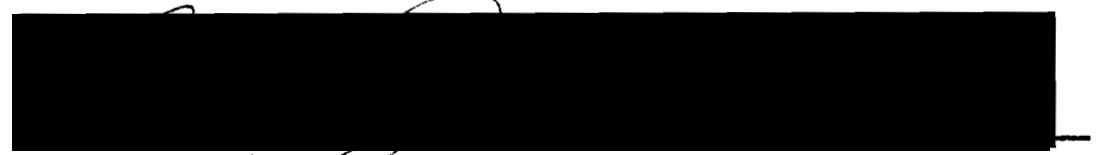

Ansel Johnson

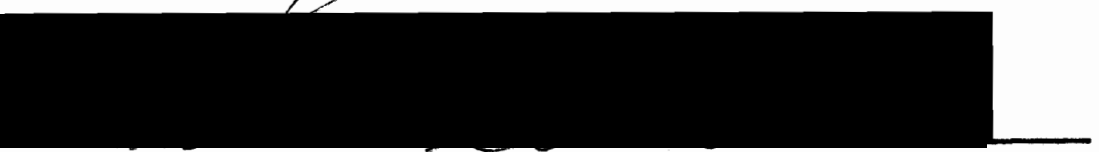

Makoto Takeo

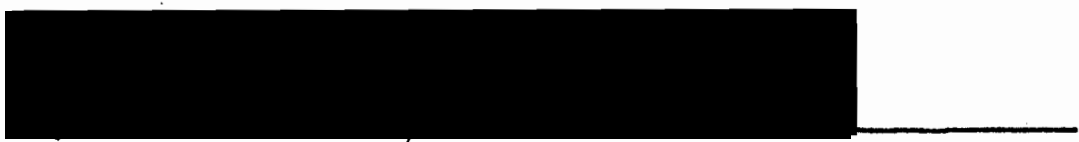

Raymond Sommerfeldt

Tilt and strain meters were installed on the Portland State University campus in the summer of 1982 and data was collected for 4 months. Instrument selection, operation, installation and performance are discussed.

Suggestions that could enhance data quality and data collection efficiency are presented. 
An analysis procedure is suggested and an example of this procedure for an interval of data is discussed. The influence of the temperature, pressure, rainfall and solid earth tides on the signal is investigated, as well as the correlation between similar channels of the different tilt instruments. The temperature, rainfall and solid earth tides were all determined to have an influence on the instruments. A statistical test of the influence of the barometric pressure on the signal revealed no significant influence. A very low correlation between similar components of the different tilt instruments was observed aside from their thermal dependence. It was concluded that in order to obtain high quality data for the use in quantitative calculations, the temperature influence on the raw record must be minimized. 


\begin{abstract}
GEOPHYSICAL STRAIN AND TILT:
MEASUREMENT METHODOLOGY AND ANALYSIS OF DATA
\end{abstract}

by

ROBERT MacKAY

A thesis submitted in partial fulfillment of the requirements for the degree of

MASTER OF SCIENCE

in

PHYSICS

Portland State University

1983 
TO THE OFFICE OF GRADUATE STUDIES AND RESEARCH:

The members of the Committee approve the thesis of Robert Mackay presented August 24, 1983.
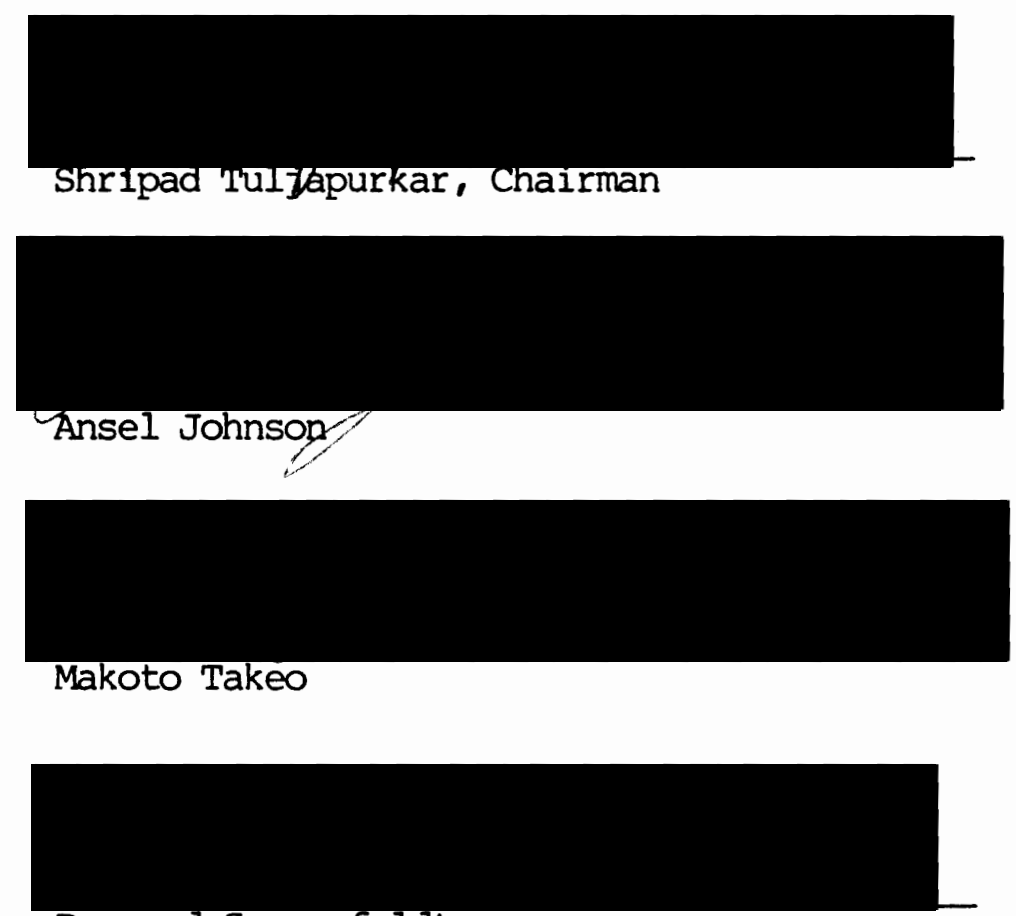

Raymond Sommer feldt

\section{APPROVED:}

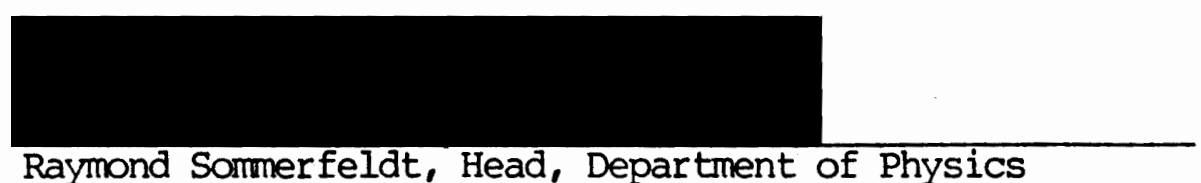

Raymond Sommerfeldt, Head, Department of Physics

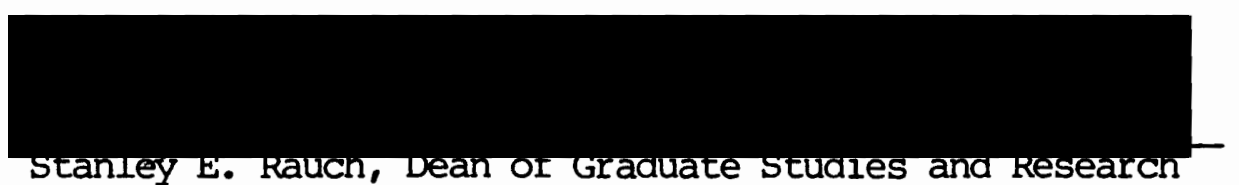




\section{ACKNOWLEDGMENTS}

This thesis was completed with the help and advice of many individuals. I would like to give special thanks to Dr. Ansel Johnson, PSU Geology, for his many hours of help throughout the study and his deeply appreciated advice and comments. Without Dr. Johnson's assistance this project would have never been realized. I would also like to thank the other members of my thesis committee for their support. In particular the advice and constructive criticism from Dr. Makoto Takeo, PSU Physics, and Dr. Shripad Tuljapurkar, PSU Physics, were greatly appreciated and the help of Dr. Raymond Sommerfeldt, PSU Physics, was invaluable for the completion of this project.

Many other individuals helped in making this project a success. I would especially like to thank Mr. Gene Pearson, PSU Geology, for his help in acquiring a study site and supplying miscellaneous materials and equipment throughout the duration of the project; Mr. Tom Bessler, PSU Geology, for modifying the program used to calculate the theoretical tidal signals so that it was compatible with the PSU computer system; Dr. Daniel Johnson, PSU Geography, 
for supplying rainfall data; Dr. Richard Lycan, PSU Geography, for the use of the geography graphics facilities; Dr. Gunnar Bodvarsson of Oregon State University for his hospitality and friendly advice; the PSU campus grounds crew for their help with the digging out and preparation of the site; Mr. Don Boileau, PSU Physics, for his help with miscellaneous equipment and supplies.

Finally I would like to thank my family for their patience and support during the writing of this thesis. 
PREFACE

In 1876 Lord Kelvin concluded that the earth is not a rigid body. Sassa, Ozawa and Yoshikawa of Japan were the first to publish strain data associated with the solid earth tides in 1951 (1). With the advent of the computer there exists the capability to collect and handle great amounts of data. Thus for the past 20 - 30 years there has been an increased interest in measurement of the elastic response of the earth as related to many sources such as faulting, volcanic or geothermal activity, thermal gradients, man-made structures, as well as other sources $(2,3,4,5,18)$. The purpose of this thesis is to study some of the techniques for the measurement and analysis of tilt and strain data. In particular, a description of the instruments, instrument installation, instrument performance and recording procedures for strain and tilt data will be given. In addition, procedures for analyzing the strain and tilt data of this study will be outlined and the results obtained from this analysis will be presented. 
This study began in June of 1982. Data was collected for approximately 4 months during the summer of 1982. Two biaxial tiltmeters and three extensometers were installed on the Portland State University campus. The campus site was selected because it was readily accessible for frequent visits. In addition, the Portland Hills fault (6) was near our location so our instruments would be ideally located for the detection of possible activity associated with the fault.

The study was terminated October 29, 1982 because of heavy rains which flooded the equipment. 
TABLE OF CONTENTS

PAGE

ACKNOWLEDGMENTS

iii

PREFACE

IIST OF TABLES

v

-

LIST OF FIGURES

$\mathbf{x}$

CHAPTER

I INSTRUMENTATION AND COLLECTION OF DATA

Introduction . . . . . . . - .

Instrumentation and Calibration . .

1

Strain Meters

Tilt Meters

Thermometers and Barometers

Instrument $\mathrm{Ma}$ intenance

Instrument Installation . . - . .

Strain Meters

Tilt Meters

Data Recovery and Digitization . . .

Data Presentation and Instrument

Performance . . . . . . . . . . .

Discussion • • • • • • • • - • • 
viii

PAGE

CHAPTER

II SIGNAL ANALYSIS PROCEDURE

Introduction .......... . 25

Visual Inspection . . . . . . 25

Filtering . . . . . . . . . 26

Cross Correlation and

Auto-correlation ......... 30

Fourier Transform ........ 31

Linear Model . . . . . . . . 32

Significance of the Linear Model

III EXAMPLE OF DATA ANALYSIS ....... 36

IV TEMPERATURE DEPENDENCE . . . . . . . 51

V RESULTS OF COMPUTATIONS . . . . . . 57

VI DISCUSSION . . . . . . . . . 60

VII CONCLUSION . . . . . . . . . 69

REFERENCES • • • • • • • • • • • • • 72 


\section{LIST OF TABLES}

TABLE

PAGE

I Calibration Summary - . . . - . . . . .

II Frequency Response of High and Low Pass Filter Combination for the Primary Tidal Frequencies . - . . . . . - . . . . .

III Summary of Data Analysis . . . . . . . 
LIST OF FIGURES

FIGURE

PAGE

1. Plan View of Study Site . . . . . . . .

2 Installation of Strain/Tilt Meter ......

3 Cross Section of Study Site Along Line C of Figure 1..............

4a Raw Tilt Record .............

$4 \mathrm{~b}$ Raw Strain Record ............

5a Strain Measured by Ruler ..........

5b Strain Measured by Potentiometer .....

6 Temperature Record from June 30, 1982 to October 28, 1982 .........

7 Rainfall from June 25, 1982 to November 1, 1982 . . . . . . . .

8 North Component of Tilt-1 from June 30, 1982 to October 28, 1982 . . . . .

9 North Component of Tilt-2 from June 30 , 1982 to October 28, 1982 . . . . . .

10 East Component of Tilt-1 from June 30 , 1982 to October 28, 1982 . . . . . .

11 East Component of Tilt-2 from June 30, 1982 to October 28, 1982 . . . . . .

12 Strain 2 from June 25, 1982 to October 28, 1982 
13 Strain 3 from August 9, 1982 to September 18, 1982 . . . . . . .

14 Strain 1 from October 11, 1982 to October 28, 1982 . . . . . .

15a Frequency Response of Low Pass Filter . . 28

15b Frequency Response of High Pass Filter... 28

16a NT1;8-16;0900;220. Raw Data....... 38

16b NT1;8-16;0900;220. Filtered Data .... 38

17a Raw Temperature Data for NT1;8-16;0900;220 39

$17 \mathrm{~b}$ Filtered temperature data for NT1;8-16;0900;220 ........ 39

18a Raw Pressure Data for NT1;8-16;0900;220 . 40

18b Filtered Pressure Data for NT1;8-16;0900;220 .........

19a Theoretical North/South Tidal Tilt Signal for NTI;8-16;0900;220 .......

19b Filtered Data -- NTI;8-16;0900;220.....

20a Cross Correlation of NT1;8-16;0900;220 with Temperature .........

$20 \mathrm{~b}$ Cross Correlation of NT1;8-16;0900;220 with Pressure ..........

$21 a$ Cross Correlation of Theoretical Tides with NT1;8-16;0900;220.......

2Ib Cross Correlation of Theoretical Tides with Temperature.......... 
22a Cross-Correlation of Theoretical Tides with Pressure . . . . . . . .

$22 \mathrm{~b}$ Cross Correlation of Theoretical Tides with T;8-16;0600 . . . . . . . .

23a Fourier Transform of NT1;8-16;0900;220 . . 45

23b Fourier Transform of Temperature . . . . 45

24a Fourier Transforms of Pressure . . . . 46

24b Fourier Transforms of Theoretical Tides. . 46

25a Residual: $\epsilon(t)$ of Example of Linear Model 49

25b Initial Signal NT1;8-16;0900;220 .... 49

26a Auto-correlation of Residual; $\epsilon(t)$... 50

$26 \mathrm{~b}$ Fourier transform of Residual; $E(t)$.... 50

27a Raw NT1;9-28;1600;240 ......... 63

$27 \mathrm{~b}$ Raw NT2;9-28;1600;240 ........ 63

28a Raw ET1;9-28;1600;240 ......... 64

28b Raw ET $2 ; 9-28 ; 1600 ; 240$......... 64

29a Filtered NT1;9-28;1600;249 ...... 65

29b Filtered NT2;9-28;1600;240 ....... 65

30a Filtered ETl;9-28;1600;240 ....... 66

30b Filtered ET2;9-28;1600;240 ....... 66

$31 a$ Cross Correlation of NTI;9-28;1600;240 with NT2;9-28;1600;240 .......

$31 b$ Cross Correlation of ETl;9-28;1600;240 with ET $2 ; 9-28 ; 1600 ; 240$....... 


\section{CHAPTER I}

INSTRUMENTATION AND COLLECTION OF DATA

\section{INTRODUCTION}

The measurement of strain and tilt data can be divided into several categories of interest. Of primary concern is the instrument type and calibration. The instrument type and calibration are essential for an understanding of the data obtained. Instrument maintenance is also important because a good maintenance program can insure reliable collection of data. Finally, the data recovery and digitization are important factors that determine the characteristics of the data as well as the limitations of the data. In this chapter data is presented as a whole and possible improvements in data quality and collection efficiency will be discussed.

\section{INSTRUMENTATION AND CALIBRATION}

\section{Strain Meters}

The extensometers used are identical to the type described by Axelsson (2). They consist of a 10-meter-long invar wire 
stretched between two ends secured to the earth. One end is an aluminum temperature compensation device that counteracts the thermal expansion of the invar wire so as to minimize the thermal influence on the signal. The other end is a probe between two parallel plates. This probe senses a voltage that is linearly related to the displacement of the end of the wire. Calibration of the strain meter is accomplished by using a precision micrometer designed to displace the end of the wire by known amounts.

\section{Tilt Meters}

The tilt meters used were Kinemetrics model TM-1B biaxial borehole tilt meters (7). The tiltmeter sensor is a cylindrical chamber that is partially filled with a conductive fluid and is capped on top with a downward concave piece of glass. This causes a bubble to be trapped in the chamber. On the inside surface of the cap are four orthogonal electrodes that are the active legs of two independent A.C. bridges. Matched pairs of precision resistors are mounted just outside the chamber for the fixed legs of the bridge. An electrode at the base of the chamber provides the A.C. excitation to the bridge. Changes of the sensor orientation relative to the gravitational vertical direction cause the electrodes to sense more or less of the 
bubble, thus producing an output voltage of the bridge which is directly proportional to the amount of "tilt" about each of the orthogonal axii of the meter for small tilts. A calibration check is accomplished by switching in a small precision resistor across one leg of each bridge. The effect of this resistor has been carefully measured by the manufacturer and can be related to the precision calibration performed by Kinemetrics.

The calibration gains for the instruments are summarized in Table I. **

TABLE I

CALIBRATION SUMMARY

Instrument

North Tilt 1 (317)

East Tilt 1 (317)

North Tilt 2 (318)

East Tilt 2 (318)

Strain 3

Strain 1 (from 10-9-82)

Strain 1 (before 10-9-82)

Strain 2 (after 10-9-82)

Strain 2 (before 10-9-82)
Gain*

$.269 \mu \mathrm{r} / \mathrm{mm}$

$.277 \mu \mathrm{r} / \mathrm{mm}$

$.393 \mu \mathrm{r} / \mathrm{mm}$

$.395 \mu \mathrm{r} / \mathrm{mm}$

$4.4 \times 10^{-7}\left(\Delta \mathrm{L} / \mathrm{L}_{\mathrm{O}}\right) / \mathrm{mm}$

$6.9 \times 10^{-8}\left(\Delta L / L_{0}\right) / \mathrm{nm}$

$2.4 \times 10^{-7}\left(\Delta \mathrm{L} / \mathrm{L}_{\mathrm{O}}\right) / \mathrm{mm}$

$1.0 \times 10^{-7}\left(\Delta L / L_{0}\right) / \mathrm{mm}$

$1.8 \times 10^{-7}\left(\Delta L / L_{0}\right) / \mathrm{mm}$

* /mm as measured on chart recording paper

** In this paper positive strain is compression; North/South and East/West tilt are positive for downward tilt of the instrument to the South and East respectively. 
Thermometer and Barometer

The thermometer used in this study was a continuous reading thermograph. The thermometer is a bi-metallic coil that produced deflections of an ink pen with temperature changes. The recording paper was wrapped around a drum which was rotated by a clock motor. The thermometer was manufactured by Casella of London, England.

The barometer was similar to the thermometer in that the chart paper was placed on a drum that was rotated by a clock motor. The ink pin was connected to an expandable airtight bellows. Thus as the pressure varied the ink pen was deflected. The barometer was a Microbarograph Model B211 made by Weather Measure Corporation.

\section{Instrument Maintenance}

Maintenance of the equipment consisted mainly of checking the equipment three or four times a week to collect the data records so as to insure proper operation and replacement of power supplies. The power supplies used were two 12 volt batteries connected in series which powered two Rustrak chart recorders, two tilt meter channels, and one strain meter. These batteries had to be recharged about every 10 days. 


\section{INSTRUMENT INSTALLATION}

\section{Strain Meters}

Three extensometers and two biaxial tilt meters were installed for this study (see Figure 1). The extensometers were located approximately 1.3 meters below the ground surface and were horizontally oriented at $76^{\circ}, 138^{\circ}$, and $299^{\circ}$ clockwise from true North. In Figure 1, locations S1, S2 and S3 designate the sensor ends of the strain meters and $F$ is the location of their other ends. The ends of the strain meters were located inside large fiberglass drums, approximately 1.0 meter in diameter and 1.5 meters high, and were attached to the top of 5 inch aged steel casing that was buried an additional 1 meter in the ground. The tops of the drums were figerglass and were covered with 10 to 20 centimeters of dirt. Invar wire was stretched through 8 inch plastic pipe between the ends of the extensometers. See Figure 2 for a sketch of the installation. The strain meters were arranged to give the best coverage of the area available. A symmetrical array of $0^{\circ}, 120^{\circ}, 240^{\circ}$ would be preferred but because of limited space this was not possible. 


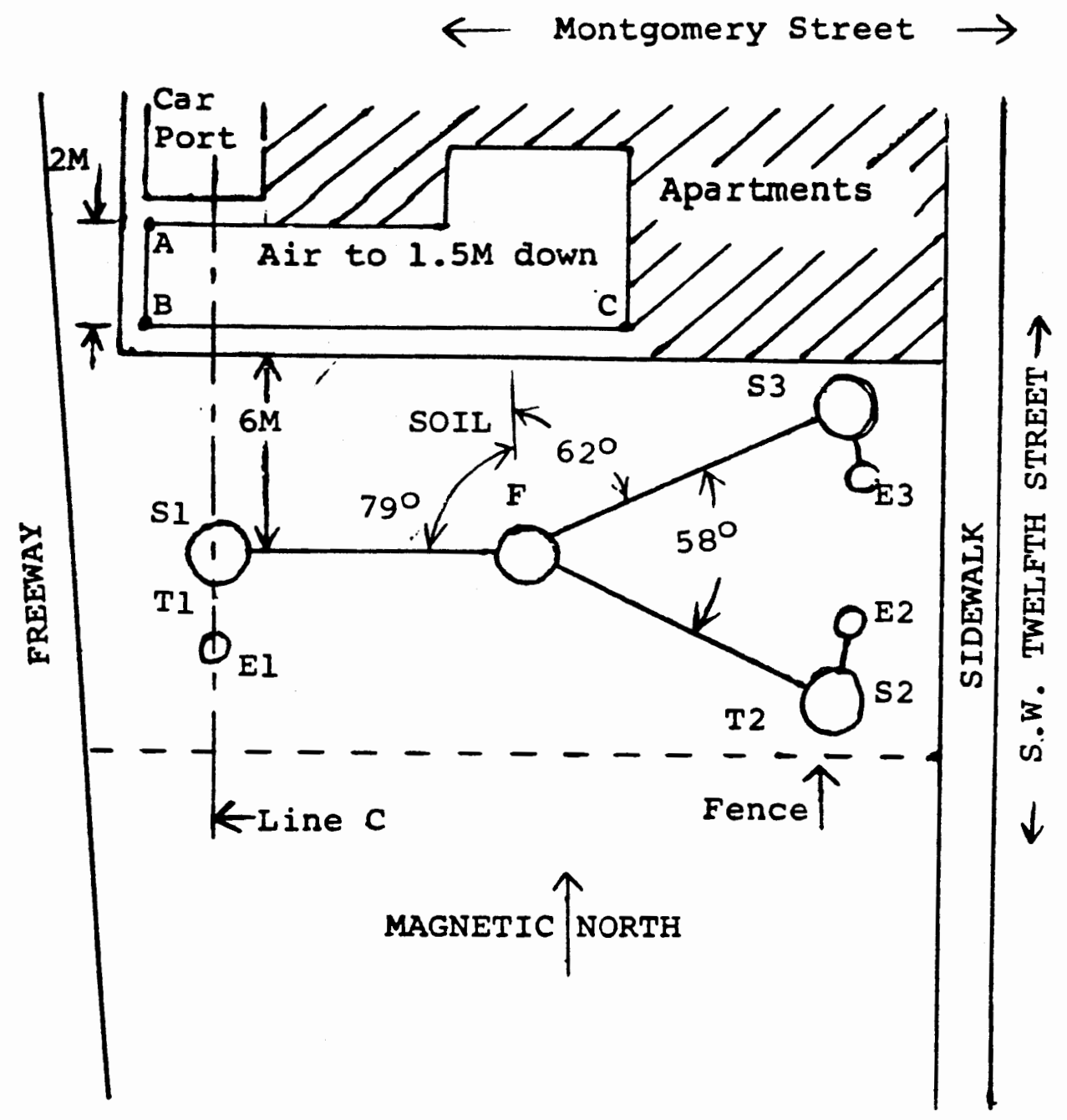

A. B, C Points of reference for calculations

T1. T2 Tilt meter locations

S1. 52. 53 Movable ends of strainmeters

$F$

Fixed end of strainmeters

E1, E2, E3 Electronic and power supplies

Figure 1. Plan view of study site. 

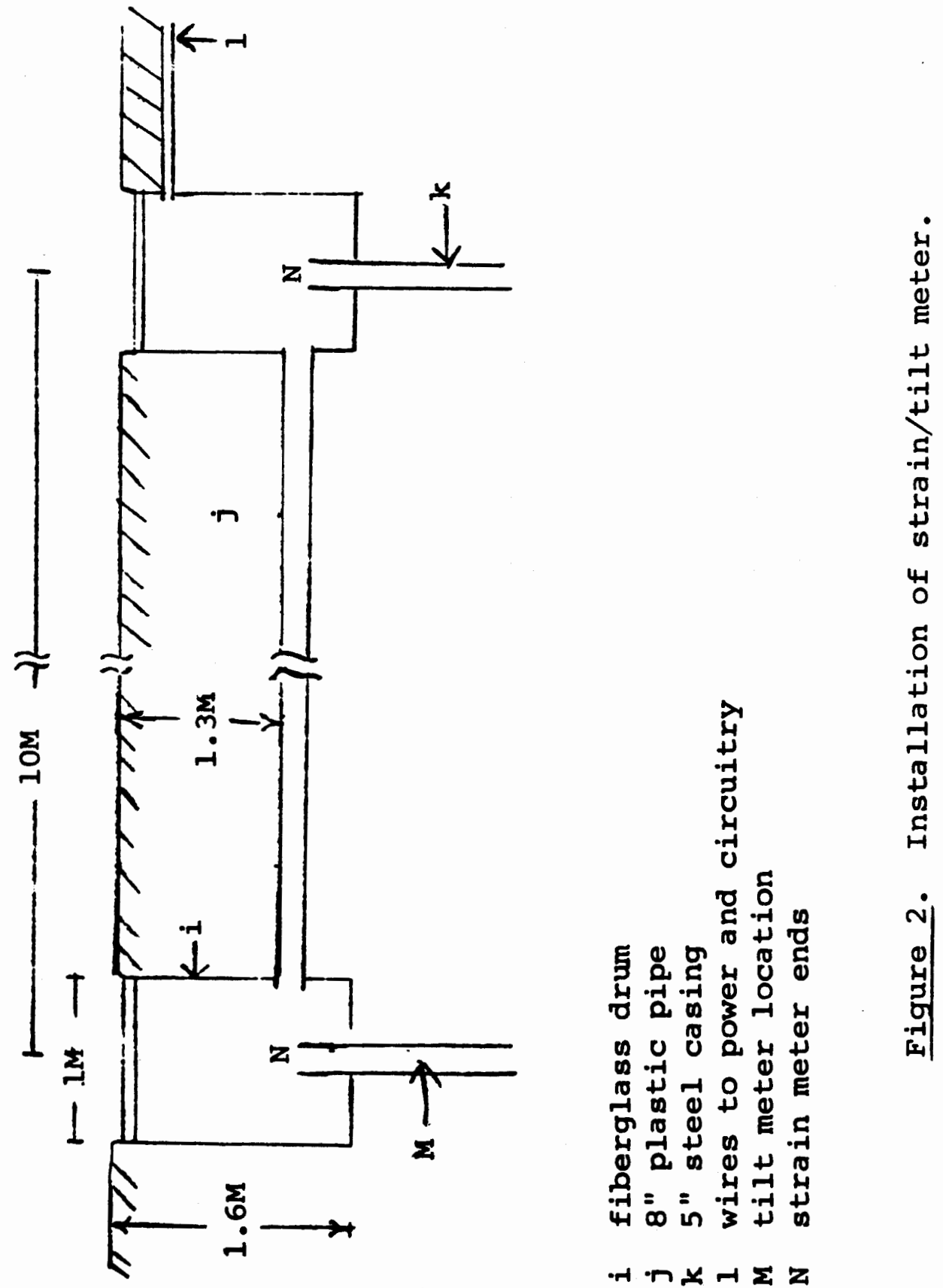

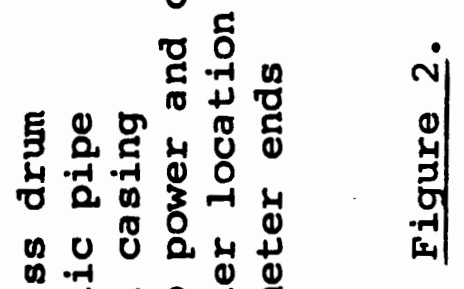

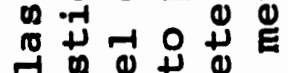
每思 年 م 出 1 in - ח ח 


\section{Tilt Meters}

The tilt meters were placed at two locations labeled $\mathrm{T} 1$ and $\mathrm{T} 2$ in Figure 1. They were set in the same 5 inch casing used for the strain meters and were surrounded by fine grain silica sand. This technique of installation is relatively standard (2).

The tilt meter electronics were located about $10-20$ centimeters below the top of the fiberglass drums and were electrically connected to the instrument by a large flexible cable. The power supplies and recording devices for both the strain and tilt meters were located underground in 50-gallon metal drums labeled EI, E2 and E3 of Figure 1. Also in these drums were the main circuitry for the strain meter amplification and power regulation. Continuous reading thermometers were also installed in Positions E2 and E3. Figure 3 shows a close-up sketch of a tilt meter installation.

\section{DATA RECOVERY AND DIGITIZATION}

The strain and tilt data were recorded on Rustrak strip chart recorders. Marks were made on the chart paper every 2 to 4 seconds as the paper moved with a speed of about $\frac{1}{2}$ inch per hour. The time and length for each record was measured and an average chart speed was calculated. From the chart 

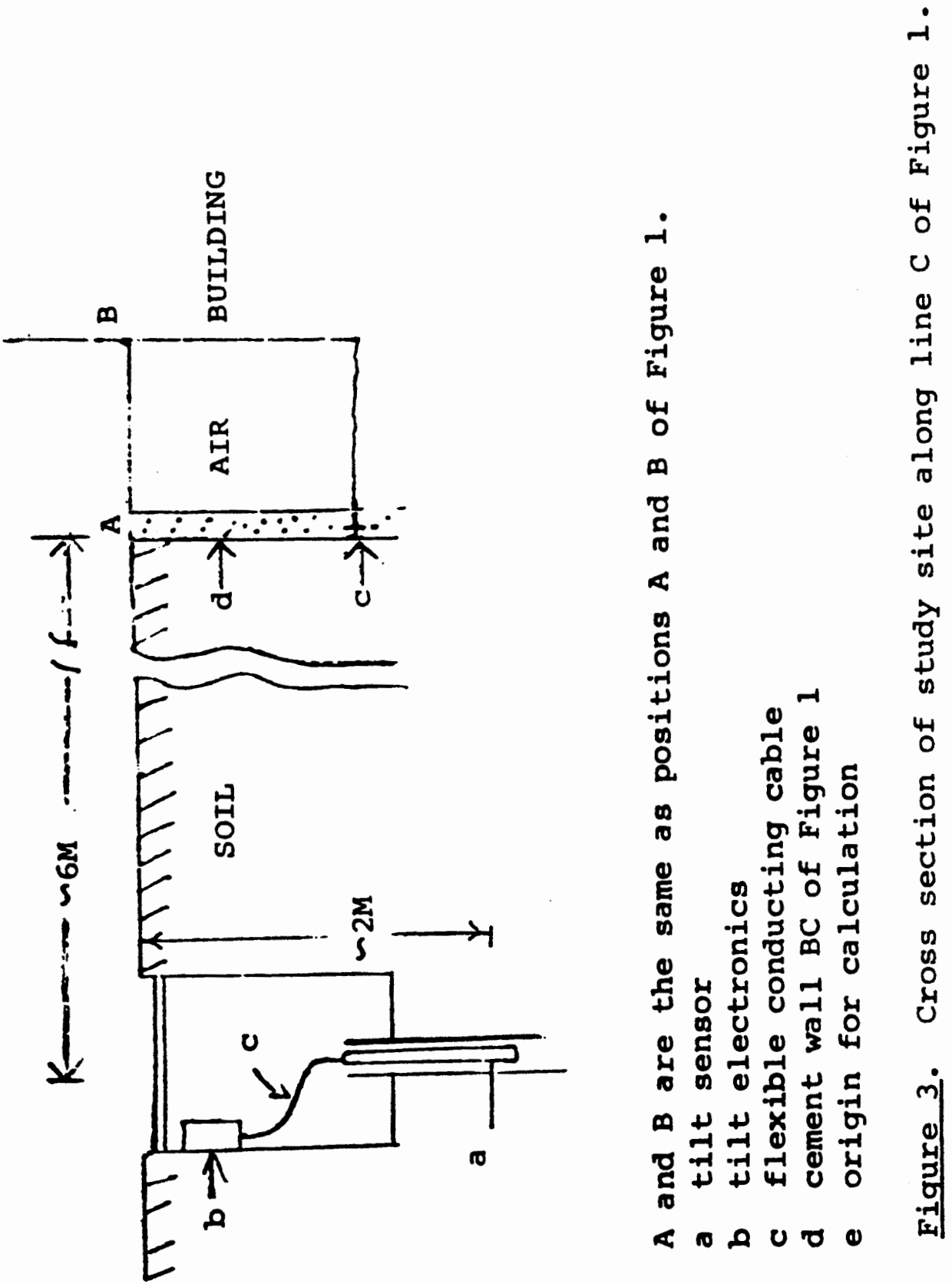
speed 1-hour time increments were marked off and the distance from a base line to the data curve was measured to the nearest $.1 \mathrm{~mm}$. The accuracy of this measurement was about $\pm .2 \mathrm{~mm}$ for most records that had little high frequency noise. High frequency noise associated with large trucks on the nearby Freeway caused the strain record line to be broader. Figure $4 a$ shows a raw strain record with high frequency noise appearing during hours of heavy traffic and very little noise at later hours. Several times it was noticed that this noise was amplified appreciably. When this occurred spider webs were found connected to the invar wire from the 8-inch plastic pipe. Removal of the webs eliminated this amplification. With a broad record line the best that could be done was to estimate the center of the distribution of points, thus losing some precision. The tilt meters were equipped with filters with time constants on the order of 80 seconds; hence they were not affected as much by traffic noise (Figure 4b).

To aid in the tedious process of digitization a simple transducer was designed. The chart record was fed through a spool, identical to the spool in the recorder, and then under a potentiometer. A pointer was moved across the potentiometer to the position of the recorded line. The output 

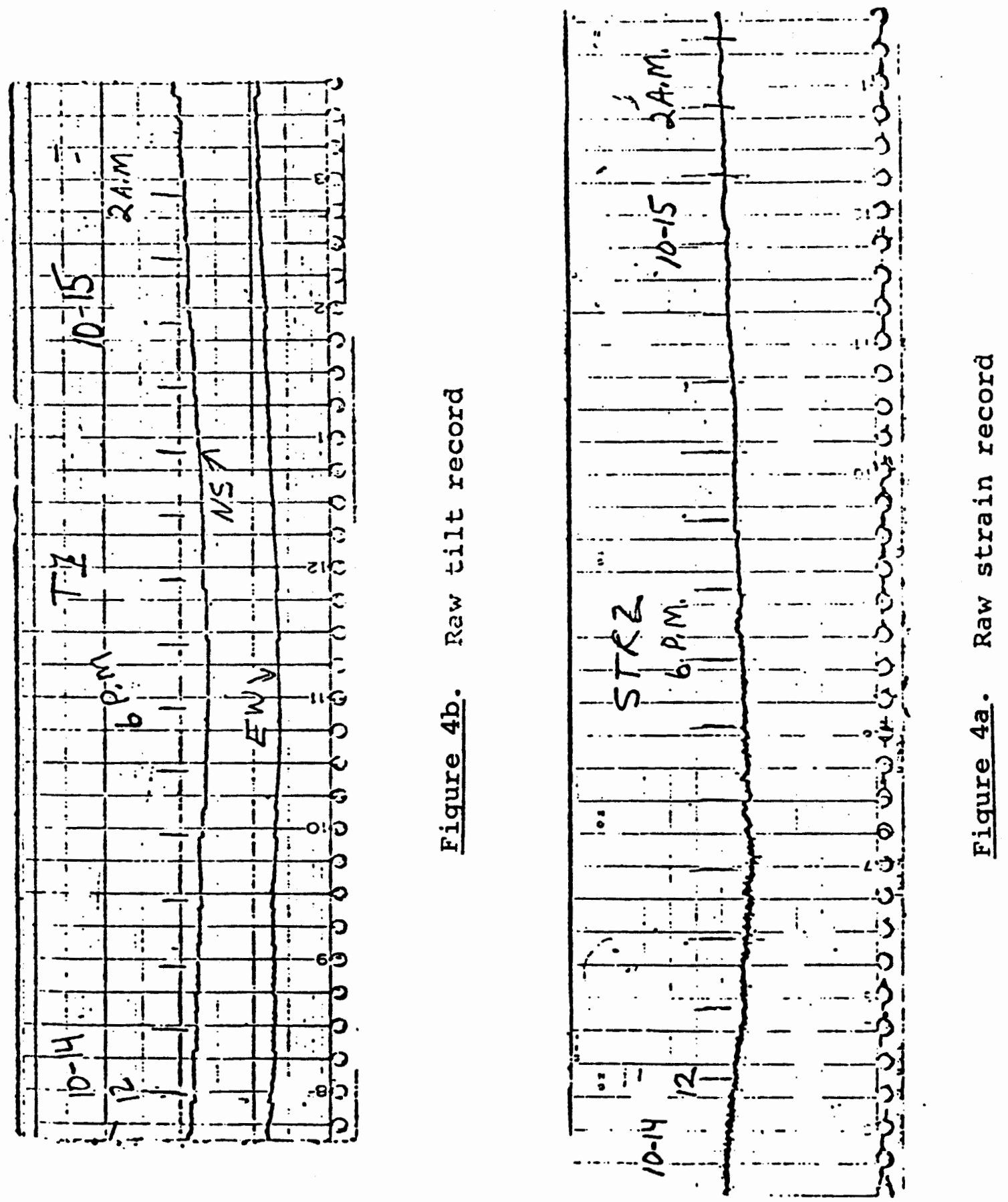
voltage of the potentiometer was linearly related to the distance from the base line to the recorded line. A calibration of this device gave a value of $15 \mathrm{mv} / \mathrm{mm}$. Thus the estimation of the data points was still dependent on the human eye. To aid in locating the pointer in the center of the record line a magnifying lens was placed above the apparatus. This set-up made it much more feasible to read many more records in one sitting because it made the estimation of the data points much less tedious. A comparison of the data obtained from each method is shown in Figures $5 a$ and $5 b$. The transducer could have been interfaced with a minicomputer so that the data could be directly input into the computer. This would eliminate possible errors in transferring the data from the chart to a data book and then from the book to computer by hand. Errors of this type are usually detected when inspecting the data curves and so are usually more troublesome than disastrous.

\section{DATA PRESENTATION AND INSTRUMENT PERFORMANCE}

Figures 6 through 14 show the performance of the various instruments during the study. The spurious signals and "flat" spots of the figures indicate that there were many problems with equipment operation and stability, particularly in the 

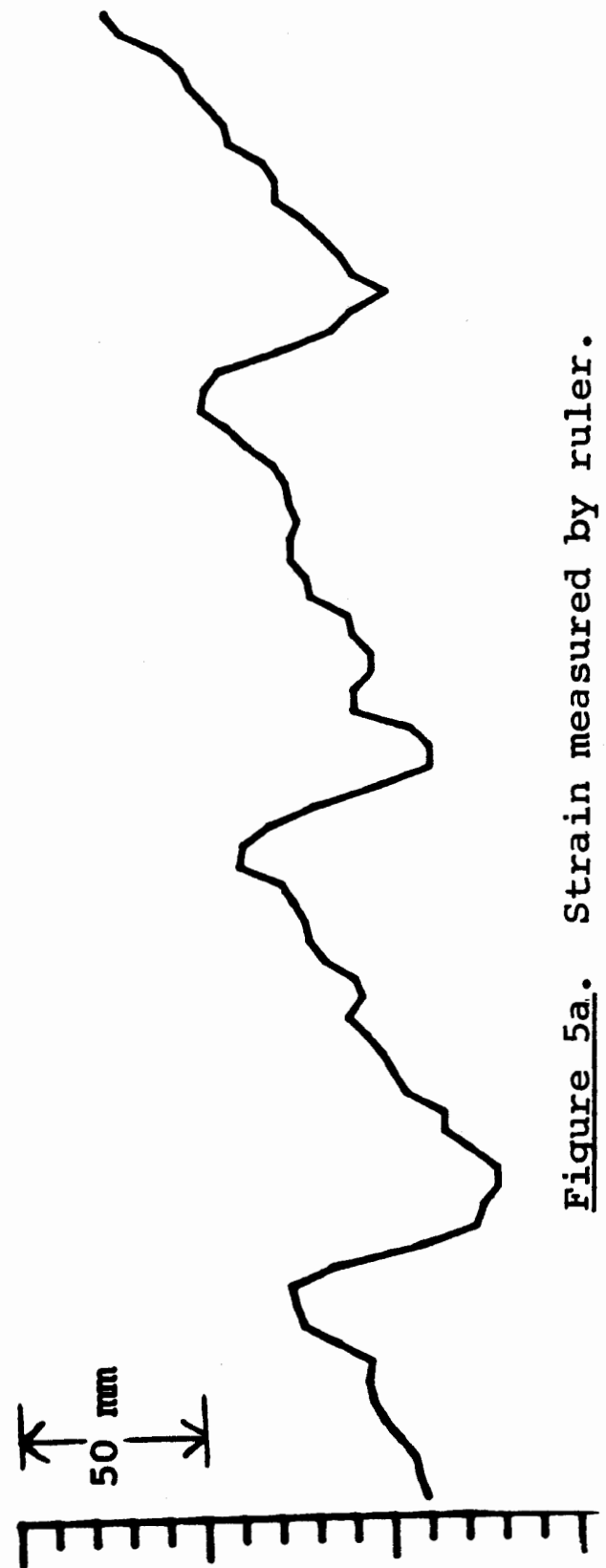

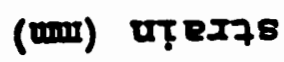

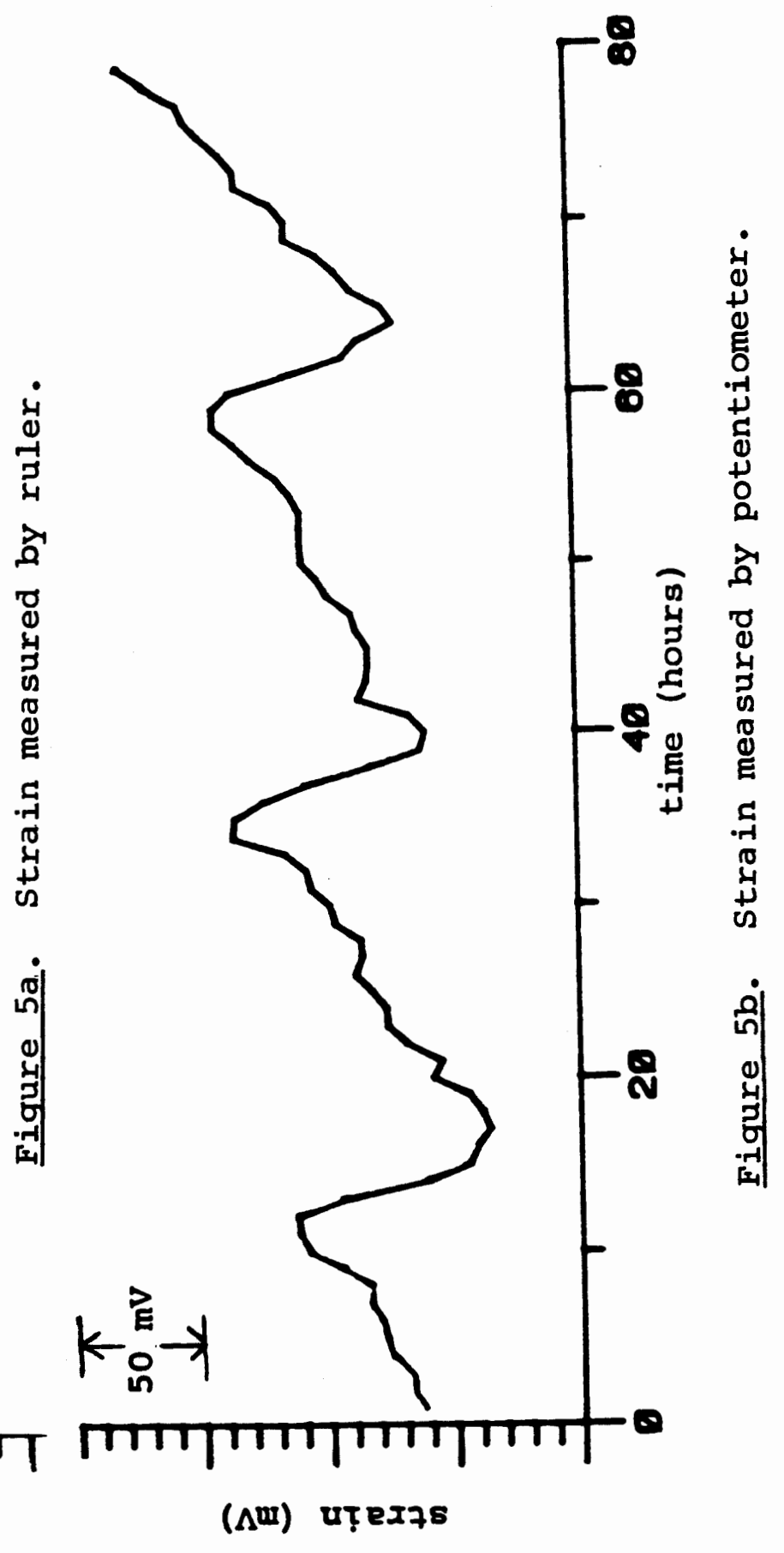




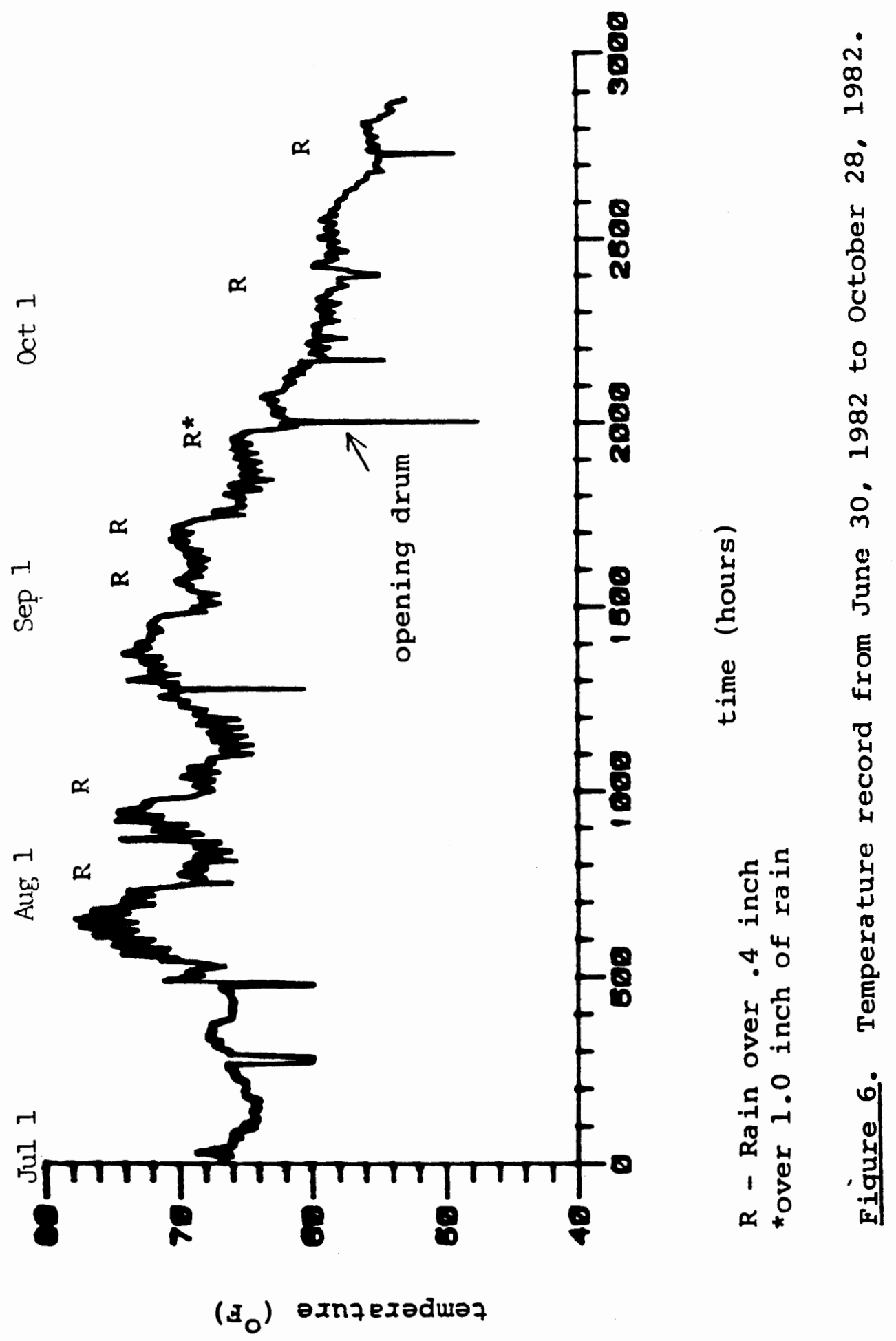




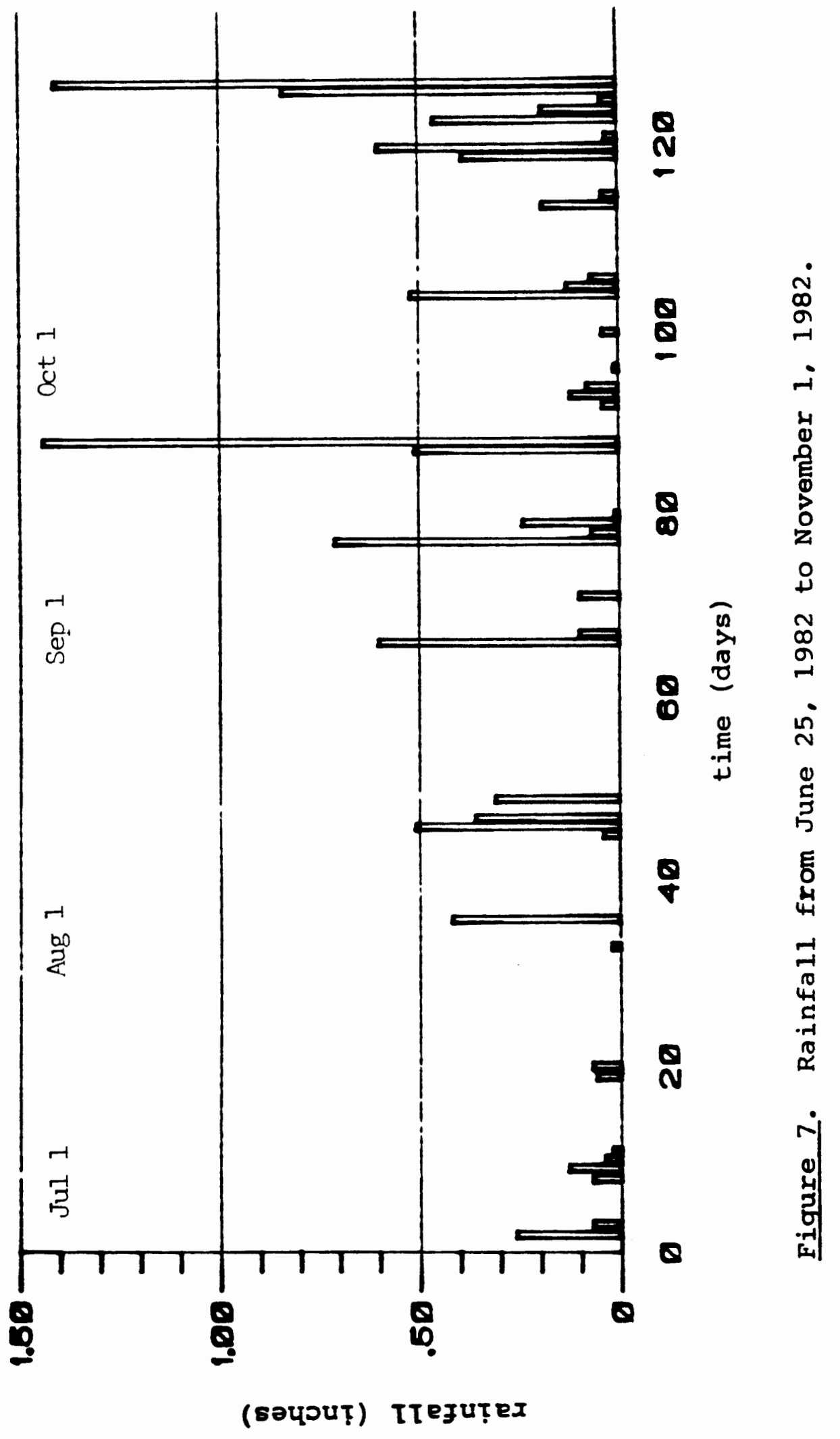




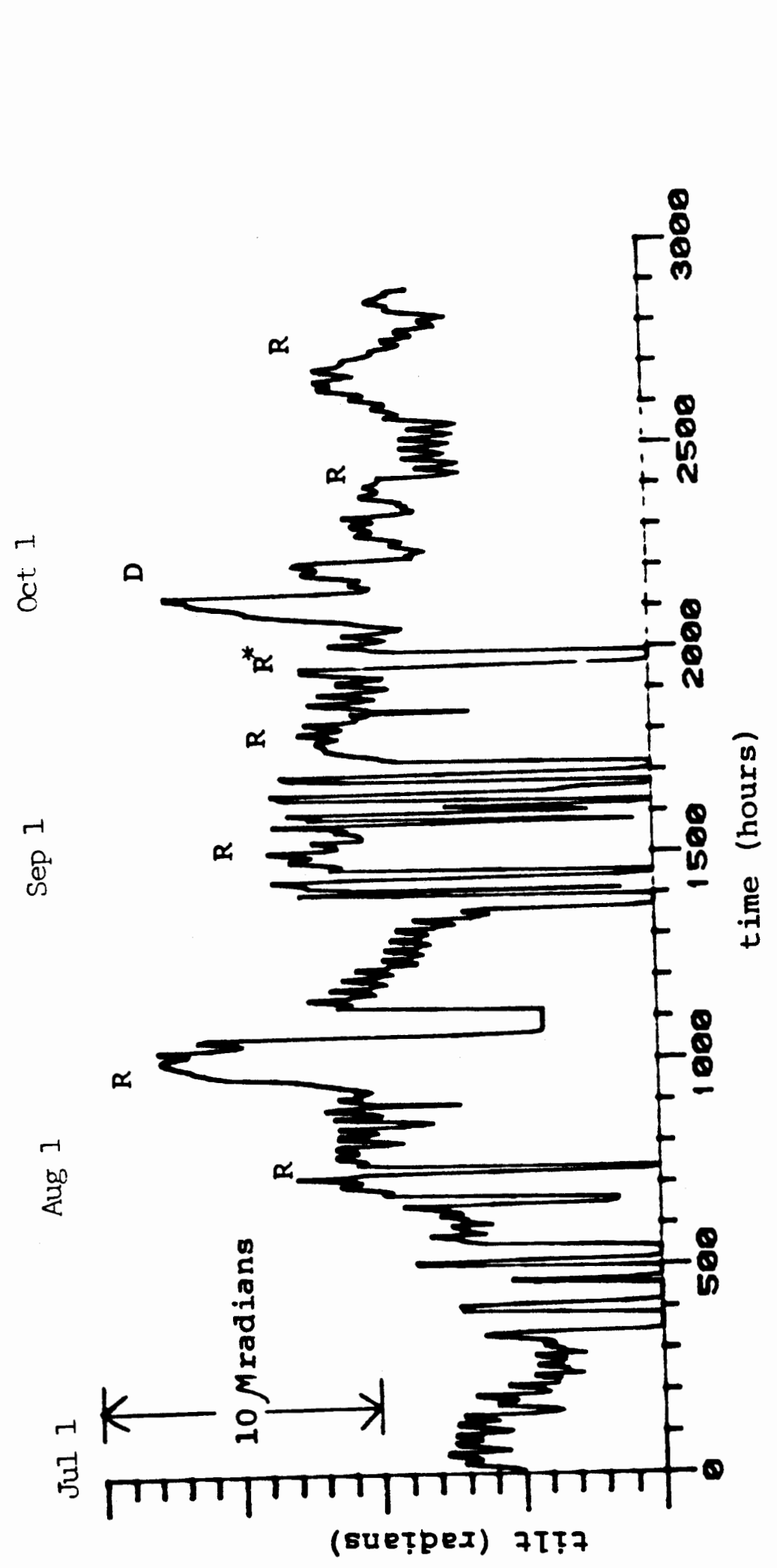

$\stackrel{\sim}{N}$

$\infty$

$\boldsymbol{N}$

4

ถู

웅

8

운

N

ฒ

$-1$

ì

岂

4 c

(1) ० 0 至 C : ह

.4

(1) 4

40
181 
$\stackrel{\square}{+}$

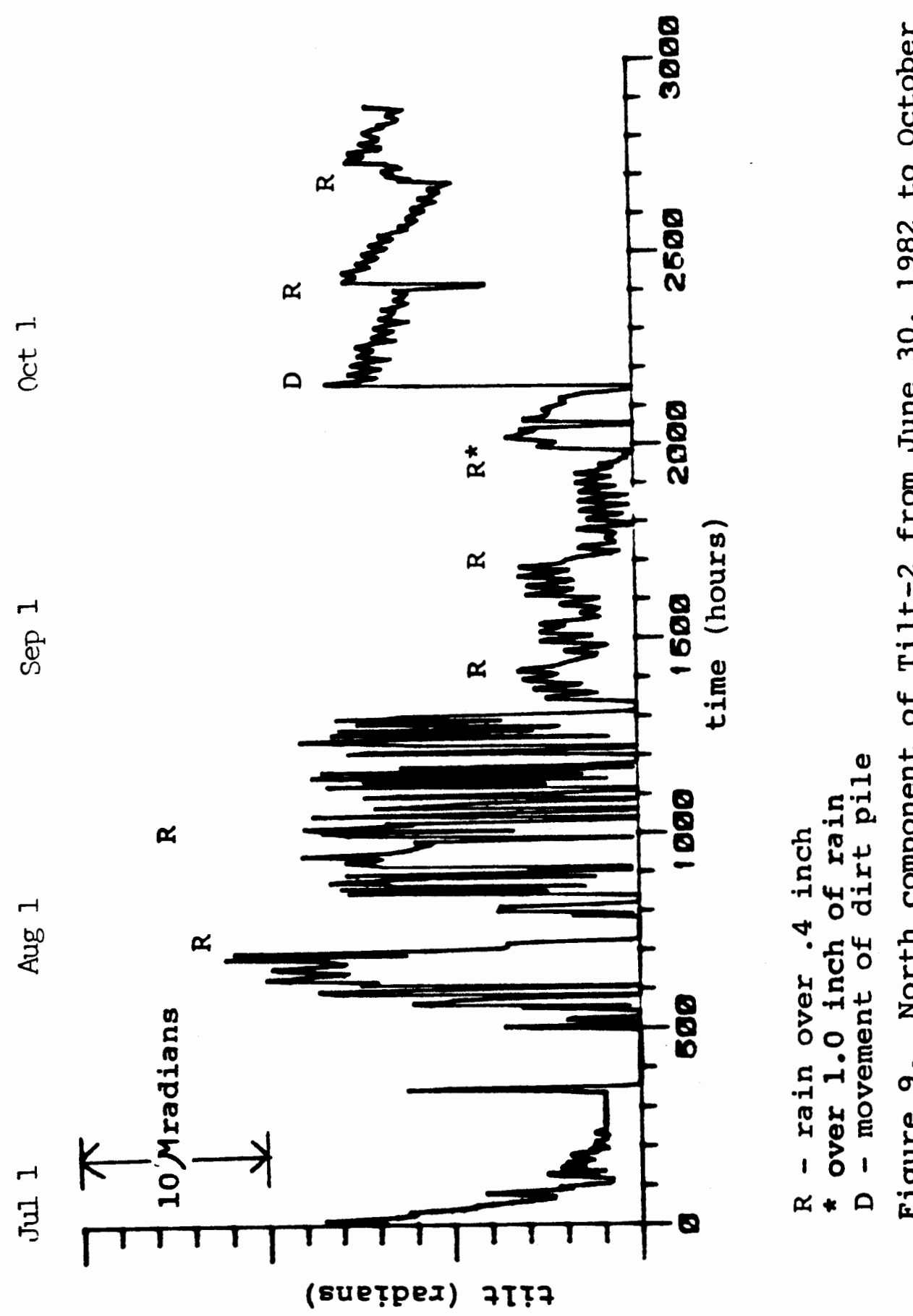

ஸ்

$\stackrel{\infty}{N}$

هั

+

N

迎

帘

్ㅜㅆ

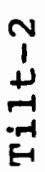

茨

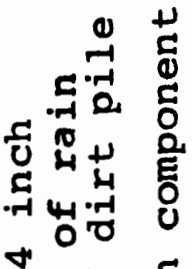

它出 站

幽艺员

ठ००

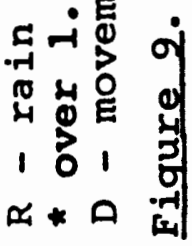

(suețpex) 7โTฺ 


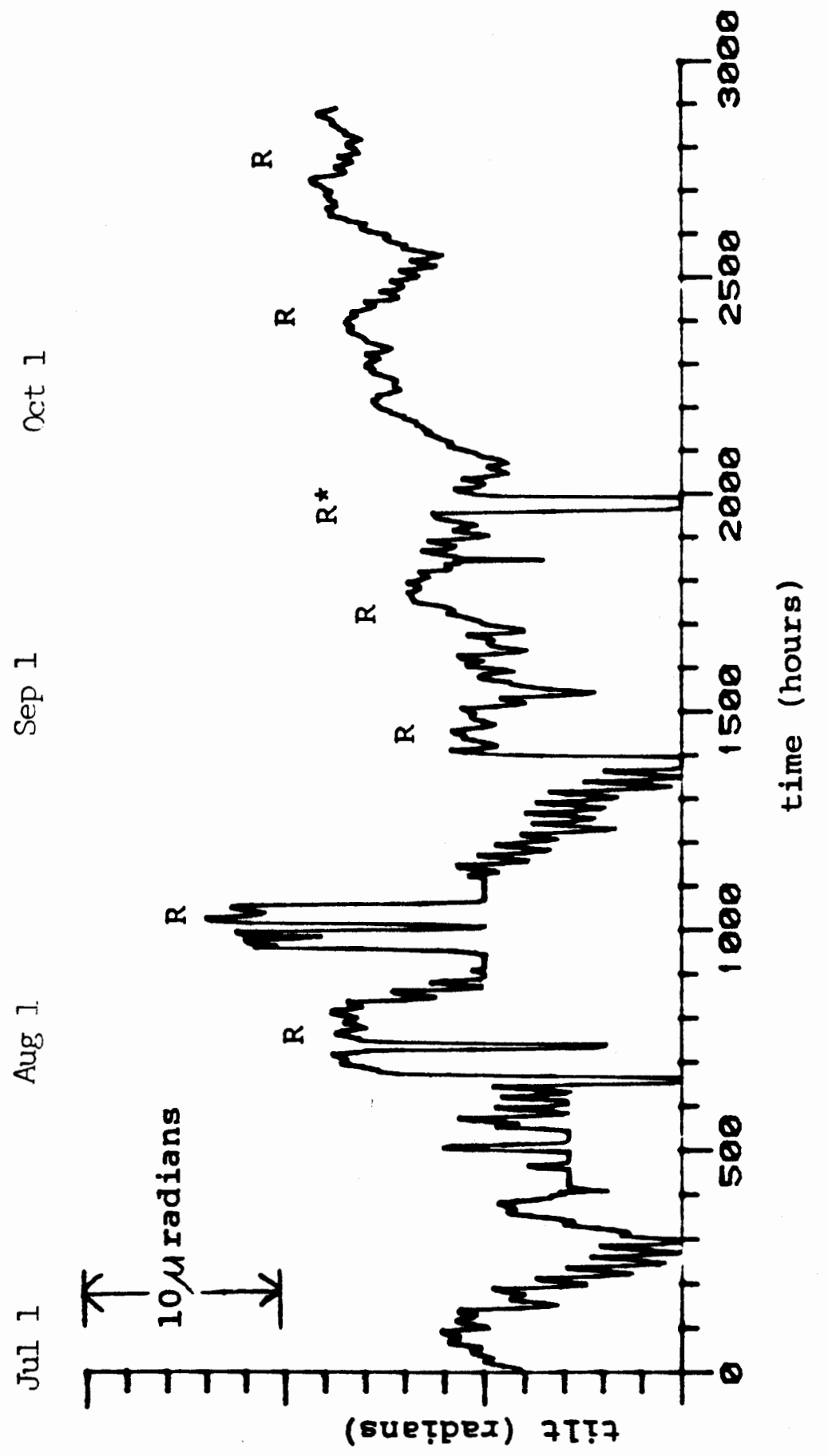

$\underset{\sim}{\dot{\infty}}$

$\stackrel{\infty}{\sim}$

4
0
0
0

i

ભ

i

岂

ह

I

崩

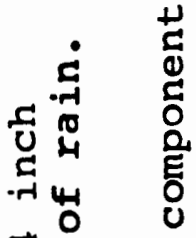

$\forall$

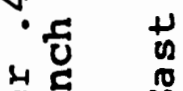

मू.

ठ००

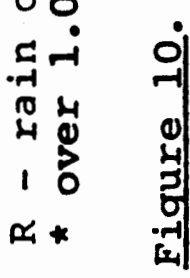




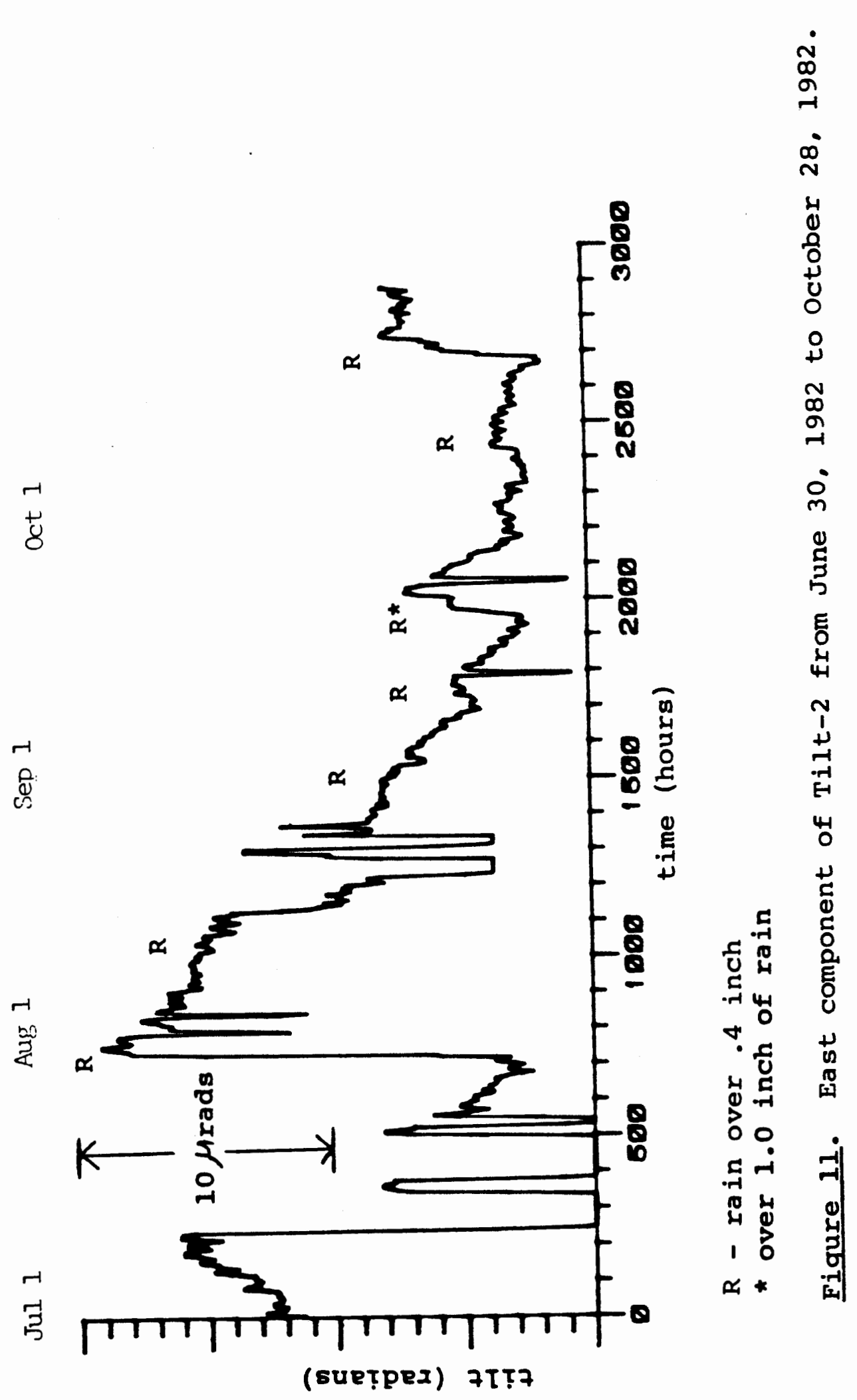




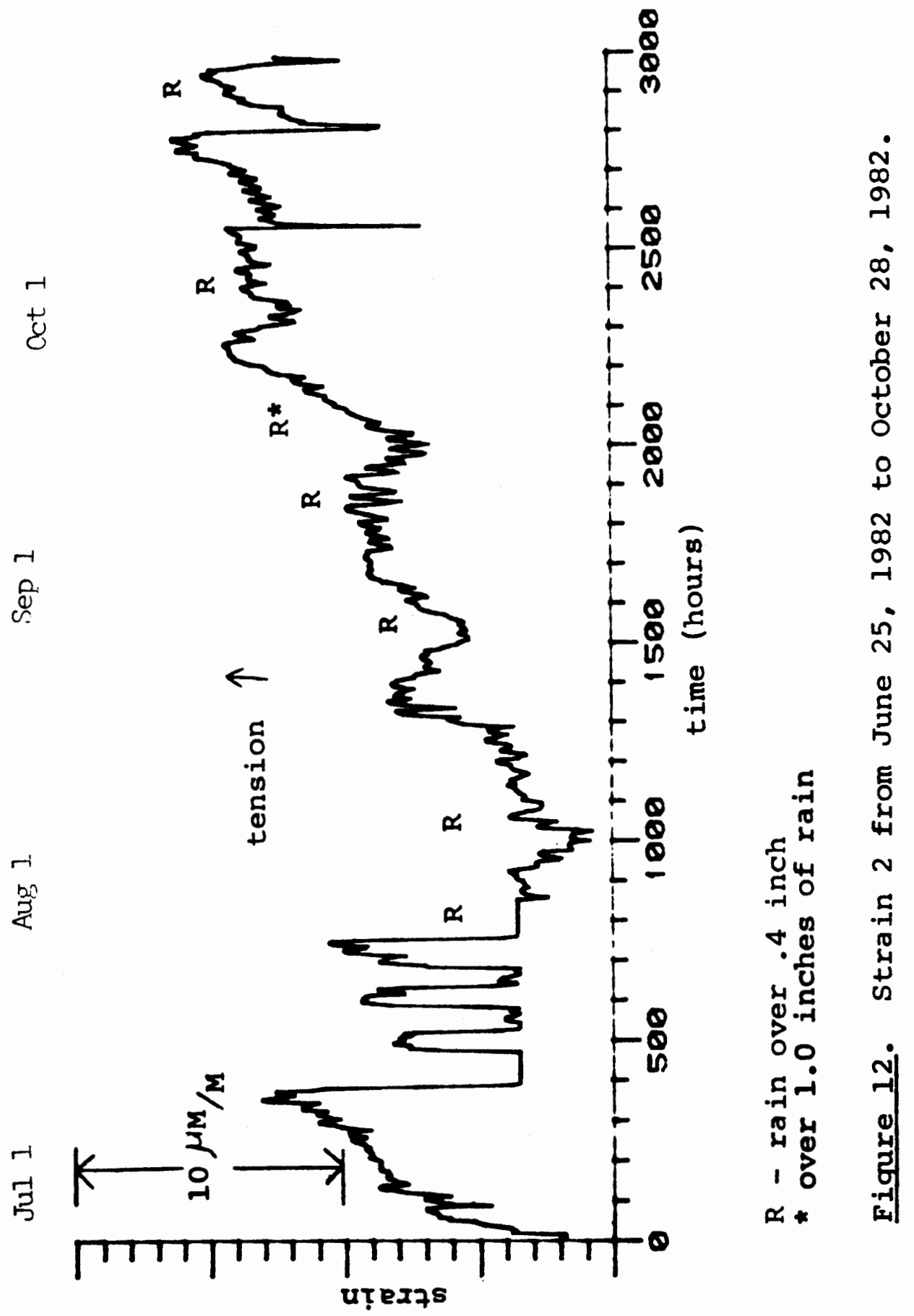




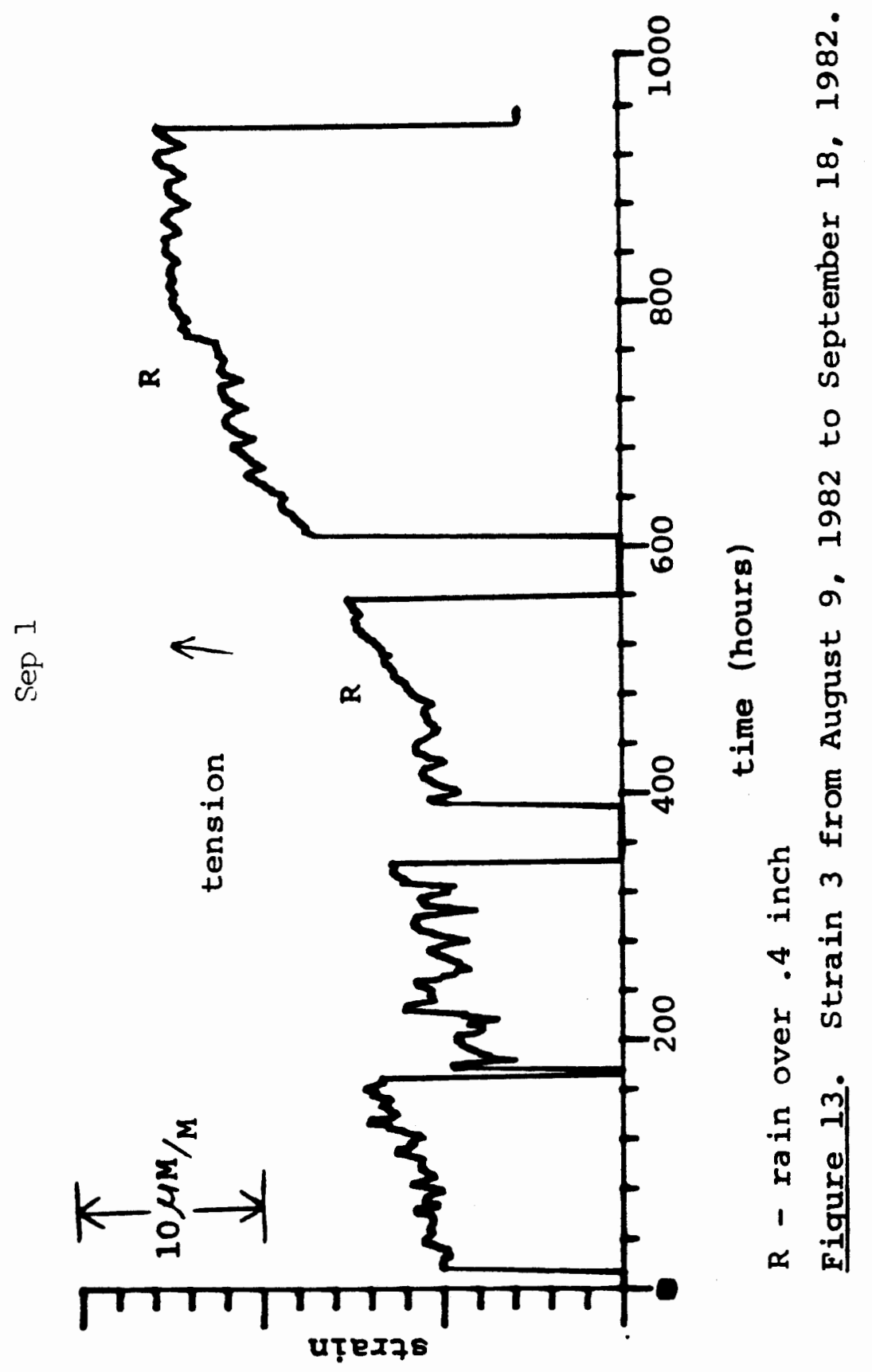




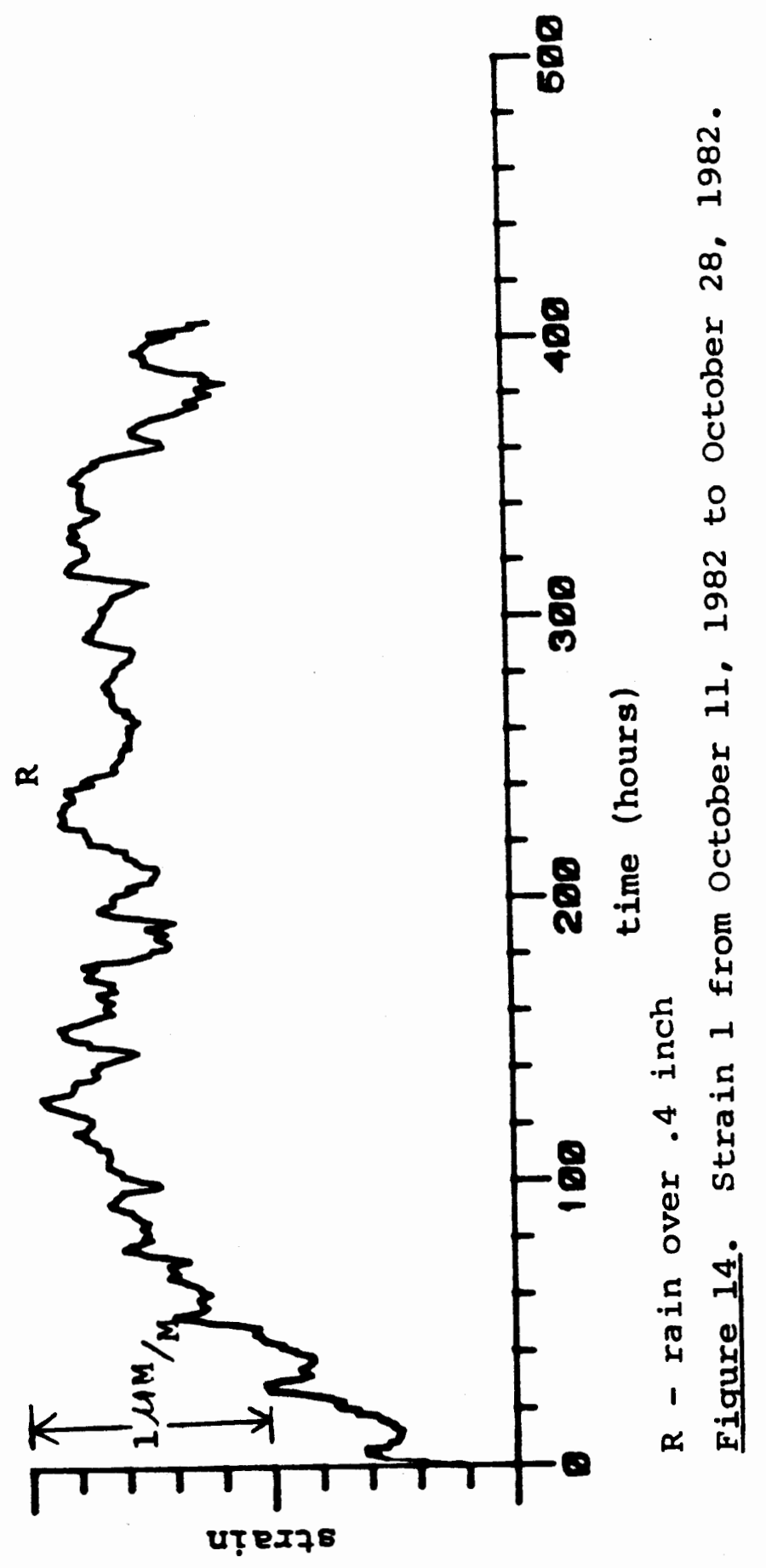


first two months of operation. Some of these problems included such simple things as the power supplies running down and not being detected for several days or the chart paper getting stuck. Other problems included occasional shorts or opens in circuitry, moisture in equipment, and recorders not operating. There also appeared to be instabilities associated with settling of the equipment and surrounding environment after installation. During August a gas line was installed near S2, S3 and T2 of Figure 1, causing some noise.

In September the movement of a large dirt pile from the south of $\mathrm{T} 2$ to the north of $\mathrm{T} 1$ caused downward tilts to the North to be observed on both records. See Figures 8 and 9 at time labeled $D$.

\section{DISCUSSION}

Some of the problems mentioned were unavoidable and are to be expected with a new installation of this type. However there are several things that could improve the quality of performance. The 50-gallon drums were crowded with recording devices, batteries and dircuitry. Every time batteries were changed or charts were removed we had to open up the drums and expose the equipment to the outside environment. In addition changing the batteries required rearrangement of 
the equipment, which seemed to increase the possibility of equipment failure. A small insulated equipment room on the surface could increase the organization and help keep things in a constant environment, thus minimizing problems and reducing noise associated with opening the drums (Figure 6). Finally a small room would make for a much easier place to repair things when repairs were necessary. Of course such a luxury could increase the time and cost of the initial installation and could also become a target for vandals. However the benefits might be worth the time and risk. Possible improvements in the data collection could be accomplished if the data was fed into a computer on real time. This would make it much easier to collect vast quantities of data.

Because power limitations and space are of concern in the field a telemetry device is most realistic. Most of the installations in the North American tilt network are equipped with such devices (8). Because they are able to deal with many more data points an analysis of a much broader spectrum can be realized. 
CHAPTER II

\section{SIGNAL ANALYSIS PROCEDURE}

INTRODUCTION

In this chapter we describe the analysis procedure used for the strain and tilt data.

A visual inspection of the series is an essential first step in the analysis. Filters can be used to isolate the frequency intervals of interest so they can be dealt with separately. The cross correlation function can reveal information about the relations between two signals and the autocorrelation function can give more information about a single signal. The use of the Fourier transform is essential for the determination of the frequency content of a signal. Various models are also available that can aid in pinpointing the sources of the observed signal.

\section{VISUAL INSPECTION}

A visual inspection of the data is essential before attempting further analysis $(9,10)$. Of primary importance is the detection and removal of "outliers" or wild observations that can greatly affect the correlograms (10). Also a visual inspection can be used to identify data that is 
questionable due to excessive noise or poor instrument performance.

\section{FILTERING}

After a visual inspection of the series a filtering operation was used to isolate the frequency intervals of interest. The observable frequencies have an upper and a lower bound. The sampling period, $\tau=1$ hour, sets the Nyquist frequency, $V_{n}=\frac{1}{2 \tau}$ which is the highest frequency obtainable from the data. The record length $\mathrm{L}$ determines the lowest frequency obtainable, $V_{L}=\frac{1}{2 L}$ The primary frequency interval of interest in this study is the interval containing the diurnal (24 hour period) and semidiurnal (12 hour period) components of the solid earth tides. Because of some high frequency noise present, a moving average filter, $I_{\mathrm{k}}$, was used such that

$$
\text { Eqn } 1 \quad z(t)=1 \underset{k}{(t)} * x(t)
$$

Where * denotes the convolution operation, $x(t)=\left(x_{1}, x_{2} \ldots x_{i} \ldots x_{n}\right)$ is the original signal, $z(t)=\left(z_{z} \ldots z_{i} \ldots z_{n}\right)$ is the filtered signal, and $l_{k}$ is defined by

$\underline{\text { Eqn } 2}$

$$
z_{i}=\frac{1}{2 k+1} \sum_{p=-k}^{k} x_{i+p}
$$


From the definition of the convolution of two signals, equation 2 gives

$$
\underline{\text { Ean } 3} \quad\left(I_{k}\right)_{i}= \begin{cases}0 & |i|>k \\ \frac{1}{2 k+1} & |i| \leq k\end{cases}
$$

and is thus a discrete square wave. This is a well known low pass filter $(2,11)$ whose frequency response is

Eqn 4

$$
\left[L_{k}(\omega)\right]=\left[\frac{\sin [(2 k+1) \omega \Delta t / 2]}{(2 k+1) \sin (\omega \Delta t / 2)}\right]
$$

Successive applications (convolutions) of this filter $n$ times yields a filter whose frequency response is given by

Eqn 5

$$
\left[L_{k}(\omega)\right]^{n}
$$

and can thus sharpen the cut-off frequency and minimize the tailing effect at higher frequencies. A high pass filter, $h_{m}$, was used for trend removal, where $h_{m}$ is defined by

$$
\text { Ean } 6 \quad z_{i}=x_{i}-\frac{1}{2 m+1} \sum_{r=-m}^{m} x_{i+r} \text { and } z(t)=h_{m}(t) * x(t)
$$

The frequency response of $j$ applications of $h_{m}$ is

$$
\text { Egn } 7 \quad\left[\mathrm{~F}_{\mathrm{m}}(\omega)\right]^{j}=\left[1-\left[\frac{\sin [(2 m+1) \omega \Delta t / 2}{(2 m+1) \sin (\omega \Delta t / 2)}\right]\right]^{j}
$$

The most commonly used filters in this study were $\left[l_{1}\right]^{1}$ and $\left[\mathrm{h}_{12}\right]^{2}$ Their frequency response functions are shown in figures $15 \mathrm{a}$ and $15 \mathrm{~b}$. 


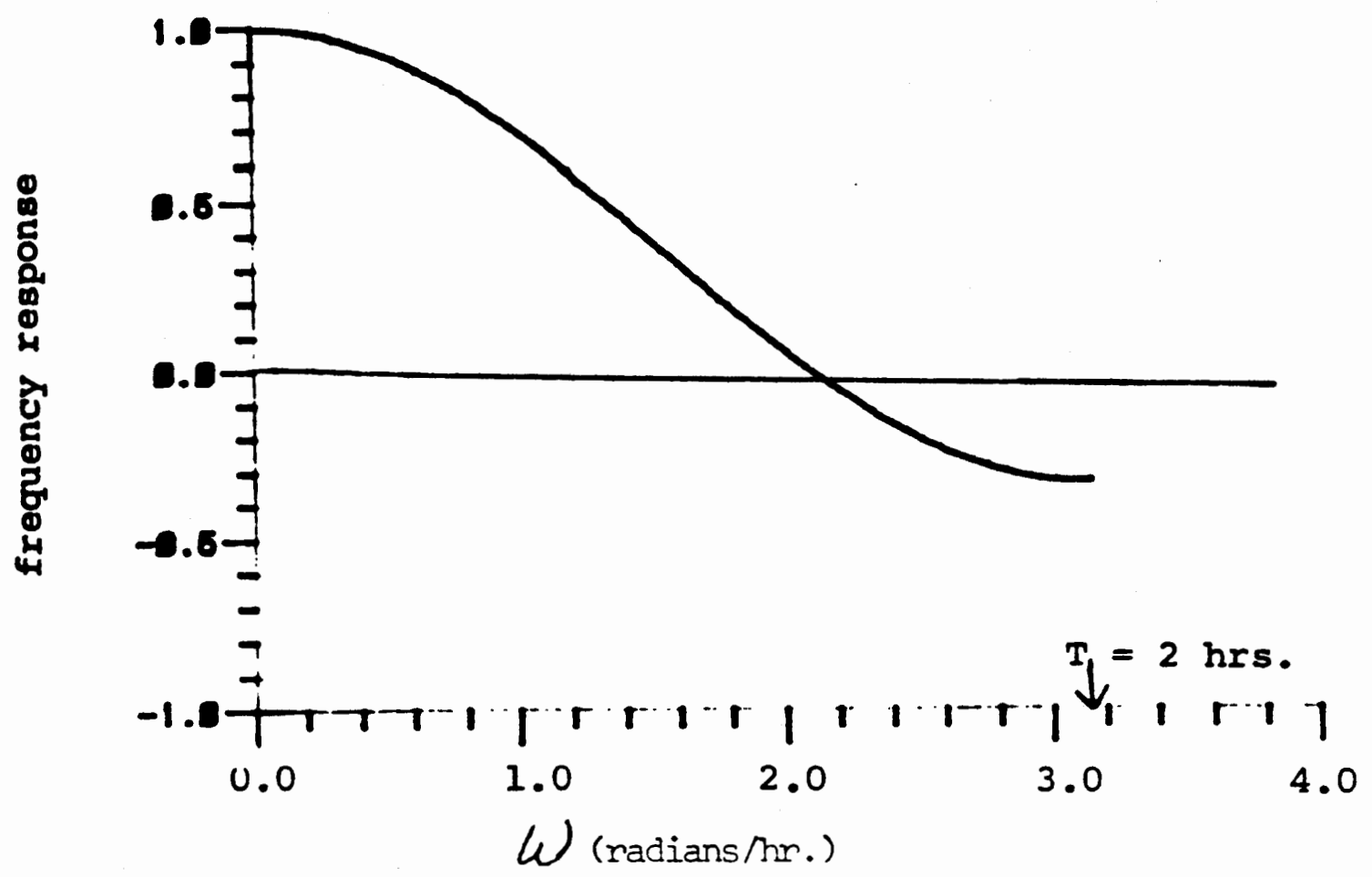

Fiqure 15a. Frequency response of low pass filter.

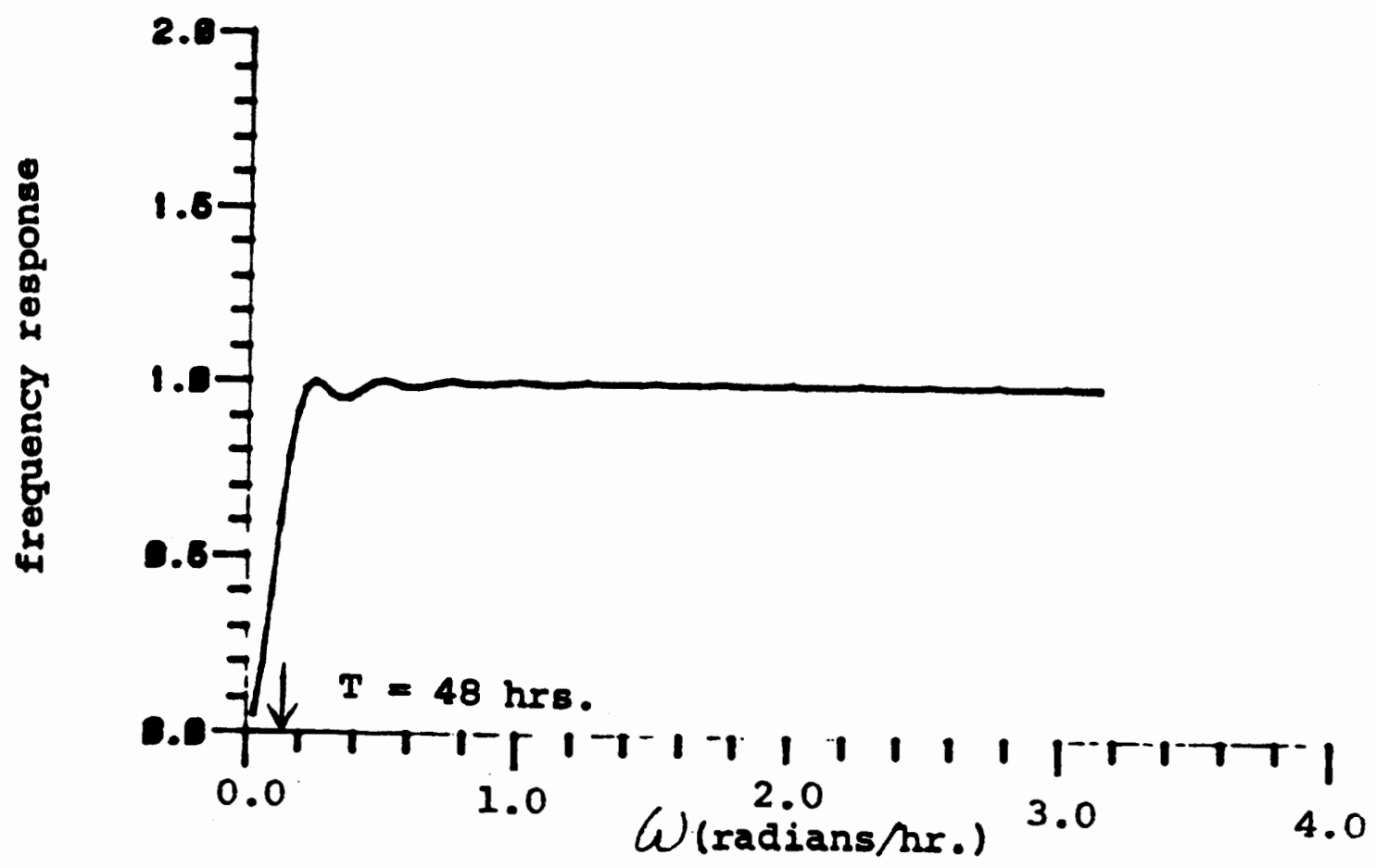

Fiqure 15b. Frequency response of high pass filter. 
Now if, $z=\left(l_{k}\right)^{n} *\left(h_{m}\right)^{j * x}$, then the Fourier transforms $z(\omega),\left[\mathrm{L}_{k}(\omega)\right]^{n} \cdot\left[\mathrm{H}_{\mathrm{m}}(\omega)\right]^{j}$ and $\mathrm{X}(\omega)$ respectively are related by

$\underline{\text { Egn } 8} \quad z(\omega)=\left[L_{k}(\omega)\right]^{n}\left[H_{m}(\omega)\right]^{j} x(\omega)$

Thus the gain $A(\omega)$ of the filtered series is frequency dependent and is given by

Egn 9

$$
A(\omega)=\left[\mathrm{L}_{k}(\omega)\right]^{\mathrm{n}}\left[\mathrm{H}_{\mathrm{m}}(\omega)\right]^{\mathrm{j}}
$$

See reference 12 .

The gain, $A(\omega)$, for the five most important tidal

frequencies in the frequency interval of interest are given in Table II for a 3-hour moving average low pass filter applied once and a 25-hour moving average high pass filter applied twice $(2 \mathrm{k}+1=3 ; \mathrm{n}=1 ; 2 \mathrm{~m}+1=25 ; j=2)$.

\section{TABLE II}

FREQUENCY RESPONSE OF HIGH AND LOW PASS FILTER COMBINATION $(2 \mathrm{k}+1=3 ; \mathrm{n}=1 ; 2 \mathrm{~m}+1=25 ; j=2)$ FOR THE PRIMARY TIDAL FREQUENCIES

\begin{tabular}{cccc}
$\begin{array}{c}\text { Tidal } \\
\text { Component }\end{array}$ & $\begin{array}{c}\text { Frequency } \\
\text { (radian/hr) }\end{array}$ & $\begin{array}{c}\text { Period } \\
(\mathrm{hr})\end{array}$ & $\begin{array}{c}\text { Frequency } \\
\text { Response } \\
\mathrm{A}(\mathrm{N})\end{array}$ \\
\hline $\mathrm{O}_{1}$ & .23385 & 26.868 & .840 \\
$\mathrm{~K}_{1}$ & .26252 & 23.934 & 1.060 \\
$\mathrm{~N}_{2}$ & .49637 & 12.658 & .943 \\
$\mathrm{M}_{2}$ & .50587 & 12.421 & .911 \\
$\mathrm{~S}_{2}$ & .52360 & 12.000 & .909
\end{tabular}


The cross correlation function, $r_{x y}(\tau)$, between two signals can reveal any dependence between the two series as well as give an indication of relative phases. Before determining the cross correlation function, the series were filtered and their averages were removed. An estimation of $r_{x y}(\tau)$ was obtained from a slightly modified program given in reference 13 such that

Egn 10

$$
r_{x y}(\tau)=\frac{1}{\sigma_{x} \sigma_{y}} \sum_{t=\tau}^{N} x(t-\tau) y(t)
$$

where $\sigma_{x}$ and $\sigma_{y}$ denote the standard deviation of $x$ and $y$ respectively, and $\mathrm{N}$ is the number of data points in the series.

In addition to the uses already stated for $r_{x y}(\tau)$, $r_{x y}(0)$ was also used in the development of the linear model to be discussed later.

The auto-correlation function $r_{x x}(\tau)$ was also used in this study. The primary use of the auto-correlation was to reveal dominant periodicities contained within the signal. The auto-correlation of a function is essentially a filter that can suppress noise from a signal (14, Chap. 14). In addition the Fourier transform of $r_{x x}(\tau)$ can yield the power spectrum; this is the well known Wiener-Khintchine theorem (14). 
FOURIER TRANSFORM

The discrete Fourier transform of the filtered signals was used to obtain their amplitude spectra. The discrete Fourier cosine and sine transforms are defined to be

Egn 1la

$$
a_{m}=\frac{2}{N} \sum_{i=1}^{N} x_{i} \cos \frac{2 \pi m}{N} i \tau
$$

and

Ean 11b $\quad b_{m}=\frac{2}{N} \sum_{i=1}^{N} x_{i} \sin \frac{2 \pi m}{N} i \uparrow$

where $\tau$ is the sampling period of 1 hour and $N$ is the number of data points in the series $X(t)$.

A program modified from Davis (15) was used which computed the Fourier transforms directly from the above equations. Other much more elegant and efficient ways of computing the Fourier transforms are available (16) and would have been utilized if the record lengths had been much longer.

In this study the amplitude of the Fourier transform

$$
\text { Eqn } 12 \quad A_{m}=\sqrt{a_{m}^{2}+b_{m}^{2}}
$$

was inspected so that similarities of frequency content between two signals could be detected. In addition, the phase of a given frequency, $\omega_{m}=\frac{2 \pi m}{N}$, present in a signal was 
determined by

$$
\text { Eqn } 13 \quad \varnothing_{m}=\tan ^{-1} \frac{b_{m}}{a_{m}}
$$

\section{LINEAR MODEL}

A linear model was used in this study to estimate the influences of various signals on the recorded tilt and strain data.

The model assumes that

Eqn $14 \quad y(t)=\sum_{i=1}^{k} B_{i} x_{i}(t)+\epsilon(t)$

where $y(t)$ is a dependent variable and there are $k$ independent variables $x_{i}(t) ; \epsilon(t)$ is a measure of the error of the model. The coefficients, $B_{i}$, are selected such that

$\underline{\text { Eqn } 15} \quad \sigma_{D}^{2}=\sum_{j=1}^{N}\left(y_{j}-\sum_{i=1}^{k} B_{i} x_{i j}\right)^{2}$

is minimized with respect to variations of $B_{i} \cdot x_{i j}$ in equation 15 denotes the $j$ th component of $x_{i}(t)=\left(x_{i 1}, x_{i 2}, \ldots x_{i j}, \ldots x_{i n}\right)$. We can minimize the squared error by solving the set of simultaneous equations 
for $b_{i}$ written in matrix form as

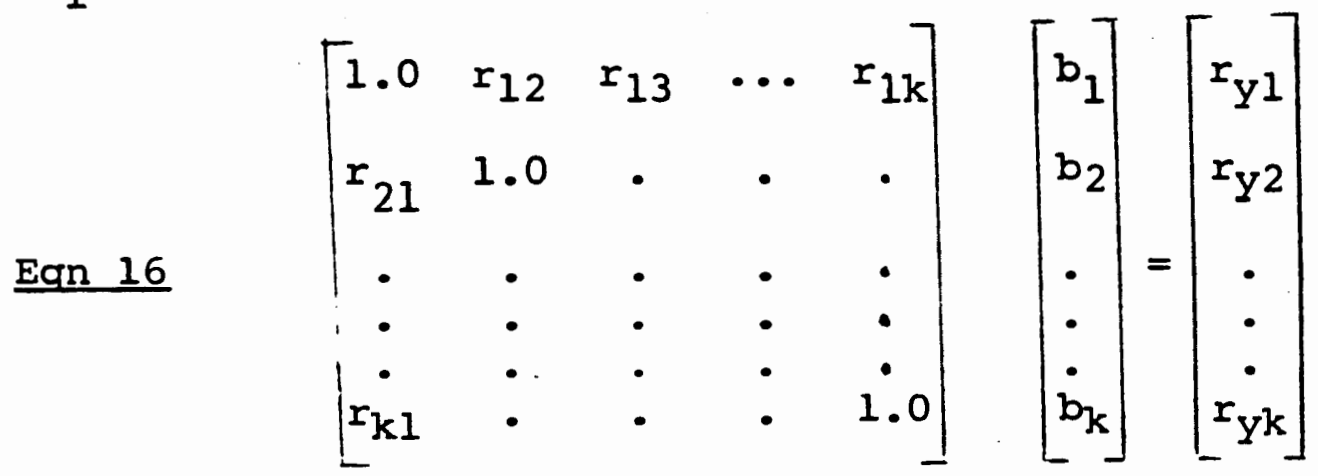

where $r_{i j}$ is the cross correlation at zero lag of $x_{i}$ with $x_{j}$. We can then find $B_{i}$ by the equation

Egn $17 \quad B_{i}=\frac{\sigma_{y}}{\sigma_{i}} b_{i}$

where $\sigma_{y}$ and $\sigma_{i}$ denote the standard deviation of $y$ and $x_{i}$ respectively. It should also be noted that equation 16 is valid only if $\mathrm{y}$ and the $\mathrm{x}_{i}$ 's have zero means. It is also assumed that any phase differences between $y$ and the $x_{i}$ 's have been eliminated. For a more detailed discussion of the above techniques the reader is referred to references 15 and 17.

Significance of the Linear Model

A statistical approach was used to obtain a quantitative estimate of the "goodness of fit" of the model to the data. An outline of the method will be given here. The reader is referred to references 15 and 17 for a more detailed discussion. 
Given the linear model

Eqn $14 \quad y(t)=\sum_{i=1}^{k} B_{i} x_{i}(t)+e(t)$

where $y(t)=\left(y_{1}, y_{2}, \ldots y_{j}, \ldots y_{N}\right)$.

$x_{i}(t)=\left(x_{i 1}, x_{i 2}, \ldots, x_{i j}, \ldots, x_{i N}\right)$ and

$\epsilon(t)=\left(\epsilon_{1}, \epsilon_{2}, \ldots \epsilon_{j}, \ldots \epsilon_{N}\right)$. We define

Egn $18 a$

$$
\sigma_{T}^{-2}=\sum_{j=1}^{N}\left(y_{j}\right)^{2} \text { and }
$$

Eqn $18 b$

$$
\sigma_{D}^{2}=\sum_{j=1}^{N}\left(\epsilon_{j}\right)^{2}
$$

$\sigma_{T}^{2}$ is the estimated variance of the original series and $\sigma_{\mathrm{D}}^{2}$ is the estimated variance of the error or residual series.

The "goodness of fit" of the data to the model can be defined as

Eqn 19

$$
\mathrm{R}^{2}=\frac{\sigma_{\mathrm{T}}^{2}-\sigma_{\mathrm{D}}^{2}}{\sigma_{\mathrm{T}}^{2}}
$$

The square root of $\mathrm{R}^{2}$ is known as the multiple correlation coefficient (15).

To test the statistical significance of using an additional independent variable $x_{i}(t)$ in our model we use an $F$ statistical test. Bevington (17) defines a statistic which 
follows an $\mathrm{F}$ distribution with $\nu_{1}=1$ and $\nu_{2}=\mathrm{N}-\mathrm{k}-1$ to be

Egn 20

$$
F_{\chi}=\frac{\chi^{2}(k-1)-\chi^{2}(k)}{\chi^{2}(k) /(N-k-1)}
$$

where

$\underline{\text { Eqn } 21} \quad \chi^{2}(k)=\frac{1}{\sigma_{I^{2}}} \sum_{j=1}^{N} \quad\left(\epsilon_{j}\right)^{2}=\frac{\sigma_{D^{2}(k)}}{\sigma I^{2}}$

$\sigma_{I}^{2}$ is the uncertainty of the data points and is inserted for a normalization factor and $\sigma_{D}^{2}(k)$ is $\sigma_{D}^{2}$ for a model with $\mathrm{k}$ independent variables. We can rewrite equation 20 for our purposes as

Ecn 22

$$
F_{x}=\frac{\left(\sigma_{D(k-1)}\right)^{2}-\left(\sigma_{D}(k)\right)^{2}}{\left(\sigma_{D}(k)\right)^{2} /(N-k-1)}
$$

A large value of $\mathrm{F}_{\chi}$ indicates a statistically significant decrease in the squared error by the addition of the kth term to the model. For example, a value of $\mathrm{N}-\mathrm{k}-1=215$ an $F_{\chi}$ value of 3.8 suggests a contribution to the model at the $5 \%$ level of significance. 
Some simplifying notation will be used throughout the rest of this paper. A segment tilt or strain record will be designated by:

INSTRUMENT; DATE; STARTING TIME (PDT); RECORD LENGTH For example, NTl; 8-16; 0900;220 -- will be used to indicate data obtained from the North/South component of the tiltmeter located at position $\mathrm{Tl}$ on Figure 1. The collection of the data began on August 16, 1982 at 0900 PDT, and two hundred twenty hours of data were obtained. The temperature and pressure data will be labeled by $T$ and $P$ respectively and will have the same starting time and length as the primary tilt or strain signal. If phase shifts are made in the temperature or pressure data, the date and time will be given as for the tilt or strain. The theoretical values of the primary signal for the example above will be denoted as TH(NT1) and, as with the temperature and pressure, will have no date or hour indicated unless different from the primary signal. 
Figures 16a and $\mathrm{b}, 17 \mathrm{a}$ and $\mathrm{b}$, and $18 \mathrm{a}$ and $\mathrm{b}$ show the raw data and filtered data NTl; 8-16;0900; 220, T and P respectively. Figures $19 \mathrm{a}$ and $\mathrm{b}$ show the theoretical tidal tilt values TH(NT1) for NT1; 8-16; 0900; 220 with the filtered raw data repeated for comparison. The theoretical values of tilt and strain were calculated from a program referenced and documented by Axelsson (2). It assumes the earth to be a homogeneous solid and uses Love numbers for the earth as a whole (1).

Figures 20a and $\mathrm{b}$ and Figure 2la show the cross correlation of NT1; 8-16; 0900; 220 with T, P, and TH(NT1) respectively. Figures $21 b, 22 a$ and $22 b$ show the cross correlation of TH(NT1) with T, P and NT1; 8-16;0600. Finally, figures 23a, 23b, 24a and 24b show the Fourier transform of NT1; 8-16;0900; 220, T, P, and TH(NT1) respectively. The data was presented after a visual inspection was performed and any spurious spikes associated with opening the drums were removed by linear interpolation.

Notice that from a visual inspection of the filtered data it appears that all signals satisfy the condition of being weakly stationary, i.e.. the mean and variance of the signals appear to be independent of time (9). However, 


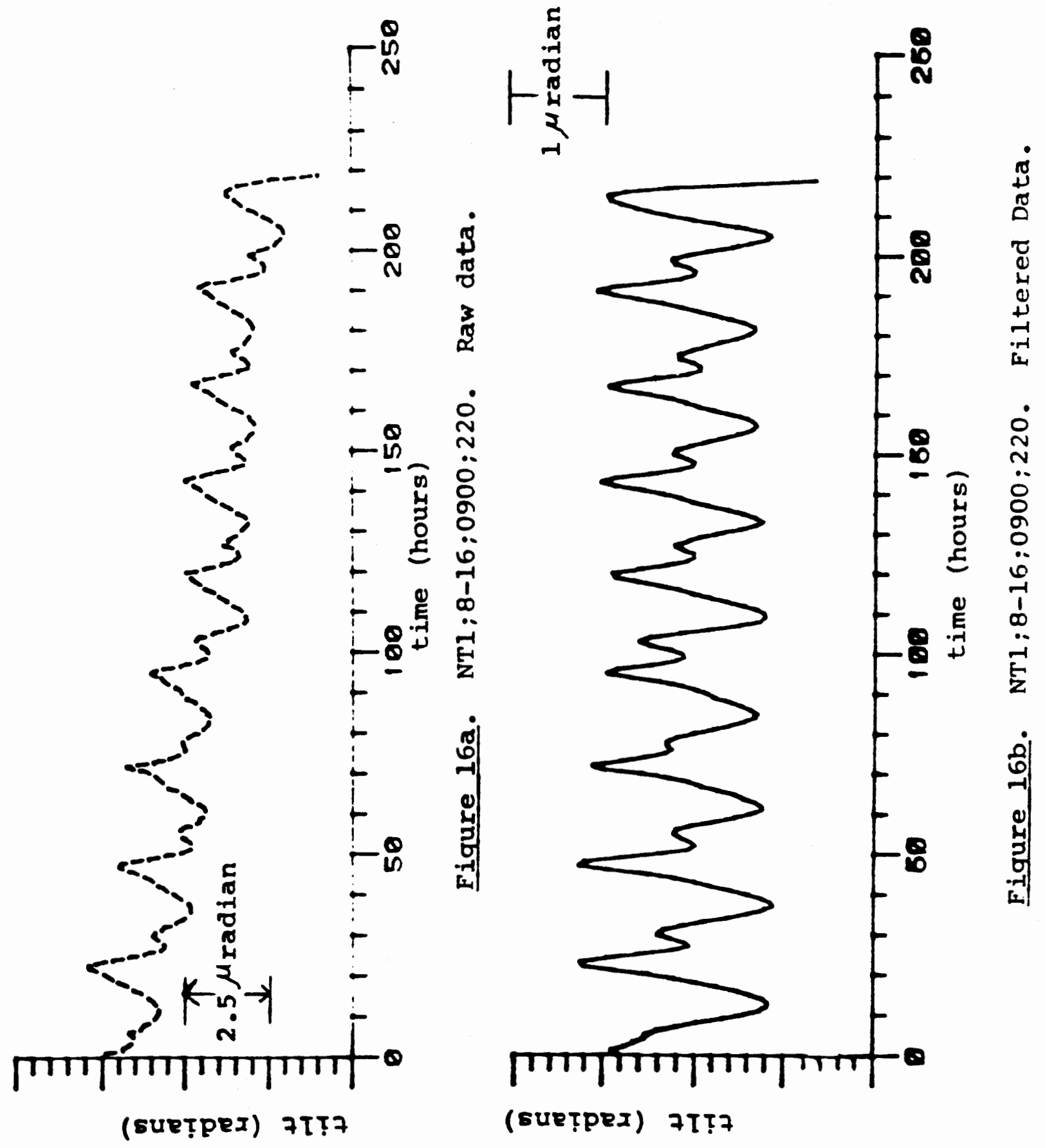




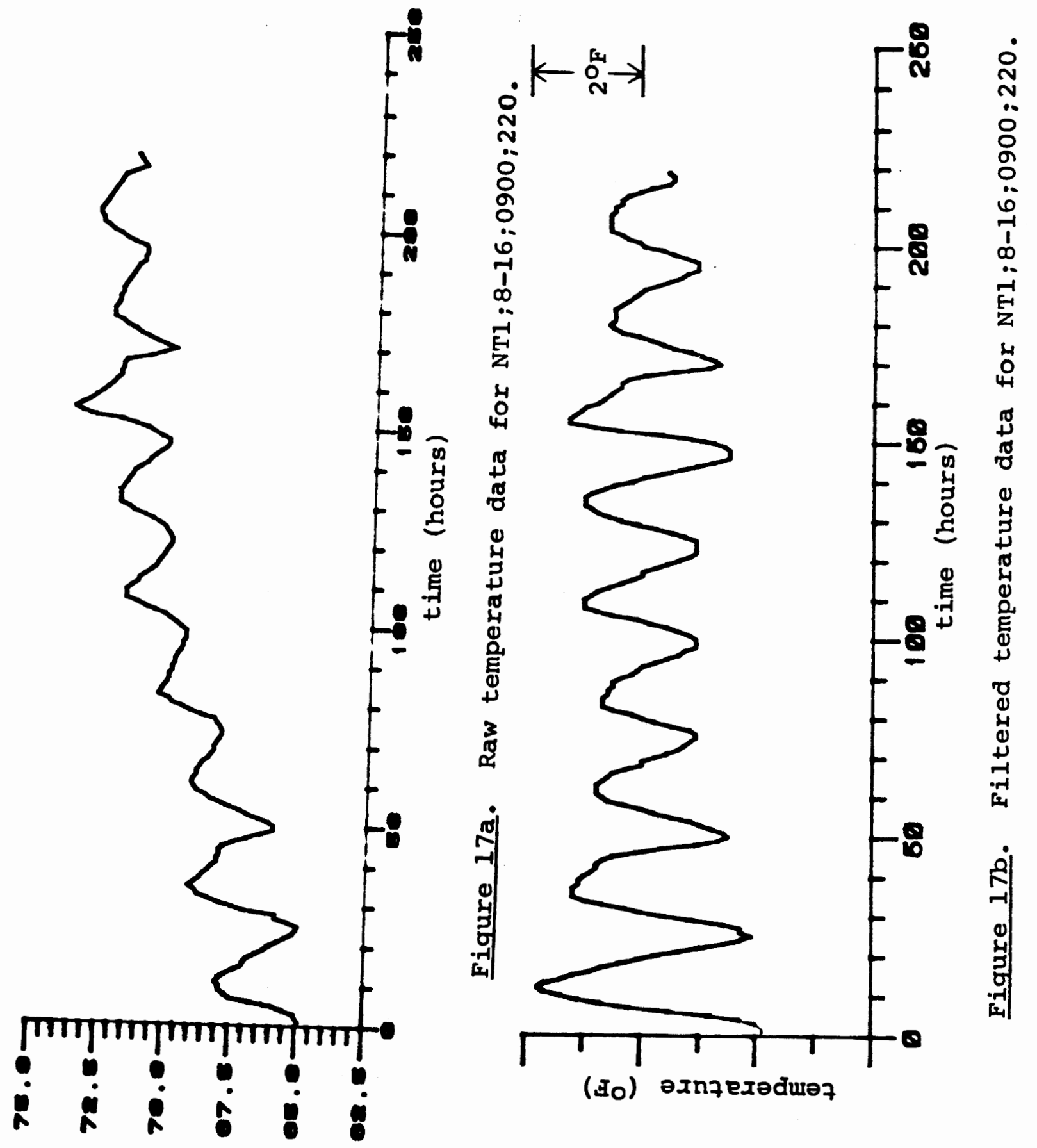

(जo) әxnzexәdurz 


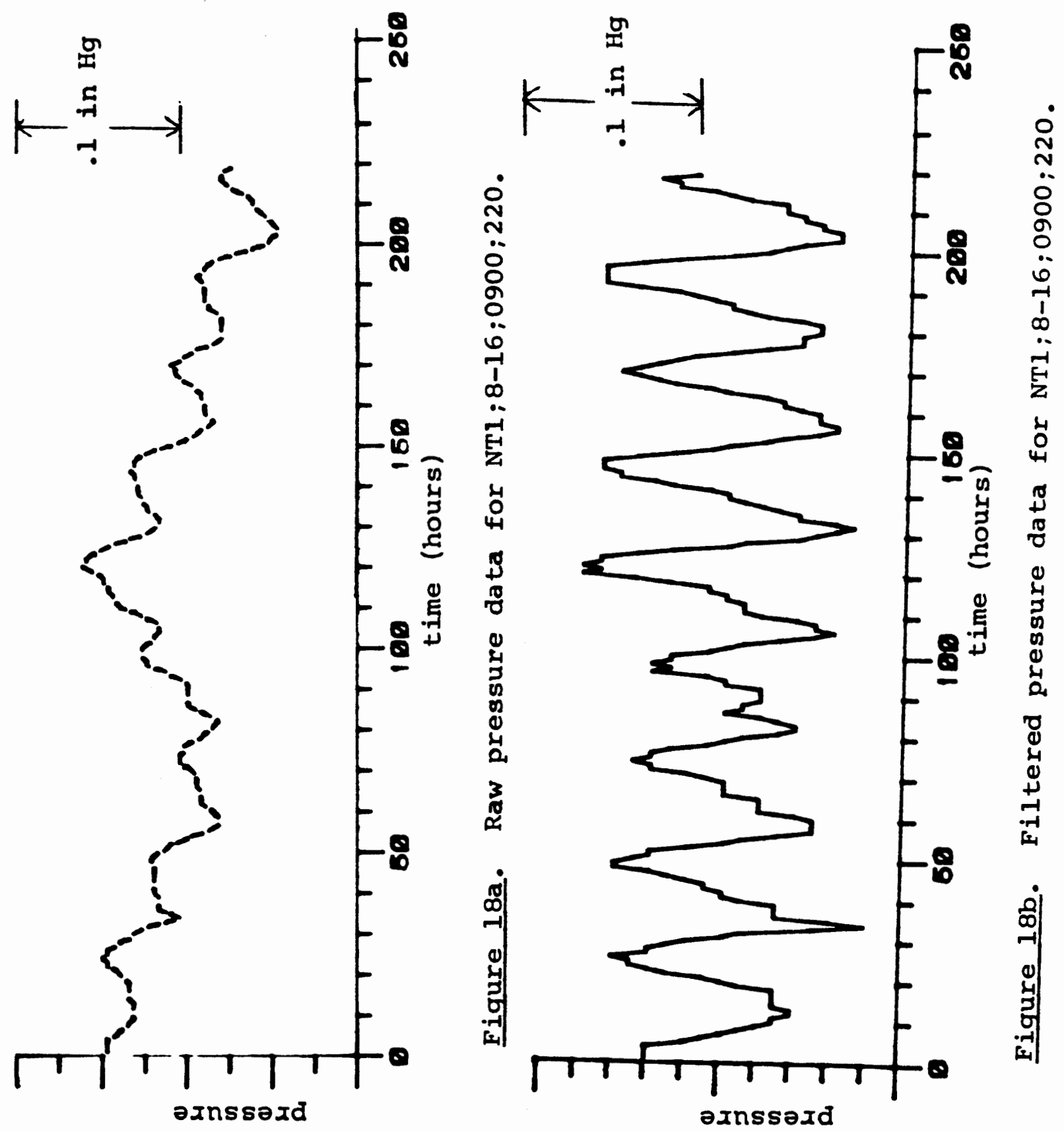


$k+\frac{\pi}{2}$
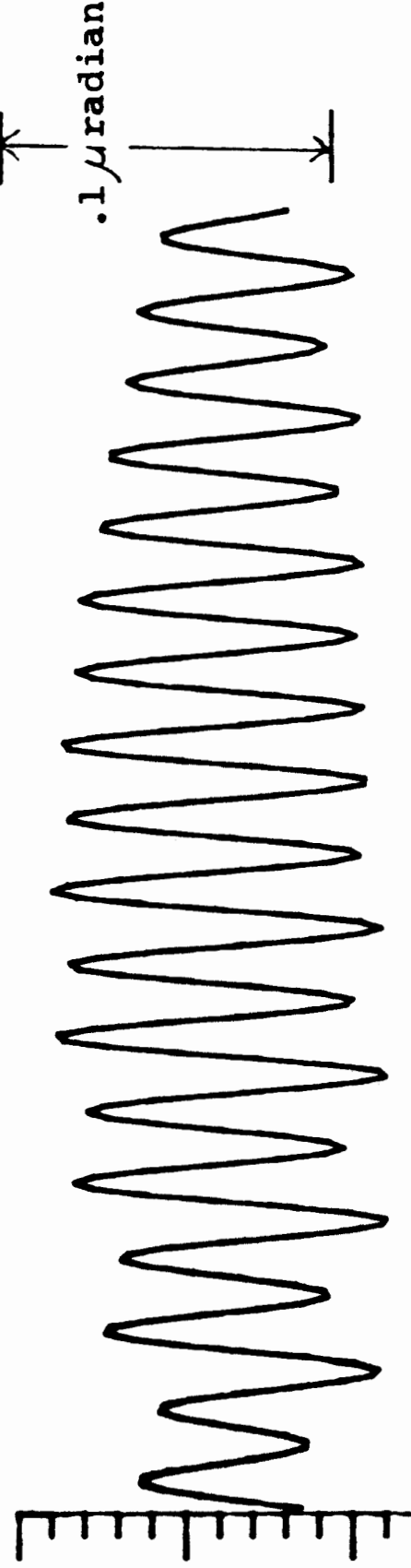

(surțpex) 7IT7
กั

-in $\ddot{0}$

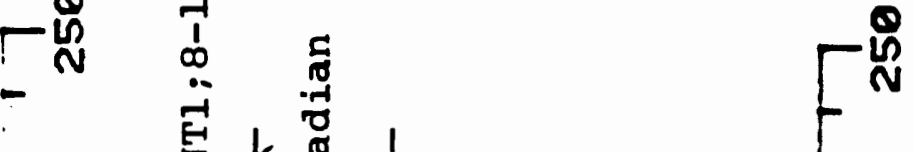

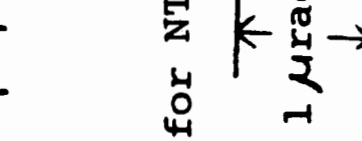

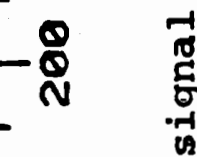

-

$-$

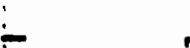

$-8$

-

i 40

-

-

-

-

告



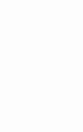

.
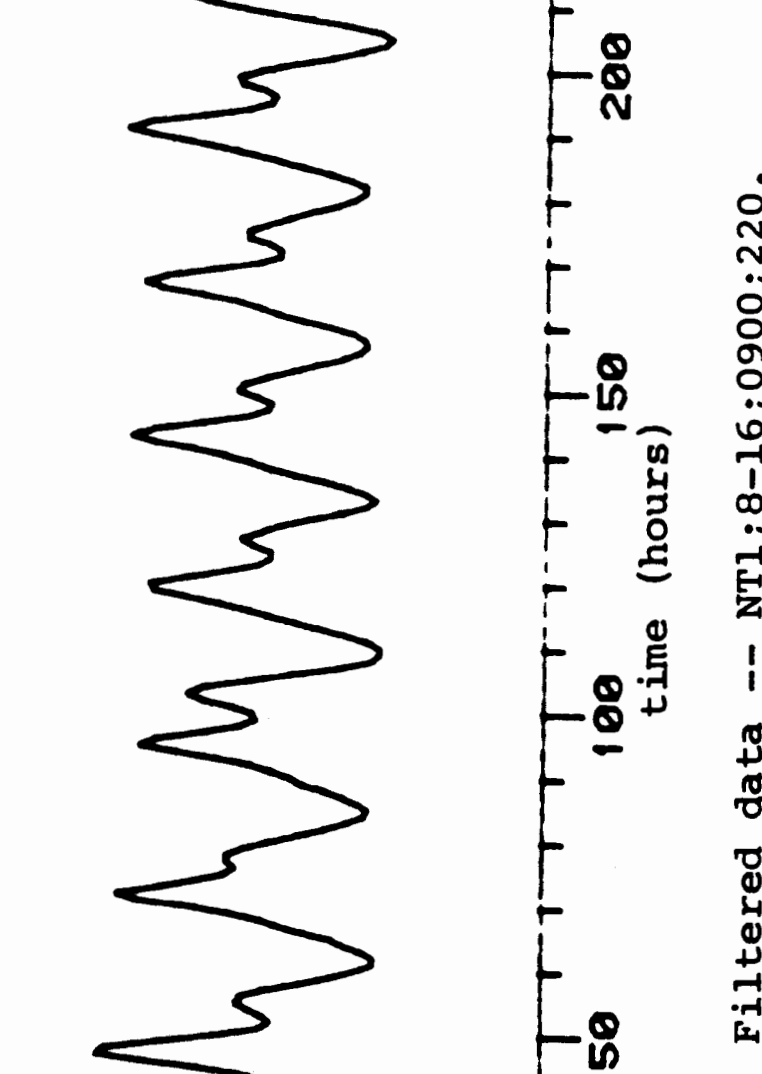

वे|

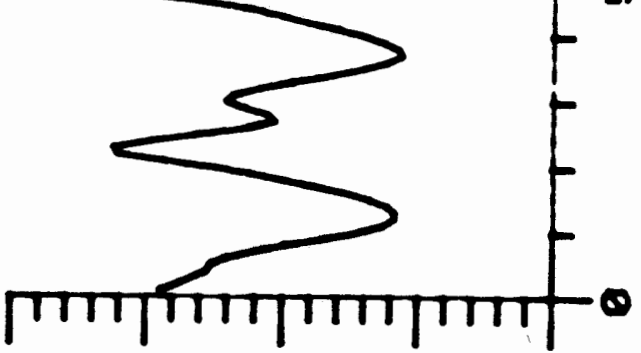

की 


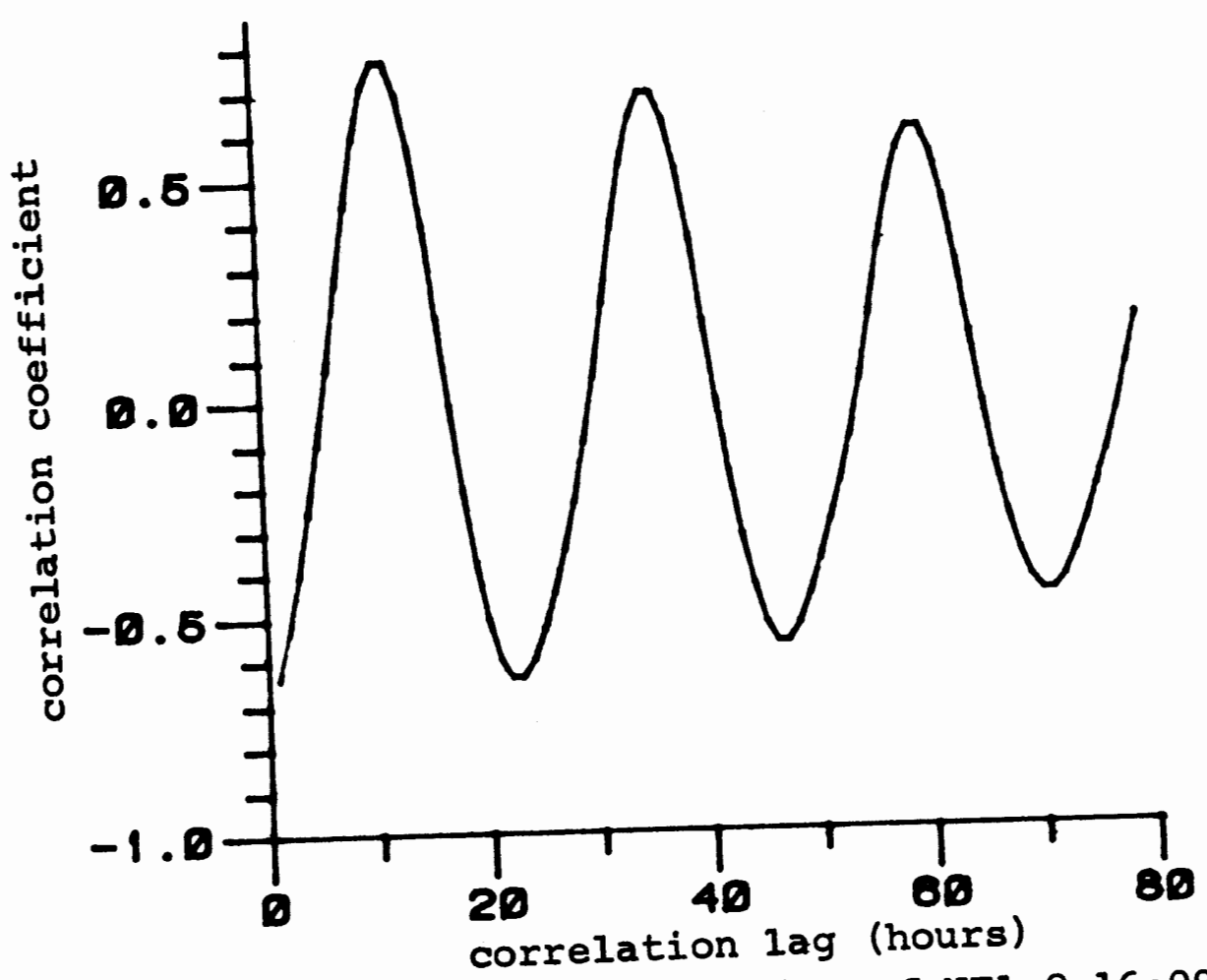

Figure 20a. Cross-correlation of NT1;8-16;0900;220 with temperature.

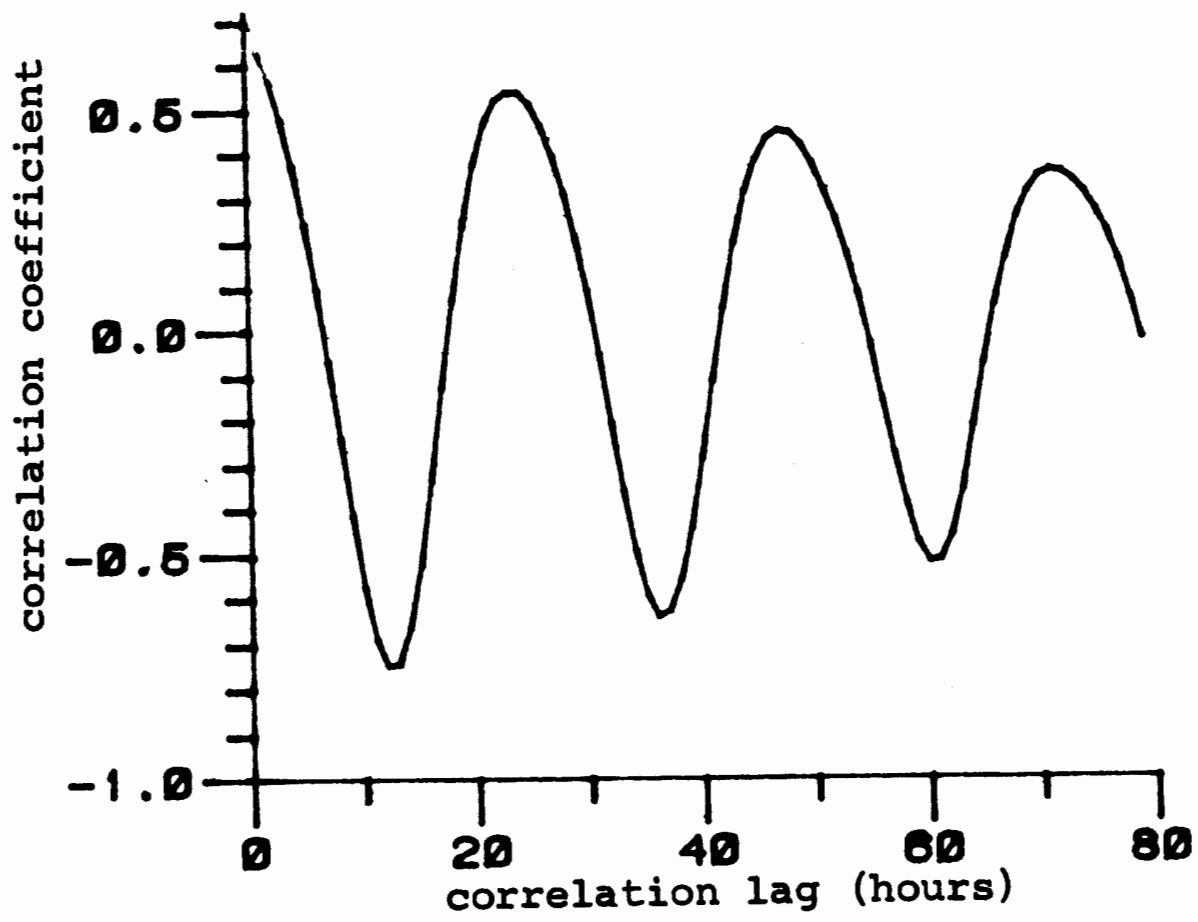

Fiqure 20b. Cross correlation of NT1;8-16;0900;220 with pressure. 


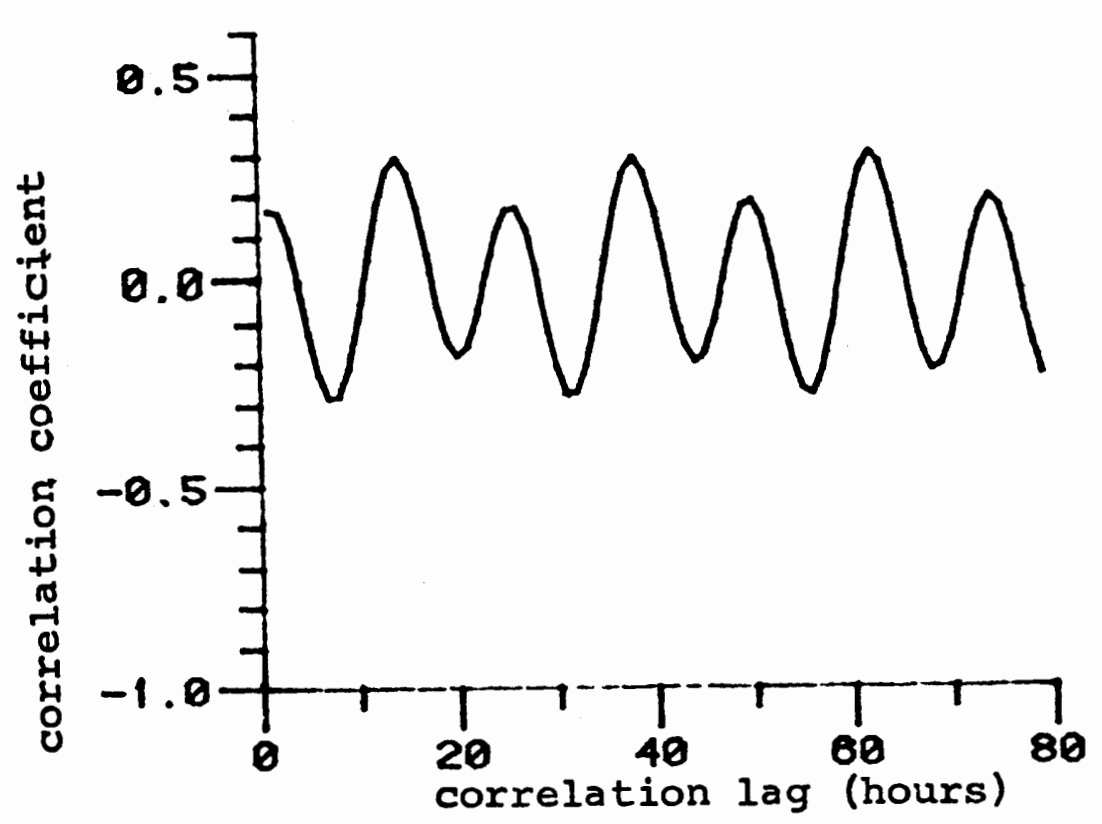

Figure 2la. Cross-correlation of theoretical tides with NT1;8-16;0900;220.

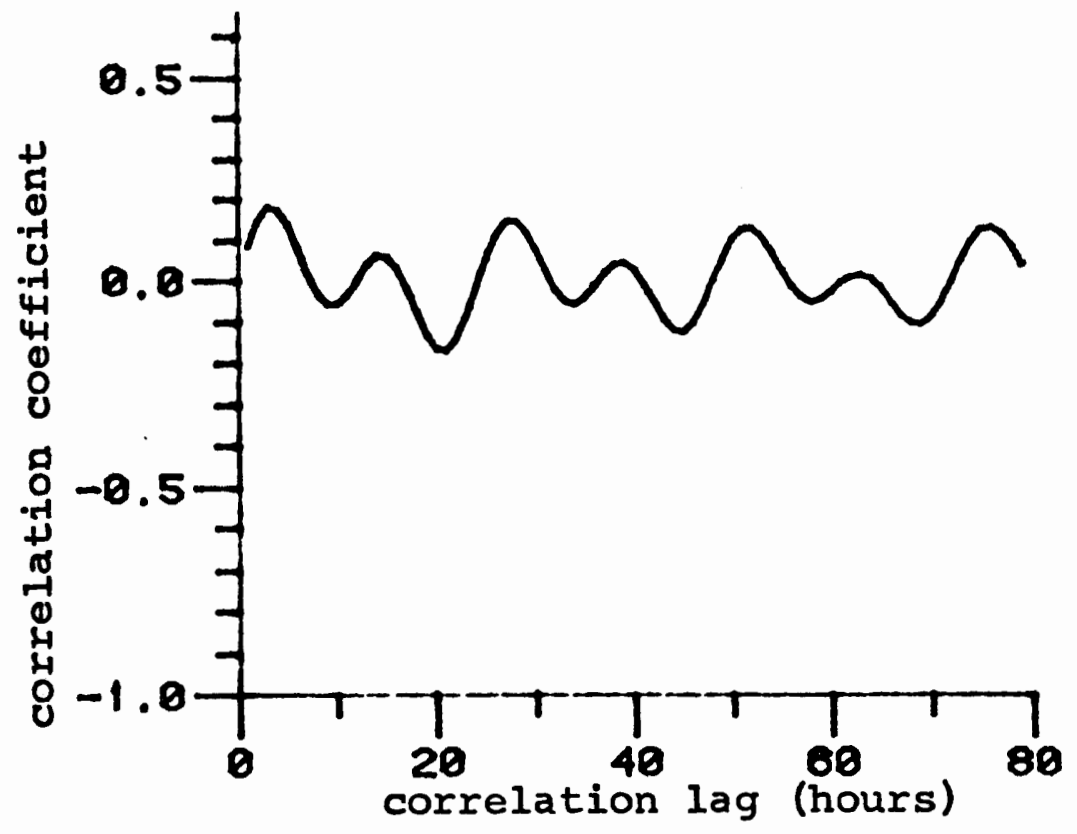

Fiqure 21b. Cross-correlation of theoretical tides with temperature. 


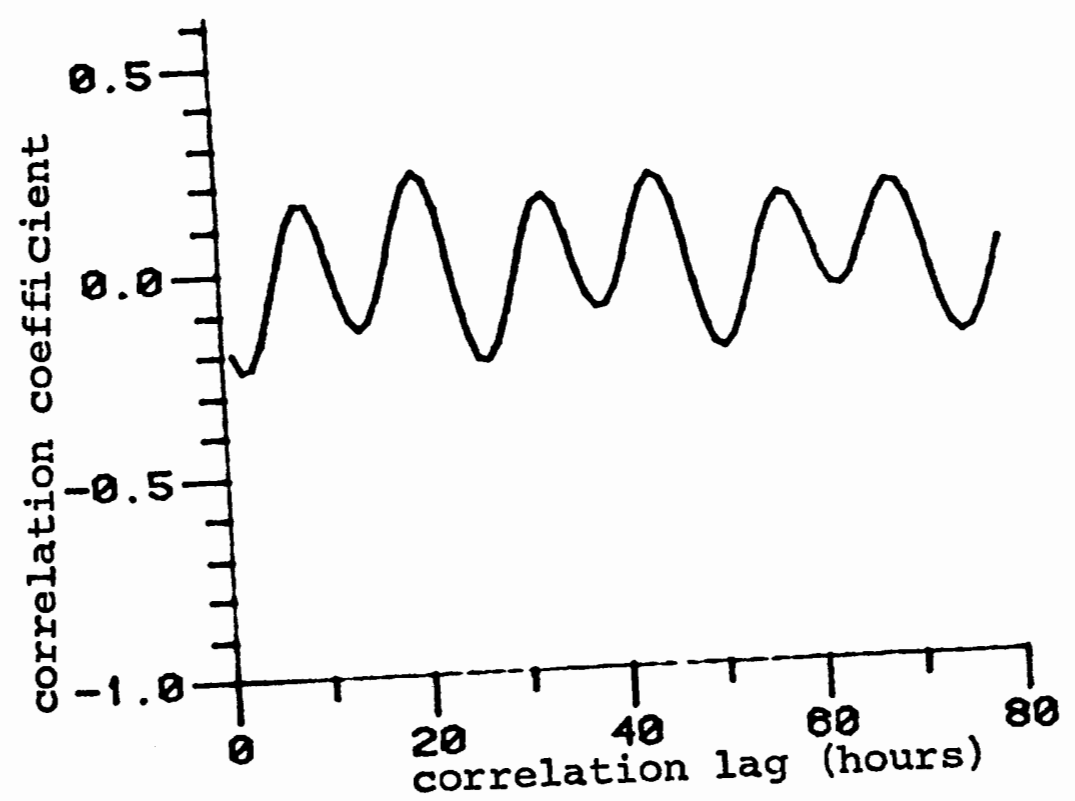

Fiqure 22a. Cross-correlation of theoretical tides with pressure.

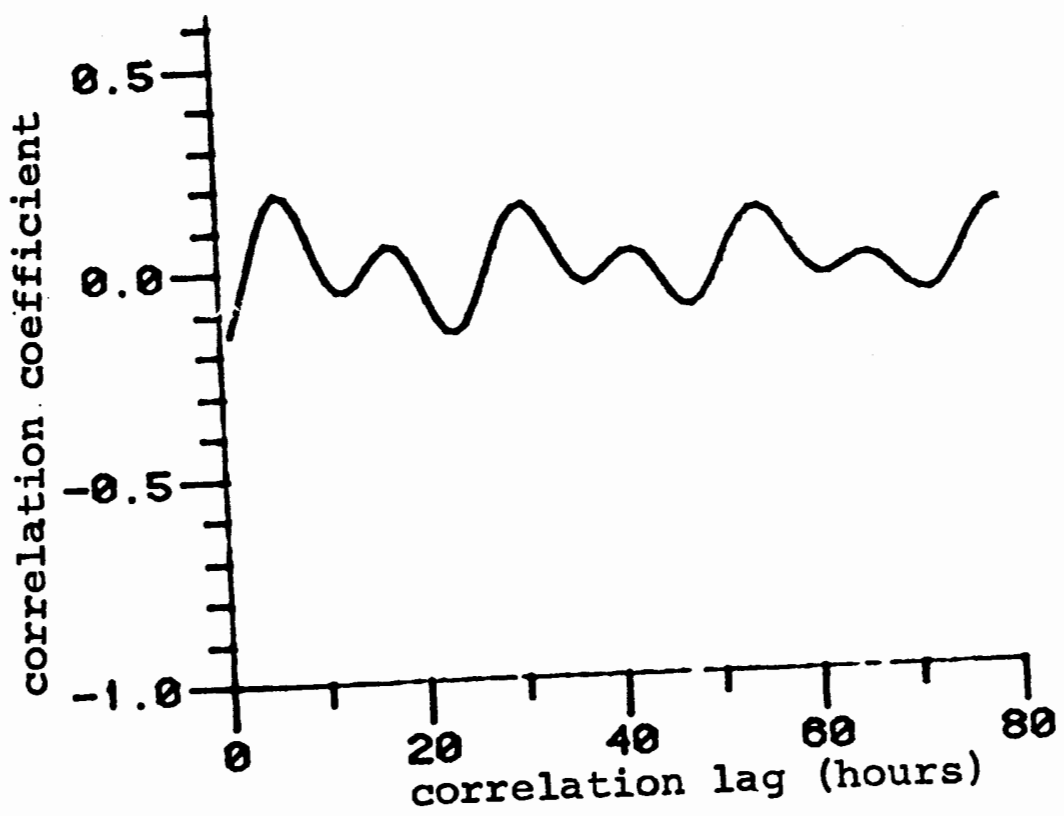

Figure 22b. Cross-correlation of theoretical tides with $T ; 8-16 ; 0600$. 


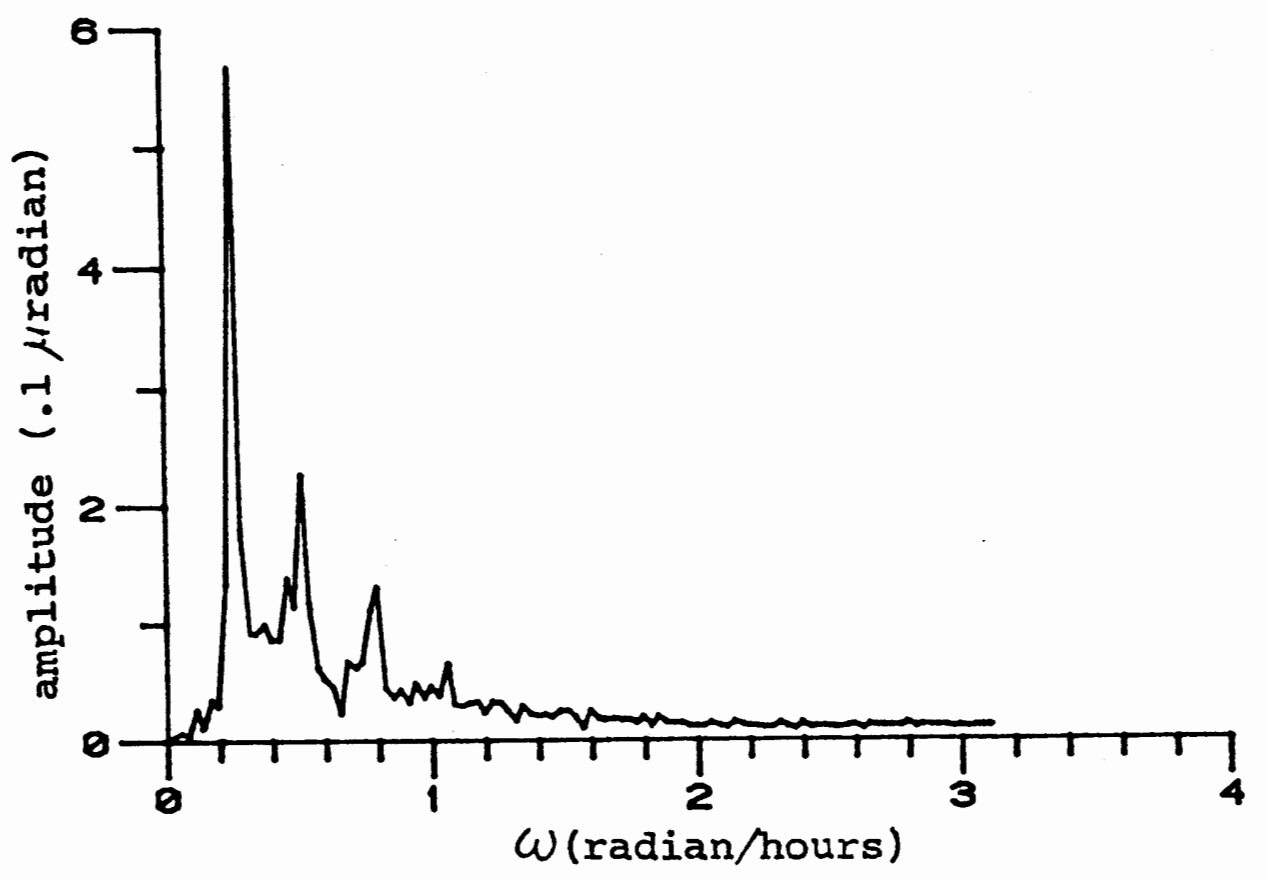

Figure 23a. Fourier transform of NT1;8-16;0900;220.

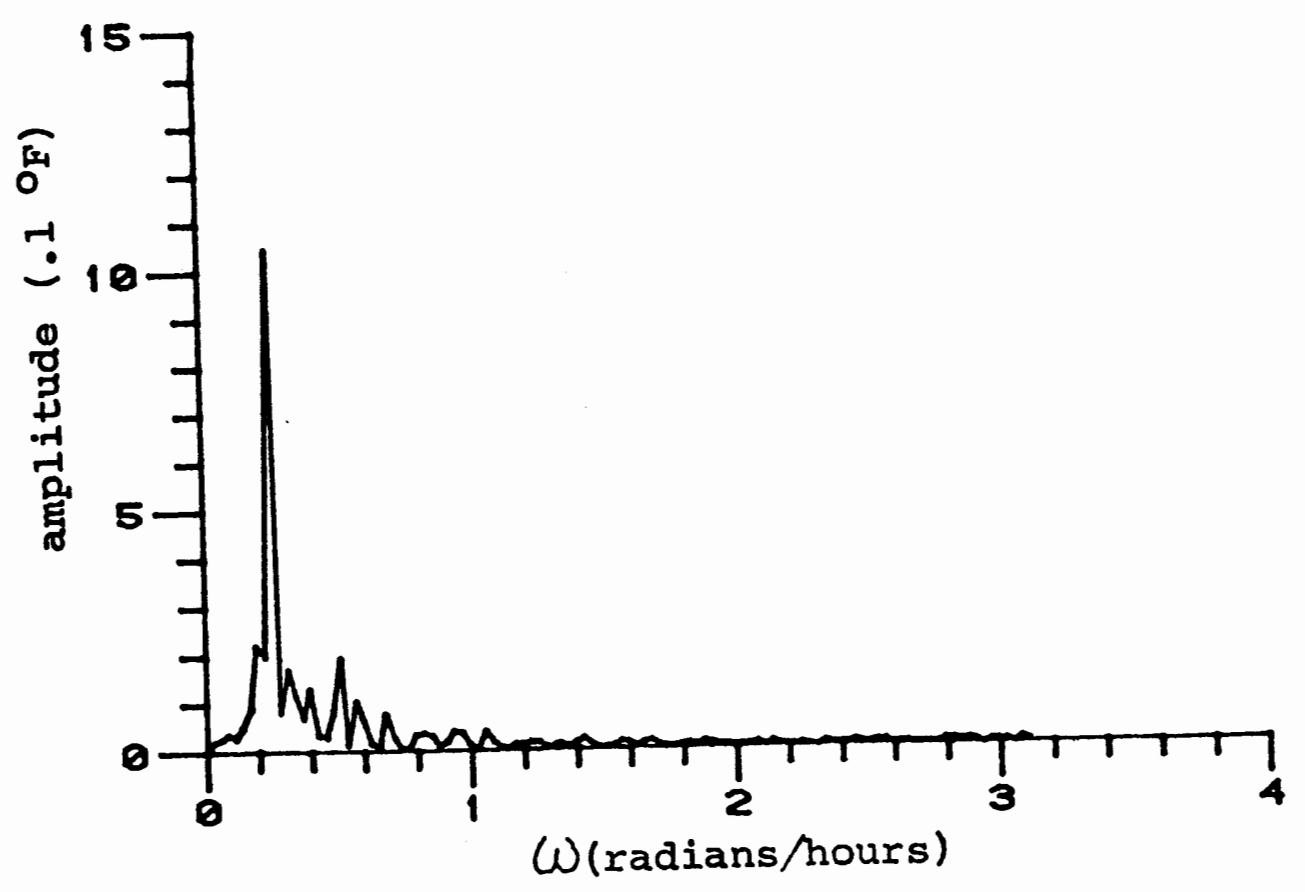

Fiqure 23b. Fourier transform of temperature. 


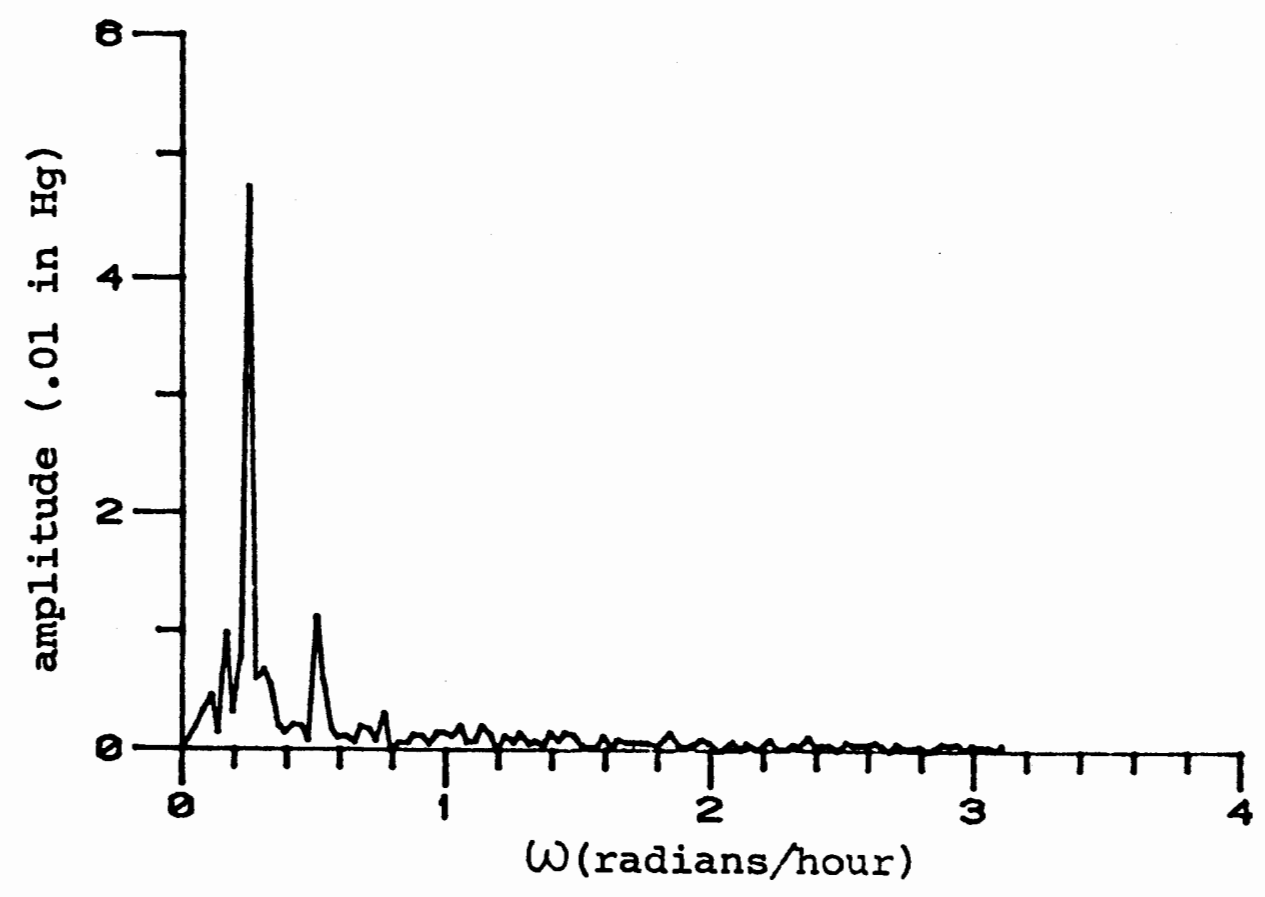

Fiqure 24a. Fourier transforms of pressure.

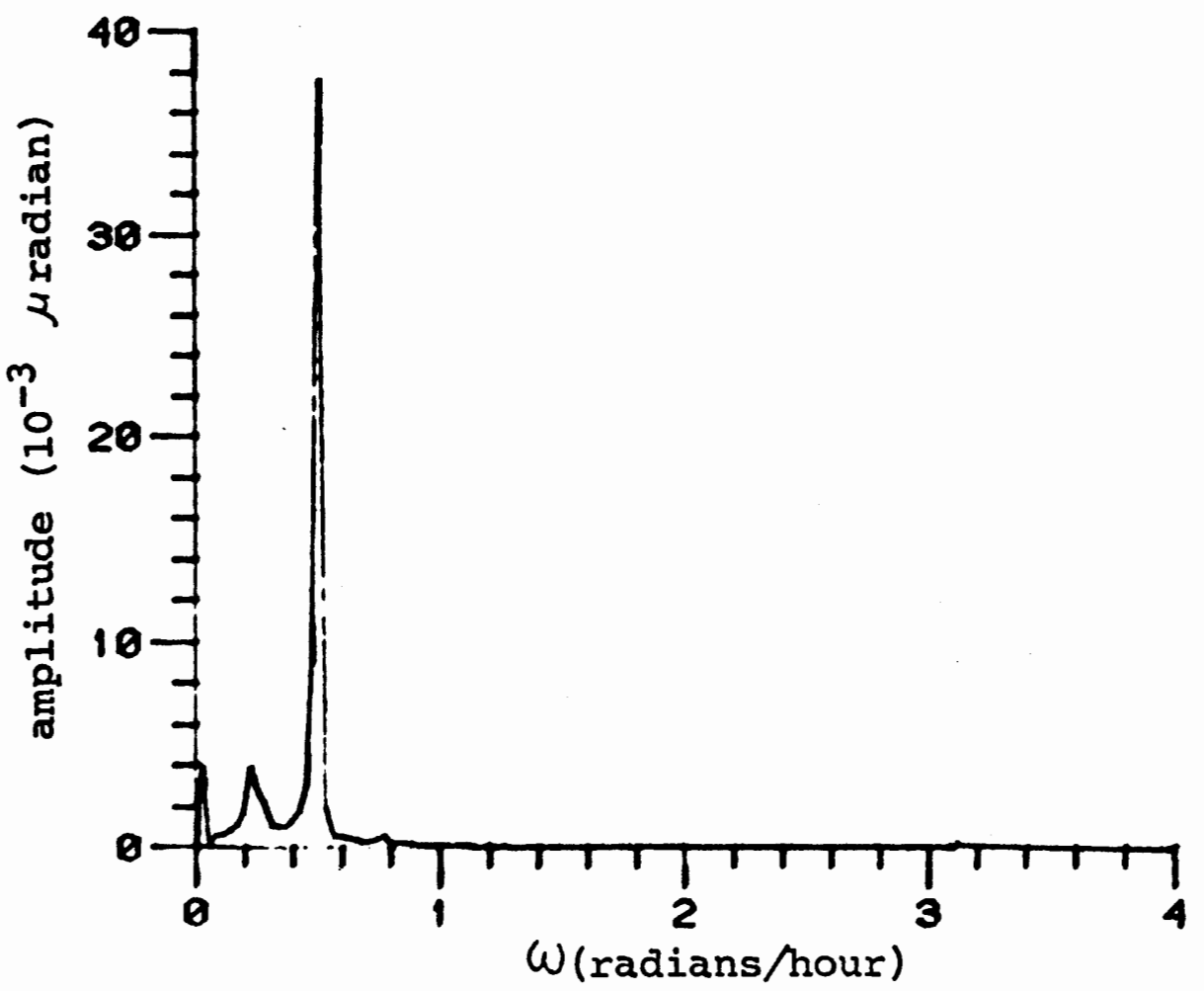

Figure 24b. Fourier transforms of theoretical tides. 
the raw data did not appear to be stationary and they became so only after the filtering process. Computations were not made to test the stationary property of the filtered data because a visual inspection was determined adequate (9).

From an inspection of the signals and the cross correlations it was determined that the temperature affected the tilt signal in 2 independent ways, which will be discussed later in more detail. The pressure also appeared to be correlated with the signal, suggesting a possible dependence of the signal on the pressure. Finally, the solid earth tides were believed to be present in the signal.

The present linear model assumes that

$$
y(t)=\sum_{i=1}^{4} B_{i} x_{i}(t)+\epsilon(t)
$$

where $\mathrm{y}, \mathrm{x}_{1}, \mathrm{x}_{2}, \mathrm{x}_{3}$ and $\mathrm{x}_{4}$ are NT1; 8-16;0900; 220, T, T: 8-16; 0600, $P$ and $T H(N T 1)$ respectively and $\epsilon(t)$ is the measure of the error of the model. All signals except the theoretical signals are filtered.

The matrix equation, equation 16, for the specified data was

$$
\text { Egn 23 } \quad\left[\begin{array}{rrrr}
1.00 & .70 & -.82 & .09 \\
.70 & 1.00 & -.41 & -.14 \\
-.82 & -.41 & 1.00 & -.19 \\
.09 & -.14 & -.19 & 1.00
\end{array}\right]\left[\begin{array}{l}
b_{1} \\
b_{2} \\
b_{3} \\
b_{4}
\end{array}\right]=\left[\begin{array}{r}
-.64 \\
-.27 \\
+.64 \\
.16
\end{array}\right]
$$


Solving equation 23 and using equation 17 yields

$$
\begin{aligned}
& \mathrm{B}_{1}=-.48 \mu \operatorname{radian} / \mathrm{O}_{F} \\
& \mathrm{~B}_{2}=.27 \mu \operatorname{radian} / \mathrm{O}_{\mathrm{F}} \\
& \mathrm{B}_{3}=.22 \mu \mathrm{radian} / .01 \text { inch } \mathrm{Hg} \\
& \mathrm{B}_{4}=6.70
\end{aligned}
$$

Figures $25 a$ and $b$ show $E(t)$ with $y(t)$ for a comparison. Figure 26a shows the auto-correlation of $\epsilon(t)$ and Figure $26 \mathrm{~b}$ shows the Fourier transform of $\epsilon(t)$. Of particular interest, the Fourier transform of $\epsilon(t)$ shows a wide assortment of frequencies which is typical of random noise.

An $F_{x}$ test using equation 22 was performed to test the significance of the addition of a term to the model. It was found that the model using $T, T ; 8-16 ; 0600$ and $P$ as independent variables compared to the model using only $T$ and $T ; 8-16 ; 0600$, gave a value of $F_{x}=.096$, which indicated no significant difference. Thus any influence due to the pressure was neglected in other models. Similar calculations of $F_{X}$ for the other independent variables showed all were statistically significant. 


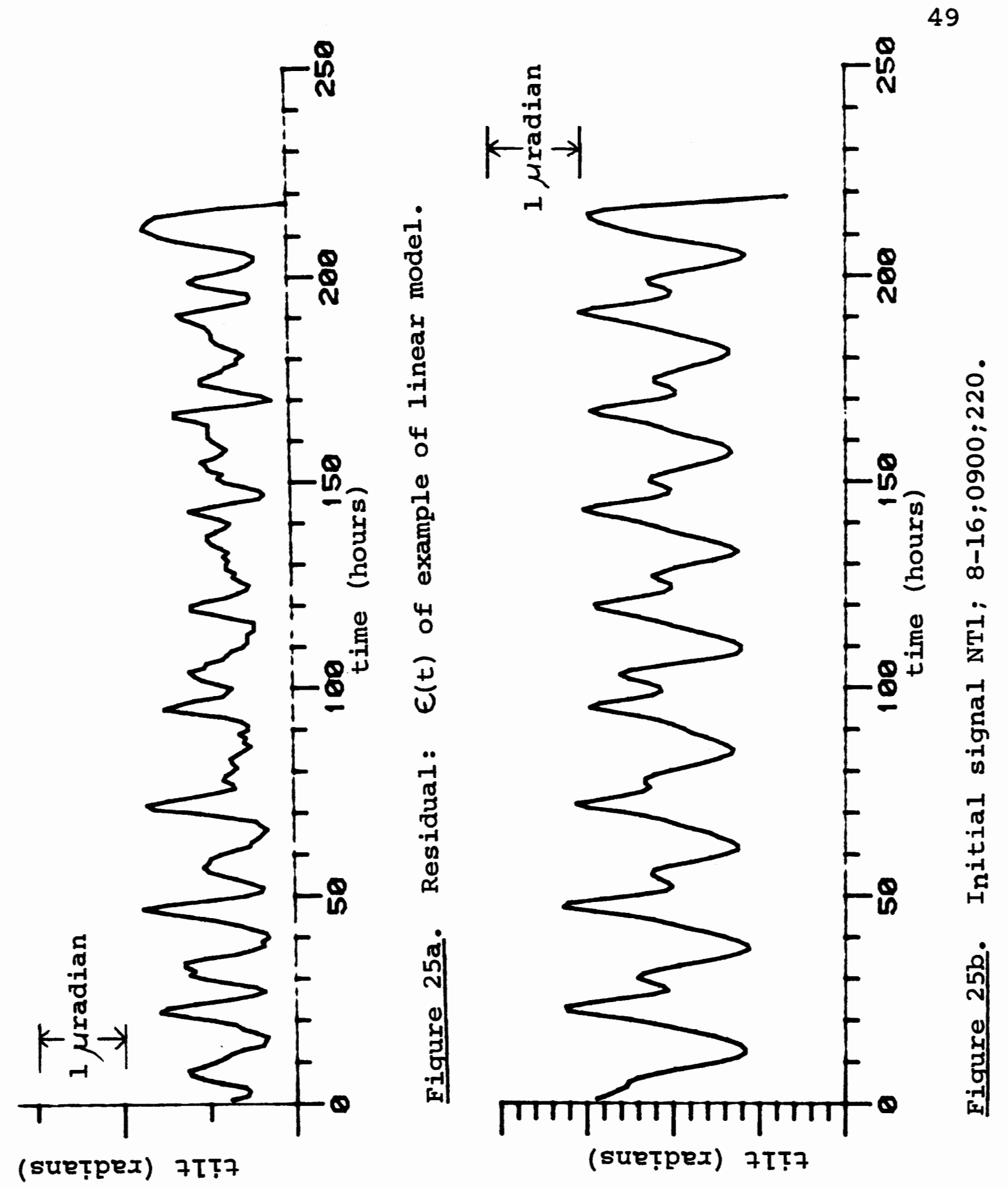




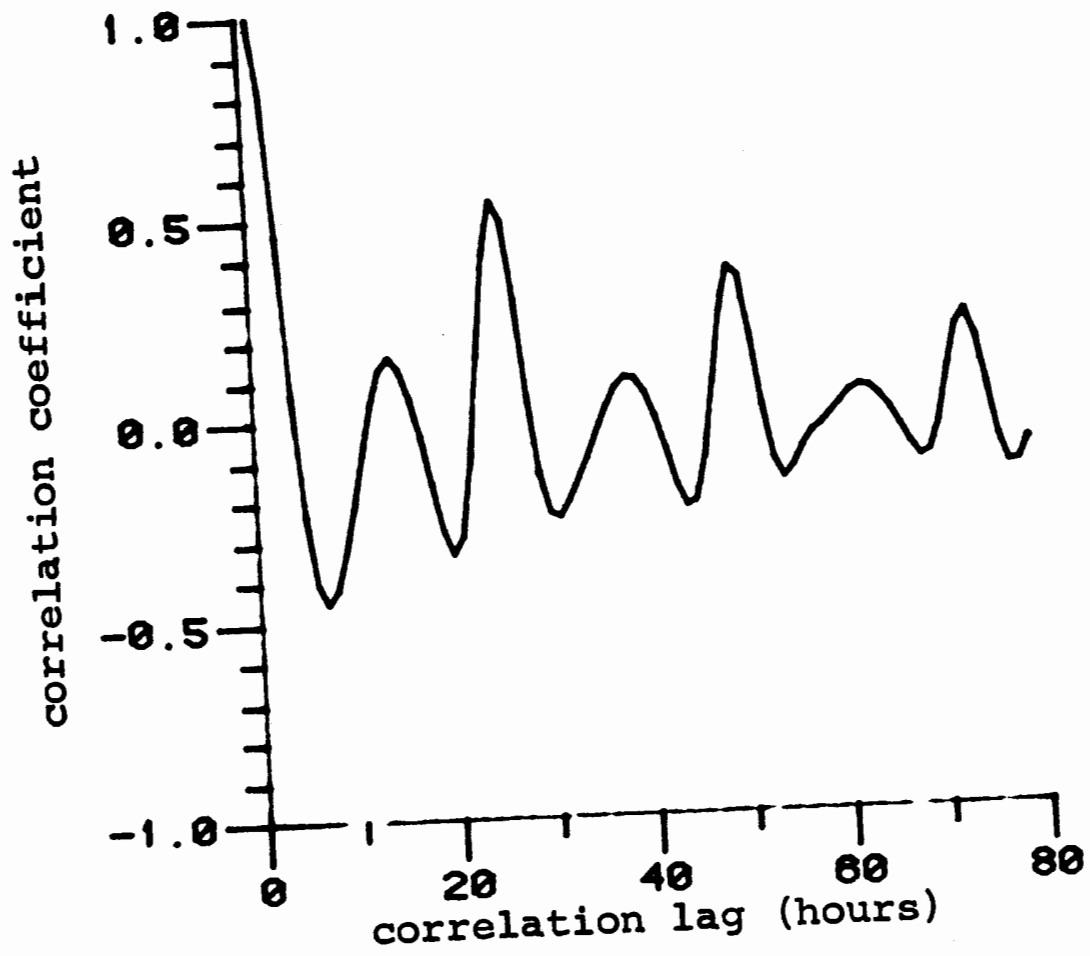

Fiqure 26a. Auto-correlation of residual; $E(t)$.

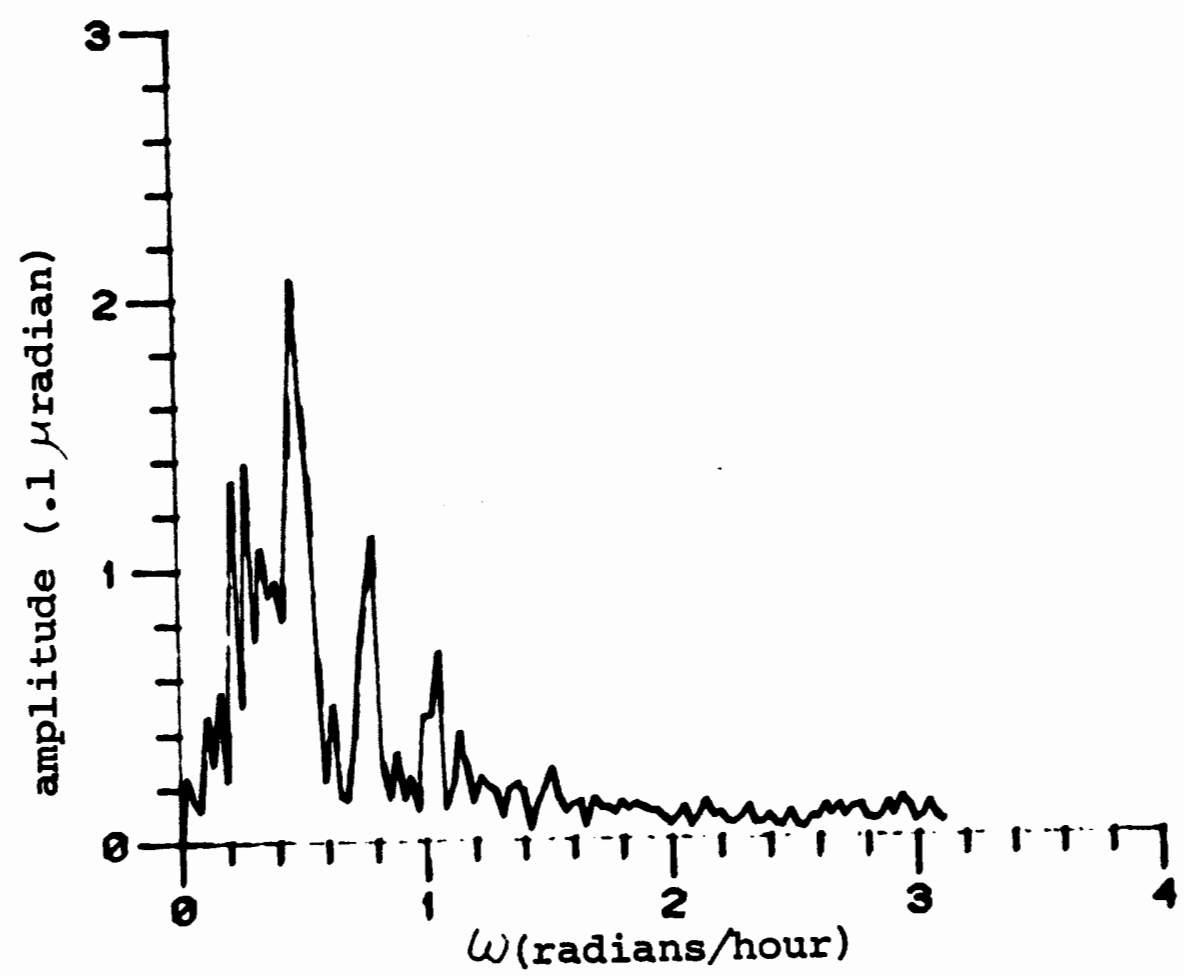

Figure 26b. Fourier transform of residual; $E(t)$. 


\section{CHAPTER IV}

TEMPERATURE DEPENDENCE

From an analysis of data NT1; 8-16; 0900; 220 it was observed that there was a large correlation between temperature and downward tilt to the North. A similar correlation existed in ET1; 8-16; 0900; 220 data. The temperature appears to be very nearly in phase with the south tilt record. The tilt meter electronics and recording devices were placed at very nearly the same depth below the ground surface as the temperature recorder. It thus appeared that something associated with the electronics or recording device created a temperature-dependent effect in the signal. An experiment was performed in the lab where the tilt electronics and recording device were subjected to fairly large temperature changes. The results indicated very little variation of the output voltage with temperature changes. The large conduction cable that electrically connects the tilt sensor to the electronics package seems to be a likely suspect for thermal mechanical variations in the signal.

The temperature record, $\mathrm{T} ; 8-16 ; 0900$ appeared to reach 
its maximum amplitude at 1900 PDT. The maximum amplitude of the air temperature was found to occur at about 1600 to 1700. There was thus a two to three hour phase lag between the air temperature and the temperature at the thermometer.

A solution of the heat conduction equation

$$
\text { Egn } 24 \quad \frac{\partial^{2} T(X, t)}{\partial x^{2}}=\frac{1}{k} \frac{\partial T}{\partial t}
$$

for a semi-infinite half space subject to the boundary conditions

$$
\begin{aligned}
& T(0, t)=T_{0} e^{i \omega t} \\
& T(\infty, t)=0
\end{aligned}
$$

yields

$$
\underline{\text { Ean } 25} \quad T(x, t)=T_{0} e^{i\left(\omega t-\sqrt{\frac{\omega}{2 K}} x\right)} e^{-\sqrt{\frac{\omega}{2 K}} x}
$$

Equation 25 indicates that an amplitude decrease as well as a phase lag for the temperature as $\mathrm{X}$ increases into the half space. Although the thermometer was not in a homogeneous half space, equation 25 is consistent with the observed phase lag and amplitude decrease of 3 hours and $1 / 8$ respectively. In addition to the large zero lag correlation of the temperature with the signal there was also a correlation at a 3 hour lag in the North/South component of the data that was not present in the East/West component. The North/South component 
appeared to be in phase with the estimated air temperature. This additional temperature dependence is believed to be from a stress field created by the thermal expansion of the cement wall, labeled $A B$ in figures 1 and 3, approximately $6 \mathrm{~m}$ north of Tl.

A model for the induced tilt due to the expansion of the wall was created as follows. The coordinate origin is designated to lie directly north of $\mathrm{Tl}$ at the base of wall BC. The $\mathrm{X}$-axis points South and the $\mathrm{y}$-axis is directed into the earth. The position of the instrument is thus located at $x=6 m, y=.5 m$.

Now assuming that there are no body forces and that the expansion of the wall can be treated statically, the differential equation for the displacement vector $\vec{U}=\left(U_{X}, U_{Y}\right)$ can be written as

$$
\text { Egn } 26 \quad \mu \nabla^{2} \overrightarrow{\mathrm{U}}+(\lambda+\mu) \nabla \nabla \cdot \overrightarrow{\mathrm{U}}=0
$$

where $\lambda$ and $\mu$ are Lamb's constants $(2,1.9)$. The boundary conditions are of the form

$$
\begin{aligned}
& \vec{U}=\left(U_{x}(x, y), 0\right) \\
& U_{x}(x, 0)=A e^{-r x ; 0} \leq x \\
& U_{x}(0, y)=\cos (b y) ; 0 \leq y \leq \frac{\pi}{2 b} \\
& U_{x}(0,0)=\delta_{s}
\end{aligned}
$$

where $\delta_{s}$ is the displacement of the soil due to the expansion 
of the wall. In addition we assume Poisson's relation, $\mu=\lambda_{1}(2)$, which is equivalent to saying that the ratio of the compressional to shear wave velocities is 2 for a homogeneous isotropic solid; which we assume the soil to be. From reference 2 we can rewrite equation 26 as Ean 27

$$
3 \frac{\partial^{2} U_{x}}{\partial x^{2}}+\frac{\partial^{2} U_{x}}{\partial y^{2}}=0
$$

A solution to this equation consistent with the boundary conditions is

$$
\begin{array}{ll}
\mathrm{u}_{\mathrm{x}}=\delta_{\mathrm{s}} e^{-\frac{\mathrm{k}}{\sqrt{3}} \mathrm{x}} \cos (\mathrm{ky}) ; & 0 \leq \mathrm{x}
\end{array}
$$

where $\mathrm{k}$ is an undetermined separation constant.

A determination of an approximate value of $k$ is our next task. As the cement wall expands the soil compresses by an amount $\delta_{s}$. Since the soil has a much smaller Young's modulus, $E_{S}$. the displacement of the soil, can be approximated to that of the wall expanding freely. That is

$$
\text { Eqn } 28 \quad \delta_{s} \approx \alpha \Delta T L 。
$$

where $\alpha$ is the coefficient of thermal expansion of cement, $\Delta \mathrm{T}$ is the amplitude of the temperature change, and $\mathrm{L}_{0}$ is the length of wall $A B$. A state of stress is created at the soil-cement interface such that 
Egn 29

$$
\sigma_{c}=\sigma_{s}
$$

where $c$ and $s$ refer to the cement and soil, respectively. Now,
Eqn 30
$\sigma=\epsilon \mathrm{E}$

Thus

$$
\underline{\text { Eqn 31 }} \quad \epsilon_{s} E_{s}=\epsilon_{c} E_{c}=\frac{\delta c}{L_{0}} E_{C}
$$

We will also assume that

$$
\underline{\text { Egn } 32} \quad \frac{\delta_{C}}{\delta_{S}}=\frac{E_{S}}{E_{D}}
$$

where $\delta_{C}$ is the amount the cement compresses due to the soil pushing back. Thus combining equations 28, 29, 30, 31 and 32 yields

$$
\text { Eqn } 33 \quad \epsilon_{\mathrm{s}}=\alpha \Delta \mathrm{T}
$$

or that the strain of the soil is equal to the thermal strain that would exist in the wall if it were to expand freely. But we know from elementary elastic theory (20) that

$$
\text { Egn 34 }\left.\quad \epsilon_{s}\right|_{\substack{x=0 \\ y=0}}=\left.\frac{\partial U_{x}}{\partial x}\right|_{\substack{x=0 \\ y=0}}=\frac{k}{\sqrt{3}} \delta_{s}
$$

Finally by combining equations 33 and 34 we get an approximate value of $\mathrm{k}$,

$$
k=\frac{\sqrt{3}}{L_{\circ}}=.87 \mathrm{~m}^{-1} \quad \text { for } L_{\circ}=2 m
$$


The amount of counterclockwise rotation in the $x-y$ plane is given by

$$
\theta x y=\frac{1}{2}\left(\frac{\partial U_{y}}{\partial x}-\frac{\partial U_{x}}{\partial y}\right)=\frac{1}{2} \delta_{s} k e^{-\frac{x}{2}} \sin (.87 y)
$$

For $x=6 \mathrm{~m}, \mathrm{y}=.5 \mathrm{~m}, \alpha=12 \times 10^{-6} \circ_{\mathrm{C}}^{-1}$ and $\Delta \mathrm{T}=10^{\circ} \mathrm{C}$ we obtain an estimate of the induced tilt at the location of the instrument

$$
\theta x y=2.2 \times 10^{-6} \text { radians }
$$

This value of $\theta x y$ is higher than the measured value by about 2 to 3 . Several aspects of our model tend to give a high estimate. First we have assumed no body forces. Thus we have neglected the vertical stress due to gravity which would yield an effective Poisson expansion of the soil to the North, hence reducing $\delta_{\mathrm{s}}$. We also assumed that wall BC would not sag appreciably. That is, when wall $A B$ expands, we assume that our coordinate origin directly north of the instrument had this same displacement. If wall BC "sagged" this would not be true. Our model does, however, offer a reasonable mechanism to explain the tilt observed on the North/South channel that was absent on the East/West channel. 


\section{CHAPTER V}

\section{RESULTS OF COMPUTATIONS}

In this chapter the results obtained for various intervals of data will be summarized. The results are based on the solution of various models of the form given by equation 14. Values of interest in determining the significance of the linear model are $R^{2}$, the goodness of fit of the model to the data, and $F_{\chi}$, the test statistic defined by equation 22 .

It can be shown (17, chap. 7) that $\mathrm{R}^{2}$ as defined by equation 19 can be written as

Eqn $35 \quad R^{2}=\sum_{i=1}^{k} B_{i} \frac{\sigma_{i}}{\sigma_{y}} r_{i y}$

where $B_{i}$ are the coefficients of equation $14, \sigma_{i}$ and $\sigma_{y}$ are the standard deviation of $x_{i}$ and $y$ respectively and $r_{i y}$ is the cross correlation of $x_{i}$ with $y$. With the use of equation 17 we can rewrite equation 35 as

Egn 36

$$
\mathrm{R}^{2}=\sum_{i=1}^{k} \mathrm{~b}_{i} r_{i y}
$$


where the $b_{i}$ 's are the solutions of equation 16. Thus the term $b_{i} r_{i y}$ gives the contribution of signal $x_{i}$ to the goodness of fit. In Table III we will summarize the results of the various models used by listing the primary signal used, $\mathrm{y}$, and the independent variables $\mathrm{X}_{i}$ used for each model. The individual values of $b_{i} r_{i y}$ will be given as well as $R^{2}$ and $\sigma_{Y}$. The $F$ statistic, $F_{X}$, from equation 22, which was used to test the statistical significance of the addition of the theoretical tidal signal to the model will also be given in Table III. Finally the value of the coefficient $B_{i}$ of the theoretical signal predicted by the linear model will be listed for each set of data. After some consideration it was concluded that the above values could best describe the influence of each signal to the model and the fit of the model to the data. 


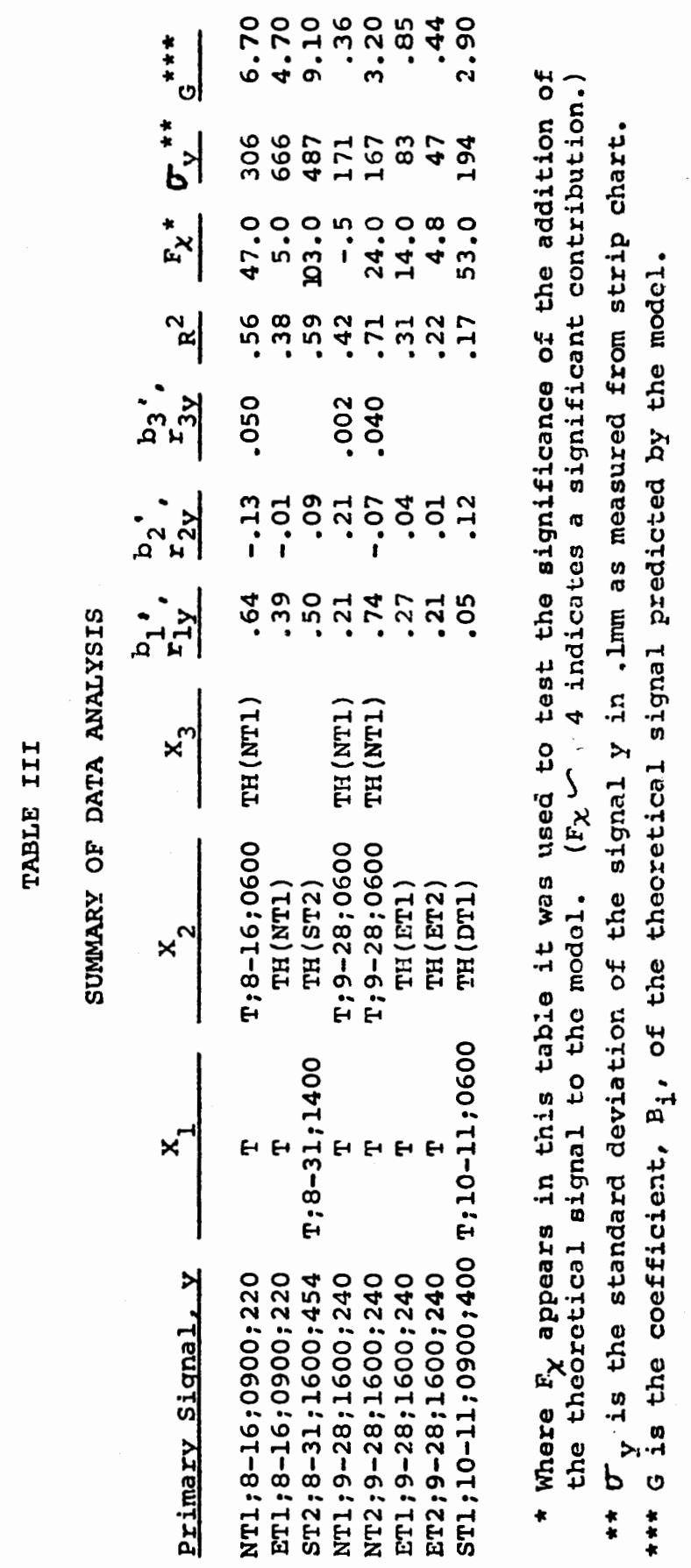


CHAPTER VI

DISCUSSION

\section{$\underline{\text { Rainfall }}$}

There appeared to be some influence on the signal due to rainfall. Figures 6 through 14 are labeled with an $R$ for each day that the rainfall exceeded .4 inch. From an inspection of the figures it can be seen that the rain affects each instrument differently. In addition each individual instrument seems to respond differently during different rains. It seems that the effect due to the rain during the months of July, August, and September was much more obvious than that in October. This was true for most all of the instruments. Several factors could cause this sort of varying dependence. First it should be noted that the temperature tended to drop substantially during a rainfall. Thus a lot of the apparent rain effect could be a temperature effect. The month of October was generally cloudy and thus the temperature drop from the mean temperature was much less noticeable. Secondly, during the month 
of October the ground was much more saturated than in the previous three months. Thus changes in water content of the ground would be less extreme, hence producing a lesser effect. Finally the rains during July and August were scattered throughout the month and were preceded and followed by drier periods. In September there were several substantial rains and the ground became soaked. Thus the rains in September seemed to contribute most to the settling of the location after initial installation than at any other time during the operation of the instruments.

From a close inspection of the individual records it is felt that there is a real elastic response of the earth to the rain. This could be attributed to the increased loading due to the increased water saturation, or possibly to a sponge-like expansion of the soil as it absorbs water. The elastic response is most likely due to a combination of both these effects, as well as possible settling of loosely packed soil found at the new location. The rain effect is thus very unpredictable during the first few rains after installation but should become somewhat more predictable after a year of settling. A daily record of the soil humidity could prove invaluable to the formulation of a model to be used for predicting the elastic response of the earth to the rain. 
Correlation of Instruments

Another important aspect of this study was to see how well the individual tilt meters related. Figures 27 and 28 show the raw north components and east components for the two instruments recorded from September 28 to October 8 . Figures 29 and 30 show the filtered data and figures 31 a and $31 b$ show the cross correlation between the same components of the different instruments.

An analysis similar to that for NT1;8-16;0900;220 was performed on the data. The results appear in Table III. Of the four channels inspected the only channels that appeared to have an appreciable tidal signal were NT2;9-28;1600;240 and possibly ETl;9-28;1600;240. The data NT1;9-28;1600;240 was somewhat noisy during this period but this time interval appeared to be the best available for a comparison of the two instruments. An amplification of 3.2 observed in NT2;9-28;1600;240 seemed to be consistent with the large amplification calculated previously for NT1;8-16;0900;220. These amplifications cannot be taken too seriously because of the low signal to noise ratio of approximately .1. They do, however, indicate qualitatively the presence of a tidal signal. As far as relating these amplifications to a physical phenomenon, the most likely suspect would be the 


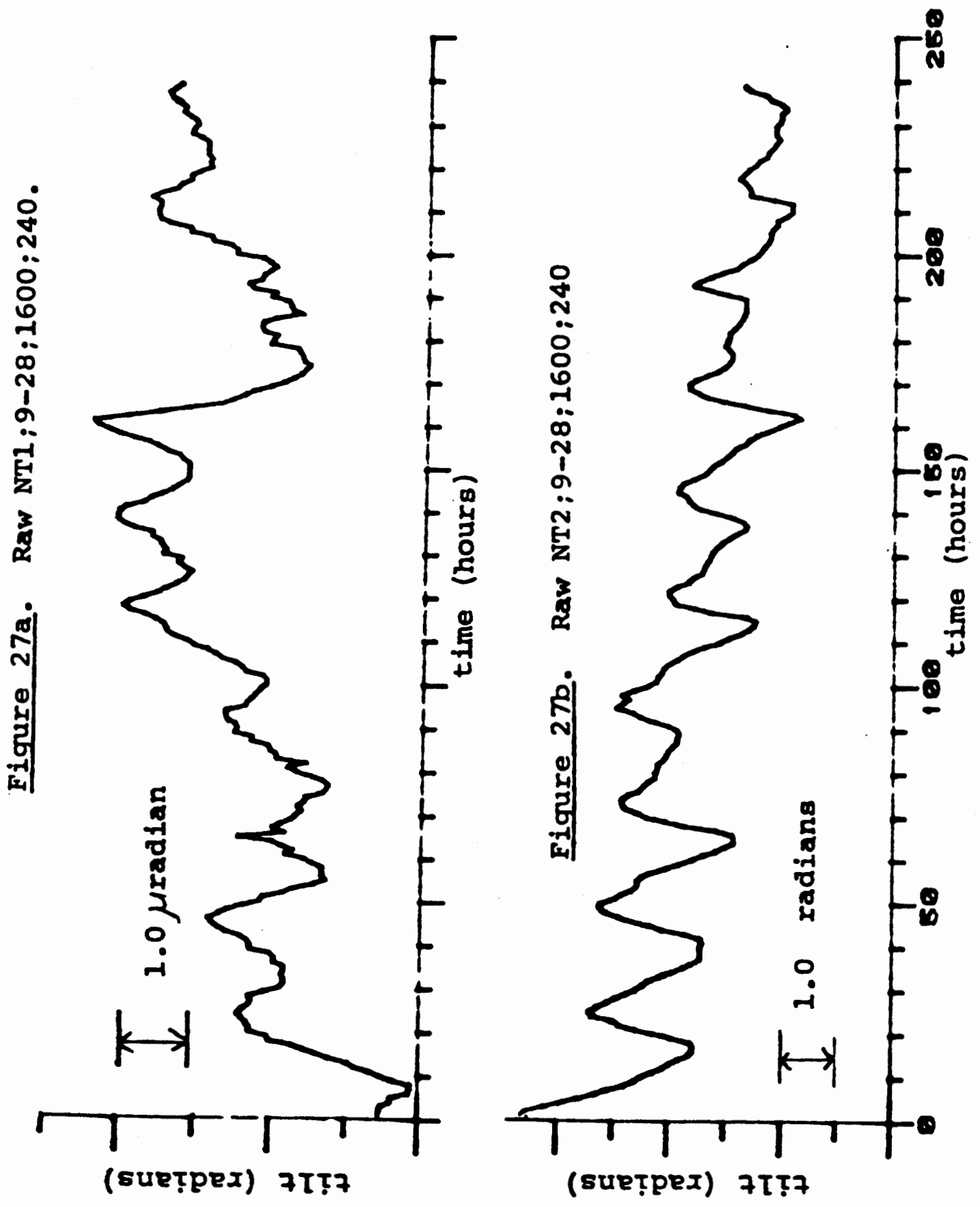



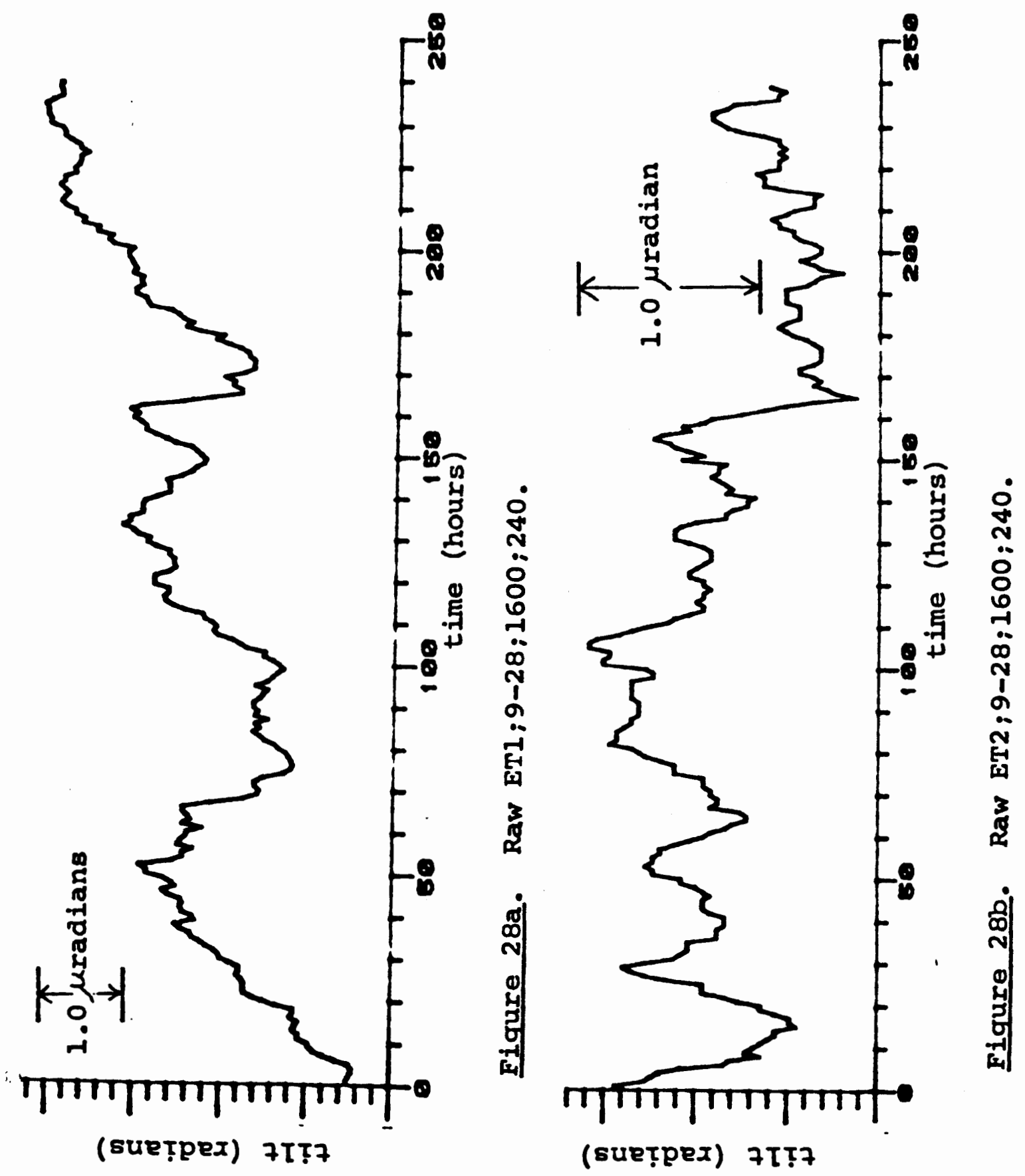

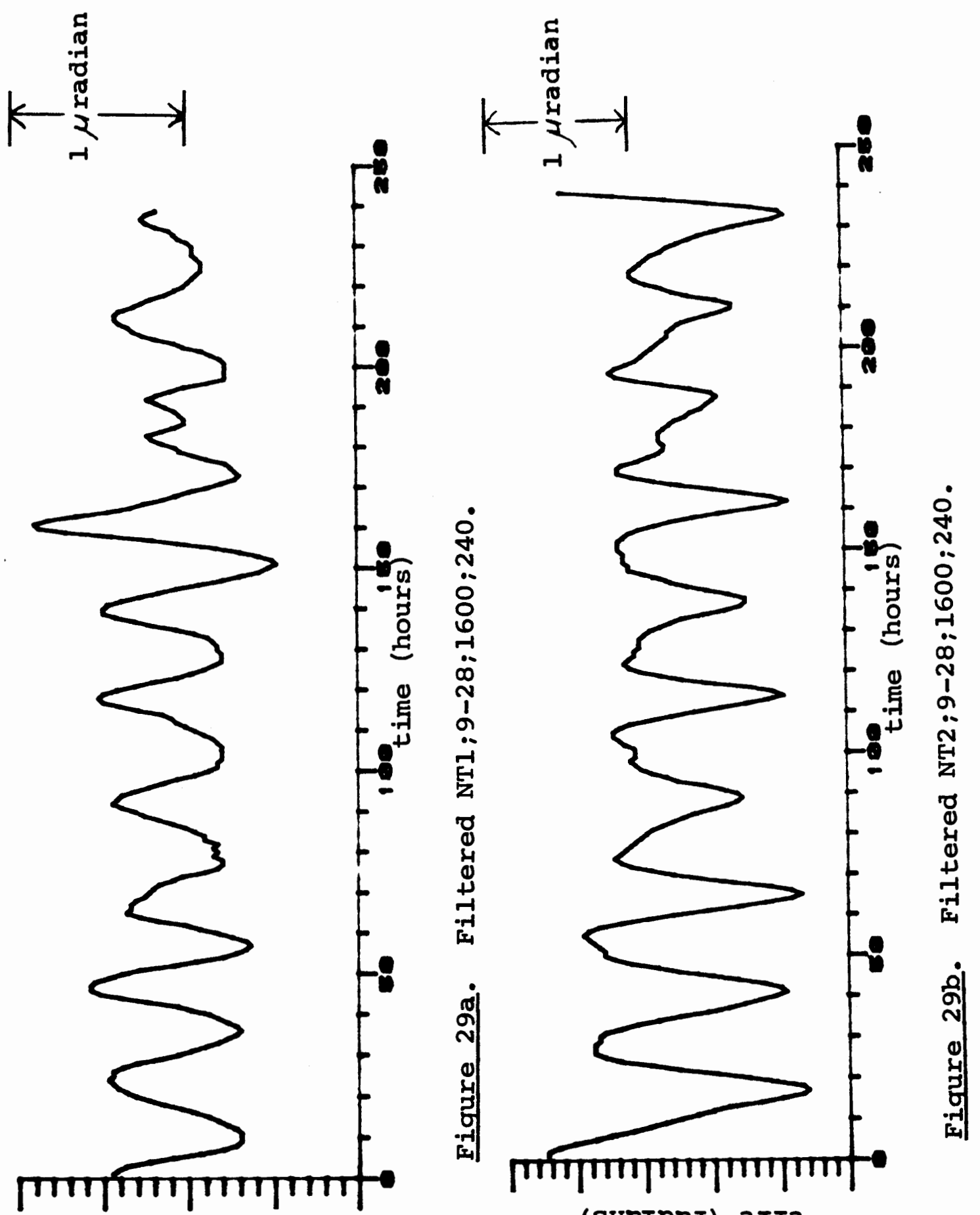

(strețpex) 7 Tฺ7

(suețpex) 7 Tฺ7 


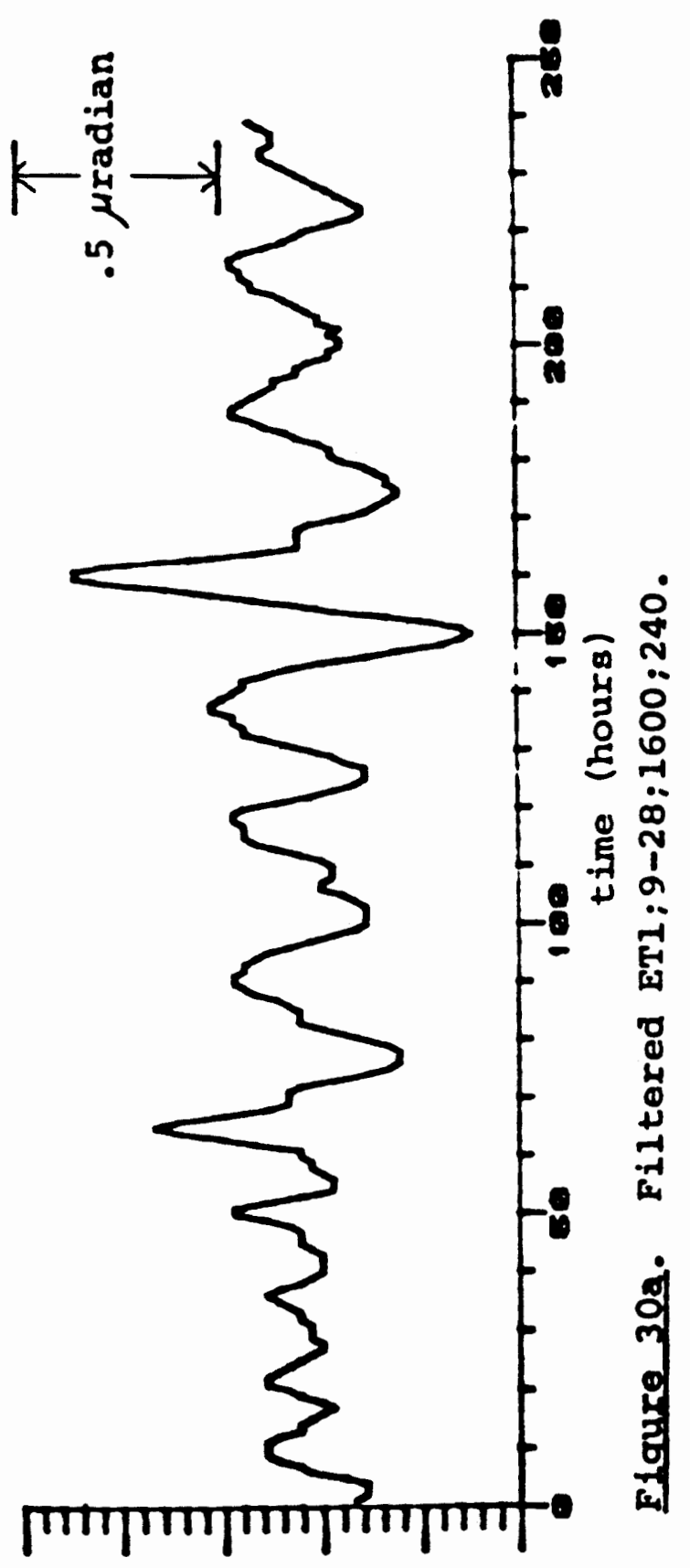

(EURṬPEI) 7TT7

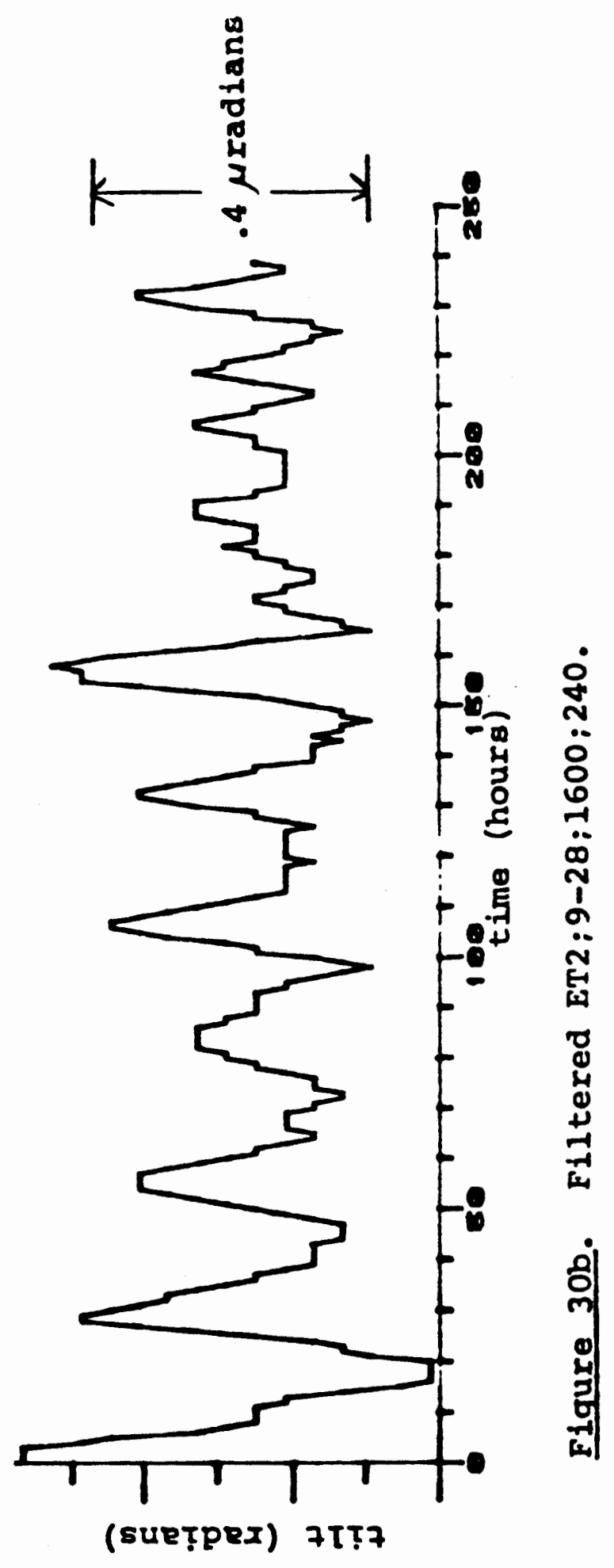




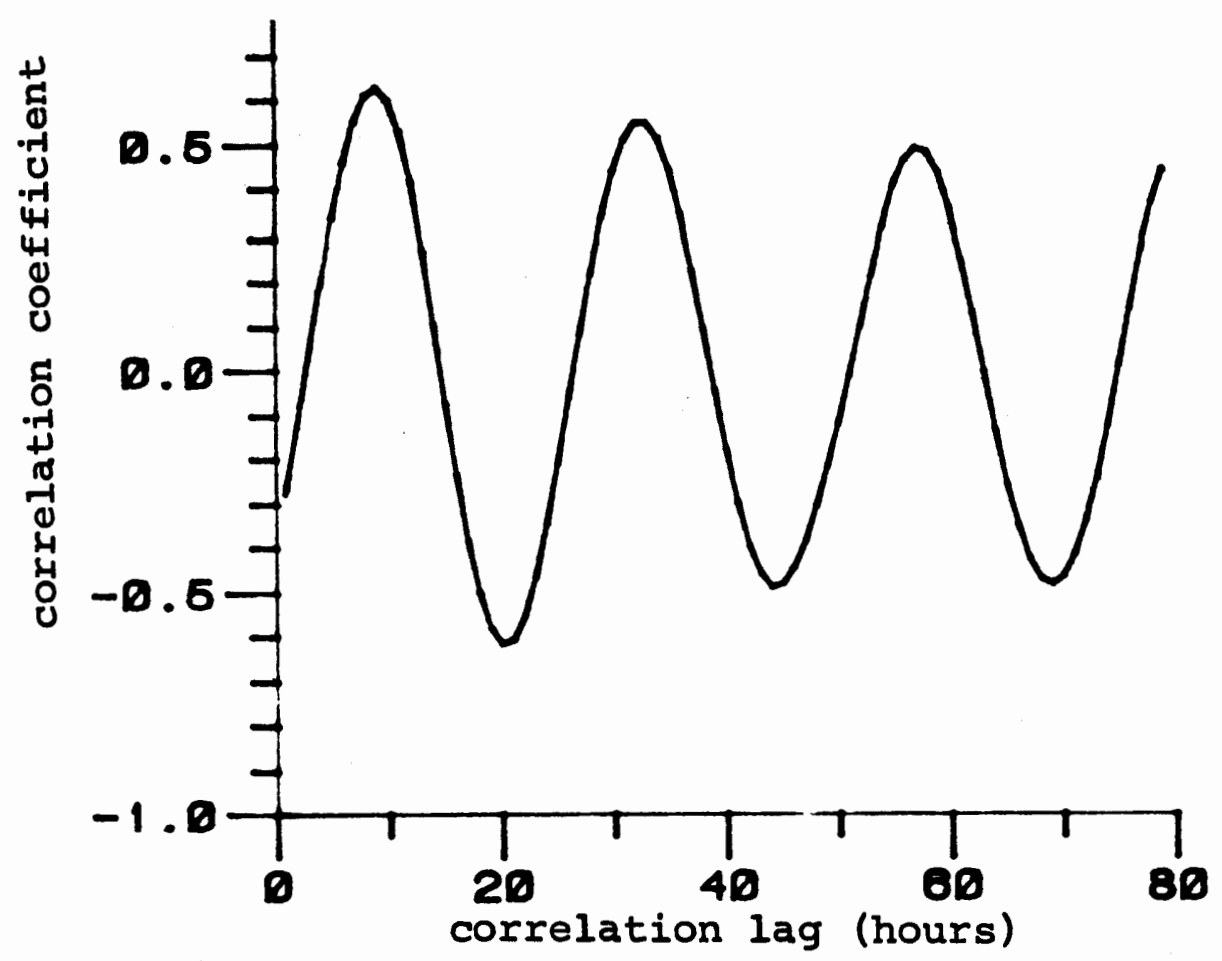

Fiqure 31a. Cross-correlation of NT1;9-28;1600;240 with NT2;9-28;1600;240.

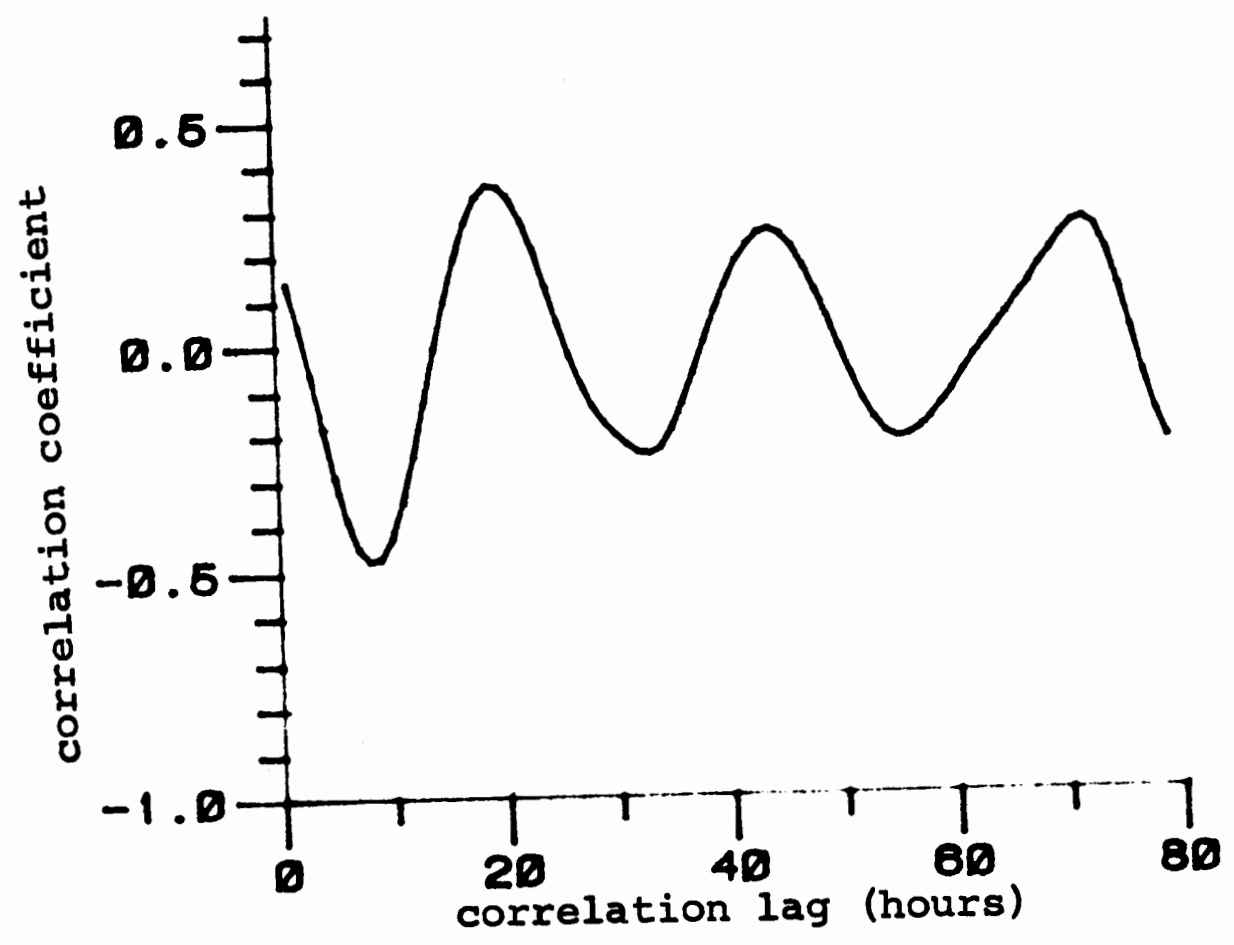

Fiqure $31 \mathrm{~b}$. Cross-correlation of ETl;9-28;1600;240 with ET2;9-28;1600;240. 
presence of the Tualatin mountains (21) less than $.25 \mathrm{~km}$ to the south of the instruments. However if they were responsible for an amplification in the North/South component of the tilt data, the East/West component of the data should also be affected since the mountains are located at approximately $45^{\circ}$ to both components. An amplification of 4.7 was observed in ETl;8-16;0900;220. However an $F$ value of 5.0 is just beyond the significant level and is somewhat questionable. See Table III. The author is thus reluctant to draw any conclusions relating the geological surroundings to the calculated amplified signal.

The instruments, even though spacially very close, $\sim 20 \mathrm{~m}$, appear to be otherwise uncorrelated. Berger (22), in reference to data collected over a 2-year period at Piñon Flat Geophysical Observatory, stated: "There is no significant coherence between signals from closely spaced tilt meters $(10 \mathrm{~m})$ outside the microseismic and tidal bands." Thus it would be surprising if the instruments of this study did exhibit a stronger correlation. However in our study there was also limited coherence in the tidal bands. This could surely be improved upon by eliminating some of the major noise sources as suggested previously, thus increasing the signal to noise ratio. 
CHAPTER VII

\section{CONCLUSION}

\section{Measurement}

In Chapter I measurement of the data was discussed. Several improvements were discussed with respect to the quality of the data. As was seen from Table III, a large value of $b_{1} r_{1 y}$ for $x_{1}=T$ indicated that the thermal influence on the signal appeared to be the largest source of noise. It is thus concluded that the isolation of the equipment from thermal fluctuations is of the utmost importance. With the thermal fluctuations minimized the separation of the other signals present in the tilt or strain data would be much easier and much more certain. It is suggested that insulation could be incorporated with the lid of the drums. This would allow easy access to the instruments without disturbing them.

The positioning of the flexible cable was also found to influence the signal. It was believed that this was the major source of thermal variations in the tilt signal. This conclusion was made after observing the phase difference 
between the recorded tilt signal and the recorded temperature, and doing an experimental check of the temperature dependence of the tilt electronics and recording device. A tripod support for the flexible cable should be considered.

\section{Signal Analysis}

There are an unlimited number of ways to model a time series, each requiring various assumptions about the physical processes involved. In this study a linear model was selected because of its simplicity, which in turn gives availability to physical insight of the processes that determine the characteristics of the signal.

The model showed that the temperature fluctuations influenced the signal the most. A statistical F test of the addition of the pressure signal to the model indicated that the pressure had little influence on the recorded signal and thus the pressure influence was assumed to be negligible. The results of $F$ tests as to the significance of the addition of the theoretical tidal signal almost always indicated a significant influence. See Table III. Thus it seems that the tidal signal was present in most of the signals inspected. In order to obtain more quantitative results of the tidal amplitudes the signal to noise ratio must be increased. 
Final Notes

Other geological events such as movement along faults, volcanic or geothermal activity would be much less sensitive to the noise present because the signal would be much larger than the expected tidal signal. As an example of a larger effect, the effect of the expansion of a cement wall was successfully modeled. The use of the tilt and strain meters could prove to be useful in problems of geological engineering. Many engineering problems do not require the high precision of the instruments of this study; however there are design problems such as those associated with the design of high energy accelerators that require high precision (5). Such facilities are equipped with internal measuring devices. However, the instruments of this study could be used for a preliminary study of stability of a possible site.

It is hoped that this thesis will prove valuable to others interested in measuring and analyzing elastic strain and tilt data. This thesis is by no means a complete study of the procedures involved but could prove to be a useful reference to those undertaking a project requiring the use of strain and tilt data. 


\section{REFERENCES}

1. Melchior, Paul 1966. "The Earth Tides," 1st ed., Permagon Press Ltd.

2. Bodvarsson, Gunnar; Axelsson, Gudni and Johnson, Ansel 1979. "Exploration of Volcanic Geothermal Energy Resources Based on Rheological Techniques," prepared for the United States Department of Energy under Contract No. Ey-76-5-06-2227, TA \#37.

3. Johnston, Malcolm, J.S. 1976. "Testing the Physical Parameters of Short Baseline Tiltmeters Indended for Earthquake Prediction," Open File Report 76-556, United States Geological Survey, Menlo Park, Calif.

4. Berger, Jon 1974. "The Spectrum of Earth Strain from $10^{-8}$ to $10^{2} \mathrm{~Hz}$," Journal of Geophysical Research, Vol. 79, No. 8 .

5. Spranza, Joseph J. and Nur, Amos M. 1971. "Seasonal Deformation of a Two-mile Straight Line," SLAC-PUB-891, Stanford Linear Accelerator Center, Stanford University, Stanford, Calif. 94305

6. Benson, G.T. and Balsille, J.H. 1971. "Evidence for the Portland Hills Fault," The Ore Bin, Vol. 33, No. 6 .

7. Kinemetrics, Inc. 1975. "Operating Instructions for Model TM-1B Biaxial Borehole Tiltmeter," Kinemetrics, Inc., 222 Vista Avenue, Pasadena, Calif. 91107

8. Mortensen, Carl E.; Iwatsubo, Eugene Y.; Johnston, Malcolm, J.S.; Myren, Douglas G.; Keller, Vincent G.; and Murray, Thomas L. 1977. "U.S.G.S. Tiltmeter Networks, Operation and Maintenance," Open File Report 77-655, United States Geological Survey, Menlo Park, Calif. 
9. Bendat, Julius S. and Piersol, Allan G. 1971. Random Data: Analysis and Measurement Procedures. Wiley-Interscience, Chap. V.

10. Chatfield C. 1975. The Analysis of Time Series: Theory and Practice. John Wiley and Sons, Chap. III.

11. Godin, G. 1967. "The Analysis of Current Observations," International Hydrographic Review, Vol. 44, pp. 149-165.

12. Jenkins, Gwilym M. and Watts, Donald G. 1969. Spectral Analysis and Its Applications. Holden-Day, Chap. II.

13. Robinson, Enders A. 1967. Multichannel Time Series Analysis with Digital Computer Programs. Holden-Day, Chap. I and II.

14. Robinson, Enders A. and Treitel, Sven 1980. Geophysical Siqnal Analysis. Prentice-Hall, Chap. XIV.

15. Davis, John C. 1973. Statistics and Data Analysis in Geology. John Wiley and Sons, Chap. V and VII.

16. Robinson, Enders A. 1981. Time Series Analysis and Applications. Goose Pond Press, Houston, Texas, Chap. XXII.

17. Bevington, Philip R. 1969. Data Reduction and Error Analysis for the Physical Sciences. McGraw Hill, Chap. VII and $\mathrm{X}$.

18. Berger, J. 1975. "A Note on Thermoelastic Strains and Tilts," Journal of Geophysical Research. Vol. 80, No. 2, pp. 274-277.

19. Love, A.E.H. 1944. A Treatise on the Mathematical Theory of Elasticity, 4th ed. Dover Publications, Chap. V.

20. Budynas, Richard G. 1977. Advanced Strengths and Applied Stress Analysis. McGraw Hill, Chap. I. 
21. Harrison, J.C. 1976. "Cavity and Topographic Effects in Tilt and Strain Measurements," Journal of

Geophysical Research. Vol. 8, No. 2, pp. 319-328.

22. Berger, Jan and Wyatt, F. 1980. "Investigations of Tilt Measurements Using Shallow Borehole Tiltmeters," Journal of Geophysical Research. Vol. 85, No. B8, pp. 4351-4362. 